\title{
Status Report: Intergranular Stress Corrosion Cracking of BWR Core Shrouds and Other Internal Components
}

Manuscript Completed: March 1996

Date Published: March 1996

J. Medoff, NRC Technical Monitor

Division of Engineering

Office of Nuclear Reactor Regulation

U.S. Nuclear Regulatory Commission

Washington, DC 20555-0001

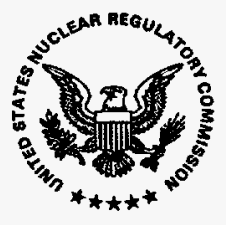




\section{DISCLAMMIER}

Portions of this document may be illegible in electronic image products. Images are produced from the best available original document. 


\section{ABSTRACT}

On July 25, 1994, the U.S. Nuclear Regulatory Commission (NRC) issued Generic Letter (GL) 94-03 to obtain information needed to assess compliance with regulatory requirements regarding the structural integrity of core shrouds in domestic boiling water reactors (BWRs).

This report begins with a brief description of the safety significance of intergranular stress corrosion cracking (IGSCC) as it relates to the design and function of BWR core shrouds and other internal components. It then presents a brief history of shroud cracking events both in the U.S. and abroad, followed by an indepth summary of the industry actions to address the issue of IGSCC in BWR core shrouds and other internal components.
This report summarizes the staff's basis for issuing GL 94-03, as well as the staff's assessment of plantspecific responses to GL 94-03. The staff is continually evaluating the licensee inspection programs and the results from examinations of BWR core shrouds and other internal components. This report is representative of submittals to and evaluations by the staff as of September 30, 1995. An update of this report will be issued at a later date. 



\section{CONTENTS}

Abstract

List of Figures

List of Figures

List of Tables $\mathbf{x i}$

List of Appendices xiii

Executive Summary $\mathbf{x v}$

Acknowledgements xvii

1 Introduction $1-1$

2 BWR and Core Shroud Designs

2.1 BWR and Core Shroud Design Characterstics

2.2 Construction Materials and Fabrication Methods

3 Intergranular Stress Corrosion Cracking of BWR Internal Components

4 BWR Core Shroud Cracking - Systems Evaluation and Safety Assessment

4.1 Structural Integrity Assessments

4.2 Safety Significance of $360^{\circ}$ Through-Wall Cracks During Normal Operations and Operational Transients

4.3 Safety Significance of $360^{\circ}$ Through-Wall Cracks During Design Basis Accidents.

5 BWR Core Shroud Cracking - Summary of Significant Operating Experience

5.1 Cracking at a Foreign BWR

5.2 Cracking at Brunswick Steam Electric Plant, Unit 1

5.3 Cracking at Commonwealth Edison Plants

5.4 Cracking at Oyster Creek Nuclear Generation Station

5.5 Cracking at Vermont Yankee Nuclear Power Station

6 Industry Efforts to Address the IGSCC Issue

6.1 Generic Approach Taken to Address the IGSCC Issue

6.2 Efforts by the Boiling Water Reactor Owners Group 
6.3 Estalinge Page

6.3 Establishment of the Boiling Water Reactor Vessel and Internals Project .......................... 6-1

6.4 Activities of the General Electric Company ................................................... $6-2$

6.5 Activities of the Electric Power Research Institute .......................................... 6-3

7 GL 94-03, "Intergranular Stress Corrosion Cracking of Core Shrouds in Boiling Water Reactors" ........ 7-1

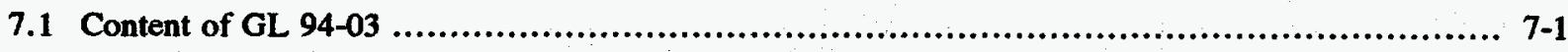

7.2 Generic Assessment of the Industry's Responses to GL 94-03 .............................. $7-1$

8 Plant-Specific Assessments and Results of Core Shroud Inspections or Repairs ......................... 8-1

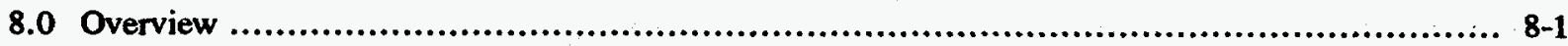

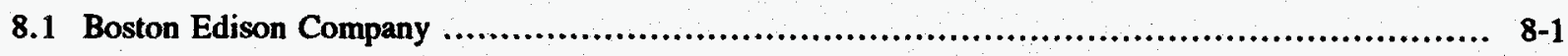

8.1.1 Assessment of the Response to GL 94-03 for the Pilgrim Nuclear Power Station ............. 8-1

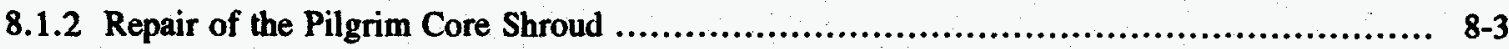

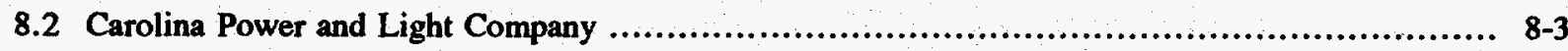

8.2.1 Assessment of the Response to GL 94-03 for Brunswick Unit 1 ........................ 8-3

8.2.2 Reinspection of the Brunswick Unit 1 Core Shroud ...................................... 8-3

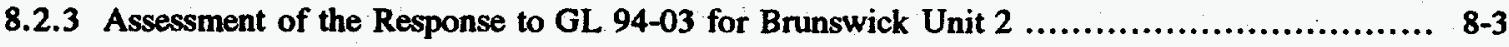

8.3 Commonwealth Edison Category " $\mathrm{C}$ " Plants ................................................. 8-4

8.3.1 Assessment of the Response to GL $94-03$ for Dresden Unit 3 and Quad Cities Unit 1 ...... 8-4

8.3.2 Assessment of the Response to GL 94-03 for Dresden Unit 2 and Quad Cities Unit 2 ...... 8-4

8.3.3 Repairs of the Dresden, Units 2 and 3, and Quad Cities, Units 1 and 2, Core Shrouds ...... 8-5

8.4 General Public Utilities ........................................................................... 8

8.4.1 Assessment of the Response to GL 94-03 for the Oyster Creek Nuclear Generation Station 8-5

8.4.2 Inspections and Repair of the Oyster Creek Core Shroud ................................. 8-6

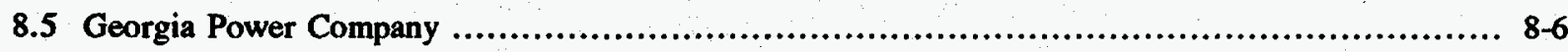

8.5.1 Assessment of the Response to GL $94-03$ for Edwin I. Hatch Unit 1 .................... 8-6

8.5.2 Repair of the Edwin I. Hatch Unit 1 Core Shroud ................................... 8-6 
Page
$8-6$

8.5.3 Assessment of the Response to GL 94-03 for Edwin I. Hatch Unit 2 ...................... 8-6

8.5.4 Repair of the Edwin I. Hatch Unit 2 Core Shroud ...................................... 8-7

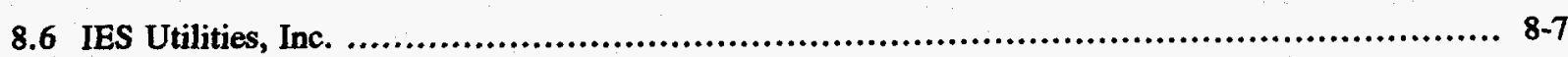

8.6.1 Assessment of the Response to GL 94-03 for the Duane Arnold Energy Center ............... 8-7

8.6.2 Inspection of the Duane Amold Core Shroud ............................................ 8-8

8.7 Nebraska Public Power District .............................................................. 8-8

8.7.1 Assessment of the Response to GL 94-03 for the Cooper Nuclear Station .................... 8-8

8.7.2 Inspection Scope for the Cooper Core Shroud ........................................... 8-8

8.8 Niagara Mohawk Power Corporation Category "C" Plants ....................................... 8-9

8.8.1 Assessment of the Response to GL 94-03 for Nine Mile Point Unit 1 ...................... 8-9

8.8.2 Repair of the Nine Mile Point Unit 1 Core Shroud ........................................ 8-9

8.9 Northeast Nuclear Energy Company ......................................................... 8-9

8.9.1 Assessment of the Response to GL 94-03 for the Millstone Unit 1 Core Shroud ............. 8-9

8.9.2 Reinspection Scope for the Millstone Unit 1 Core Shroud ............................... 8-10

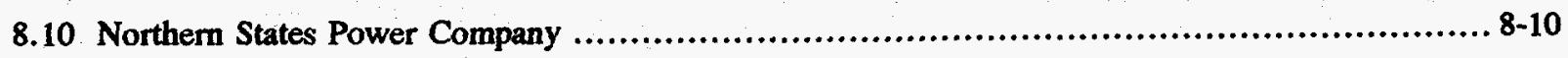

8.10.1 Assessment of the Response to GL 94-03 for the Monticello Nuclear Generation Station .... 8-10

8.10.2 Inspection of the Monticello Core Shroud .............................................8-10

8.11 Philadelphia Electric Company Category "C" Plants .............................................. 8-11

8.11.1 Assessment of the Response to GL 94-03 for Peach Bottom Atomic Power Station Unit 2 8-11

8.11.2 Inspection of the Peach Bottom Unit 2 Core Shroud ...................................... 8-11

8.11.3 Assessment of the Response to GL 94-03 for Peach Bottom Atomic Power Station Unit 3 8-12

8.11.4 Reinspection Scope for the Peach Bottom Unit 3 Core Shroud ........................... 8-13

8.11.5 Peach Bottom Core Shroud Repair Designs ...............................................8-13

8.12 Power Authority of the State of New York .........................................................

8.12.1 Assessment of the Response to GL 94-03 for the James A. FitzPatrick Nuclear Power Plant 8-13 
8.12.2 Repair of the James A. FitzPatrick Core Shroud $\begin{array}{r}\text { Page } \\ 8-14\end{array}$

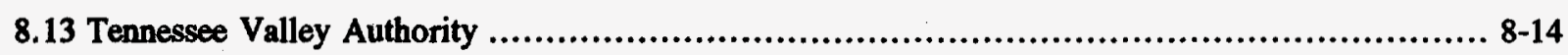

8.13.1 Assessment of the Response to GL 94-03 for Browns Ferry Nuclear Units 1, 2, and 3 ..... 8-14

8.13.2 Inspection of the Browns Ferry Unit 1, 2, and 3 Core Shrouds $\ldots \ldots \ldots \ldots \ldots \ldots \ldots \ldots \ldots \ldots . . . . . .14$

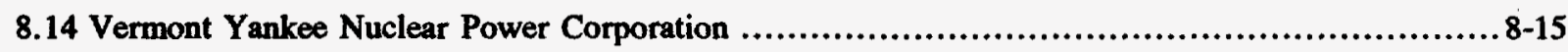

8.14.1 Assessment of the Response to GL 94-03 for the Vermont Yankee Nuclear Power Station 8-15

8.15 Plants with Category "B" Core Shrouds ..................................................... 8

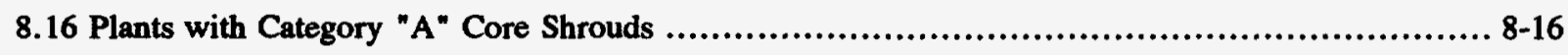

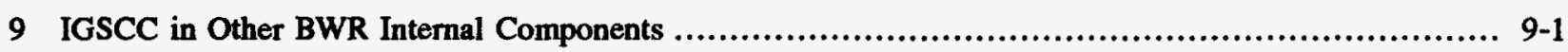

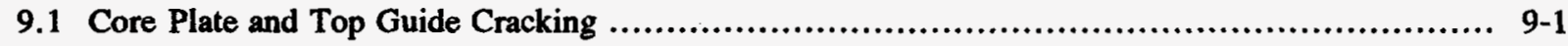

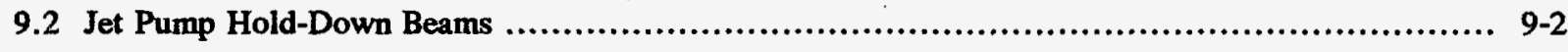

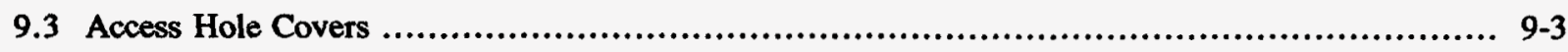

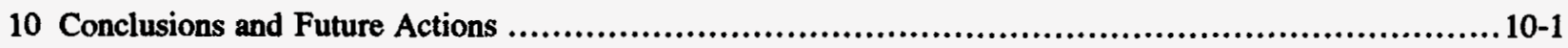

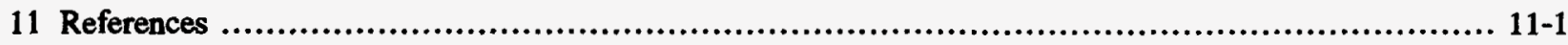




\section{LIST OF FIGURES}

Figure 2.1-1 Reactor Vessel Flow Paths in GE BWR-3, BWR-4, BWR-5, and BWR-6 Reactor Designs

Figure 2.2-1 Structural Configuration Typical of GE BWR-3, BWR-4, BWR-5, and BWR-6 Core Shroud Designs

Figure 2.2-2 Core Shroud Weld Locations Typical of GE BWR-3, BWR-4, BWR-5, and BWR-6 Core Shroud Designs.

Figure 6.3-1 Typical Modification Design Proposed for Repair of BWR Core Shrouds 6-5 


\section{LIST OF TABLES}

Page

Table 6.2-1 BWRVIP Susceptibility Rankings and Core Shroud Inspection Recommendations . $6-4$ 



\section{APPENDICES}

Page

A List of BWROG Members and BWRVIP Subcommittees ....................................... A-1

B Plant-Specific BWR Core Shroud Summaries .................................................. B-1

C List of BWR Utilities and Reactors ...............................................................

D Abbreviations and Nomenclature ............................................................. D-1

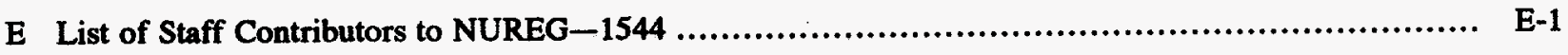





\section{EXECUTIVE SUMMARY}

Many internal components of boiling water reactor (BWR) vessels are made of materials susceptible to intergranular stress corrosion cracking (IGSCC), including stainless steel, alloy 600 , alloy X750, and alloy 182 weld metal. IGSCC is a time dependent material degradation process, which is known to be caused and accelerated by the presence of crevices, residual stresses, material sensitization, irradiation, cold work, and corrosive environments. As operating BWRs age, the number of cracking incidents is expected to increase. The U.S. Nuclear Regulatory Commission (NRC) staff has been meeting every year since 1988 with the Boiling Water Reactor Owners Group and the General Electric Company, and later with the Boiling Water Reactor Vessel and Internals Project, to review the generic safety implications of reactor internal components that are considered to be susceptible to IGSCC.

In 1990, cracking of the core shroud was visually observed in an overseas BWR. The cracking was located in the heat-affected zone of a circumferential weld in the beltline elevation of the shroud. Cracking of BWR core shrouds reported at U.S. plants in 1993, 1994, and 1995 has been the most significant cracking of BWR internal components. The core shroud is a stainless steel cylinder that separates the feedwater in the reactor vessel's downcomer annulus region from cooling water flowing through the reactor core. The core shroud also performs the important functions of properly directing coolant flow through the core and maintaining the core geometry. For GE BWR-3 and later designs, the core shroud also provides a structural boundary to allow for reflooding of the reactor core to two-thirds core height under postulated accident conditions.

Significant circumferential cracking has been discovered at the Brunswick Unit 1, Dresden Unit 3, Quad Cities Unit 1, Oyster Creek, and Vermont Yankee nuclear stations. In light of the extent of cracking observed at these plants, the staff evaluated potential safety concerns associated with the possibility of a $360^{\circ}$ circumferential separation of the shroud following a postulated loss-ofcoolant accident (LOCA). The staff considered the potential for separation of the shroud during postulated accidents to either prevent full insertion of the control rods, or open a gap large enough to preclude the emergency core cooling systems from fulfilling their intended safety functions. The accident scenarios of primary concern are the main steam line break and the recirculation line break. The more serious event associated with cracks in the upper shroud welds (e.g., $\mathrm{H} 2, \mathrm{H} 3$ ) is the steam line break, since the lifting forces generated may be sufficient to elevate the top guide and potentially cause difficulties with rod insertion. The recirculation line break is the more serious event associated with cracks in the lower elevations of the core shroud. The recirculation line break is a greater concern at lower weld elevations because this type of LOCA has the potential to result in a lateral displacement of the shroud. Such a lateral displacement of the shroud could affect the ability of control room operators to insert control rods into the core and could prevent adequate core cooling.

In consideration of the consequences of a $360^{\circ}$ throughwall failure of the shroud coincident with a LOCA, the NRC has conservatively estimated the risk contribution from shroud cracking and determined that it does not pose a high degree of risk at this time. However, the NRC has also determined that structural margins specified in the American Society of Mechanical Engineers Boiler and Pressure Vessel Code could be exceeded if the cracks were sufficiently deep and continued propagating through the shroud during normal operating, transient or accident conditions, possibly resulting in the loss of a layer of the defense-in-depth strategy. Therefore, the staff has concluded that it is appropriate for BWR licensees to implement timely inspections and/or repairs of their core shrouds. To implement this position, the NRC staff issued Generic Letter (GL) 94-03 (July 25, 1994), requesting that BWR licensees inspect their core shrouds by the next refueling outage and justify continued safe operation until inspections can be completed. This position enabled the staff to verify compliance with the inservice inspection requirements of Section 50.55a of Title 10 of the Code of Federal Regulations, and ensured that the risk associated with core shroud cracking remains low.

As of early September 1994, the NRC staff received all of the BWR licensee submittals in response to GL 94-03. The staff has completed its evaluations of the licensee responses and has transmitted the safety evaluation reports to the appropriate BWR licensees. The staff concluded that, for all cases, BWR licensees had 
provided sufficient justification to operate their facilities until core shroud inspections or repairs could be implemented. The staff based its conclusions on the following factors:

(1) No $360 \circ$ through-wall core shroud cracking has been observed to date in any U.S. BWR at which the licensee performed a shroud inspection.

(2) All analyses performed by U.S. licensees to date indicate that, even if cracking did exist in a particular BWR core shroud, sufficient ligaments would remain in the shroud so that the structural integrity of the shroud would be ensured for the remainder of the plant's operating cycle.

(3) No U.S. BWR has exhibited any of the symptoms (power-to-flow mismatch) that would be indicative of leakage through a 3600 through-wall shroud crack.

(4) Main steam line or recirculation line breaks are both considered to be low frequency events.

(5) There were only short durations until core shroud inspections were to be conducted or repairs were to be implemented by the individual BWR licensees.

To date, core shrouds have been repaired (modified) at the Brunswick Units $1 \& 2$, Hatch Units 1 \& 2, FitzPatrick, Oyster Creek, Quad Cities Units 2,
Nine Mile Point Unit 1, and Pilgrim nuclear plants. Repairs will be made at additional plants if inspection results indicate that large scale cracking of circumferential shroud welds has occurred, or may be made at the discretion of the licensee in lieu of comprehensive core shroud examinations (pre-emptive core shroud modifications). These repairs or modifications are designed to ensure the structural integrity of the core shrouds based on an assumption that the shroud circumferential welds are completely cracked, and are being reviewed by the NRC staff on a case-bycase basis.

In the spring of 1994, the industry formed a new organization, the BWR Vessel and Internals Project (BWRVIP), to address the issue of IGSCC of BWR internal components. The BWRVIP is headed by several high level utility executives to ensure that top executives in the industry are aware of its function, purpose and efforts. The BWRVIP subsequently submitted documents addressing an integrated safety assessment of the issue, guidelines on performing nondestructive examinations (NDE) of core shroud welds, guidelines on inspection scopes for BWR core shrouds, and generic guidelines and acceptance criteria in regard to performing flaw evaluations and repairs of BWR core shrouds. The NRC staff has approved the generic repair criteria document, the latest revision to the BWRVIP guidelines regarding core shroud inspection scopes and flaw evaluations, and the BWRVIP guidelines regarding core shroud NDE methods. 


\section{ACKNOWLEDGEMENTS}

The authors wish to thank the many persons who contributed immeasurably to the work documented in this report and to the quality of the final product. We would like to thank Mr. C.E. Carpenter and Mr. D.S. Brinkman, who were instrumental in coordinating the staff activities with members of the Boiling Water
Reactor Owners Group, the Boiling Water Reactor Vessel and Internals Project, the Electric Power Research Institute, and the General Electric Company. In addition, we would like to thank Ms. J. Beeson of the Technical Editing Staff, and Ms. A.D. Lowery and Ms. J.E. Brooks for proofreading this document. 


\section{INTRODUCTION}

In a memorandum dated January 4, 1994, the staff of the U.S. Nuclear Regulatory Commission (NRC) reported to the Commission that intergranular stress corrosion cracking (IGSCC) of the internal components of boiling water reactor (BWR) vessels was emerging as a technical issue (Ref. 1). The core shroud was one of the internal components listed in the memorandum as being susceptible to IGSCC.

On July 25, 1994, the NRC issued Generic Letter (GL) 94-03, "Intergranular Stress Corrosion Cracking of Core Shrouds in Boiling Water Reactors," which requested that BWR licensees inspect their core shrouds at the earliest refueling outage (RFO) for their plants (Ref. 2). Since then, most BWR licensees have inspected or repaired their core shrouds during planned RFOs. These inspections have shown that core shrouds can crack at circumferential weld locations. IGSCC has also been detected in other BWR components, including core spray spargers, feedwater spargers, jet pump hold-down beams, top guides, core support plates, and access hole covers. Nuclear licensees have implemented inspection and repair programs to ensure continued structural integrity of these components.

This report presents background information, current status, and future actions needed to address the issue of IGSCC in BWR internal components. Chapter 2 of this report describes BWR core shroud design characteristics and fabrication materials. Chapter 3 discusses the mechanism of IGSCC in BWR internal components. Chapter 4 presents an assessment of the safety significance of postulated accidents with $360^{\circ}$ throughwall cracks. Chapter 5 of this report summarizes significant BWR cracking events in the industry. Chapters 6 and 7 of this report summarize the industry and NRC efforts taken to date to address the IGSCC issue. Chapter 8 summarizes the staff's assessment of the industry's plant-specific responses to GL 94-03. Chapter 9 of this report summarizes cracking events that have occurred in other BWR internals to date. Chapter 10 presents general staff conclusions with regard to the issue of IGSCC in BWR internals and addresses future actions to be taken. Chapter 11 provides a list of references.
This report also includes a number of appendices. Appendix A lists the industry members of the Boiling Water Reactor Owners Group (BWROG) and Boiling Water Reactor Vessel and Internals Project (BWRVIP) Subcommittees. Appendix B presents plant-specific core shroud data sheets summarizing important information provided by the licensees to assist the NRC in its evaluation of core shroud cracking. Appendix $\mathrm{C}$ lists the licensees, along with their corresponding BWR units. Appendix D presents a list of acronyms, abbreviations and scientific units used in this report. Appendix E lists the staff members who have contributed to the staff's assessment of the issue of IGSCC in BWR internal components.

This report is representative of submittals to and evaluations by the staff as of September 30, 1995. An update of this report will be issued at a later date. 


\section{BWR AND CORE SHROUD DESIGNS}

\subsection{BWR and Core Shroud Design Characteristics}

The core shroud in a BWR is a stainless steel, cylindrical component within the reactor pressure vessel (RPV) that surrounds the reactor core. The core shroud separates feedwater in the reactor vessel's downcomer annulus region from the cooling water flowing up through the reactor core. In addition, the core shroud laterally supports the fuel assemblies to maintain control rod insertion geometry during operational transients and postulated accidents. For GE BWR-3 and later designs, the core shroud also provides a refloodable volume for safe shutdown and cooling of the reactor core during postulated accident conditions.

The General Electric Company (GE) has been the only manufacturer of BWRs in the United States. GE models currently licensed for operation in the U.S. range from BWR-2 reactors with Mark I type containments (drywell-torus type) through BWR-6 reactors with Mark III containments (drywell-Weir wall type). All GE BWR models are equipped with low pressure emergency core cooling systems (ECCS), and some form of automatic depressurization system. ECCS designs for later BWR models (BWR-4, BWR-5 and BWR-6) also include high pressure spray or coolant injection systems.

Some distinct differences set GE BWR-2 reactors apart from later GE BWR designs (BWR-3 through BWR-6). In BWR-2 reactors, the core shroud is vertically supported by a conical core shroud support ring, which is welded to the core shroud at one end and to the reactor vessel wall at the other. In later GE BWR models, the core shrouds are supported by core shroud support legs or cylinders, which are in turn welded to the lower reactor vessel head. Another distinct characteristic of GE BWR-2 reactors is the absence of jet pumps and recirculation loops. As a result, the core in BWR-2 models must be cooled using natural circulation, rather than forced recirculation, the method of core cooling used in later designs.

The absence of jet pumps in BWR-2 reactors also precludes the design from having any direct systematic ties between the lower plenum area and the annulus region of the reactor vessel. This is important from a defense-in-depth standpoint. For BWR-3 and later designs, the presence of jet pumps provides an easy means of maintaining emergency core cooling during postulated loss-of-coolant accidents (LOCAs), when ECCS actuation is necessary to maintain reactor safety. Recirculation of the emergency coolant back to the annulus region of the vessel, in this case, occurs by way of the jet pump diffusers. The height of the diffusers provides for a two-thirds core height re-flood capability of the reactor core. These designs allow for re-flood of the core in a relatively short time. Figure 2.1-1 depicts the reactor vessel flow paths typical of GE BWR-3, BWR-4, BWR-5 and BWR-6 reactor designs, and illustrates how the reactor water level achieved in these designs during normal operating conditions differs from that achieved during postulated LOCAs.

In contrast, short and long term cooling responses of non-jet pump (BWR-2) plants for large recirculation line breaks rely on core spray, as the vessel will not flood. Recirculation flow enters the reactor vessel from the bottom and the ECCS for large breaks are two redundant, double capacity, core sprays. Therefore, the degree of any resulting cooling deficiency depends on the final condition of the core spray system. Long term cooling is unchanged as containment flooding is unaffected.

\subsection{Construction Materials and Fabrication Methods}

BWR core shrouds are typically constructed from three shroud shells (the upper, middle and lower shrouds shells), and two support ring structures (the top guide support ring and core support rings). Some designs, such as the core shroud design at the Pilgrim Nuclear Power Station, have an additional support ring structure.

The core shroud shells are typically fabricated from welded, type 304 or 304L stainless steel plates. The ring supports are fabricated from either plates or ring forgings, of type 304 or 304L stainless steel. The carbon content of shroud plates or forgings fabricated from type 304 stainless steel in these shrouds typically ranges from $0.03 \%$ to $0.07 \%$. The carbon content of shroud plates or forgings fabricated from 304L stainless steel is typically less than $0.03 \%$.

Fabrication of BWR core shrouds involves both axial and circumferential welds. Welding of the core shroud shells and ring segments is typically accomplished using 
shielded metal arc welding (SMAW), automated submerged arc welding (SAW), automated gas tungsten arc welding (GTAW), automated gas metal arc welding (GMAW), or a combination of these welding techniques. Figure 2.2-1 illustrates the structural configuration that is typical of GE BWR-3, BWR-4, BWR-5 and BWR-6 core shroud designs. Figure 2.2-2 illustrates the locations of circumferential welds that are typical of these designs, although the exact number and numerical notation of the shroud welds may vary from plant to plant. The structural configuration of core shrouds in GE BWR-2 designs is similar to later designs, with the exception that the shroud is supported by a truncated conical support plate. 


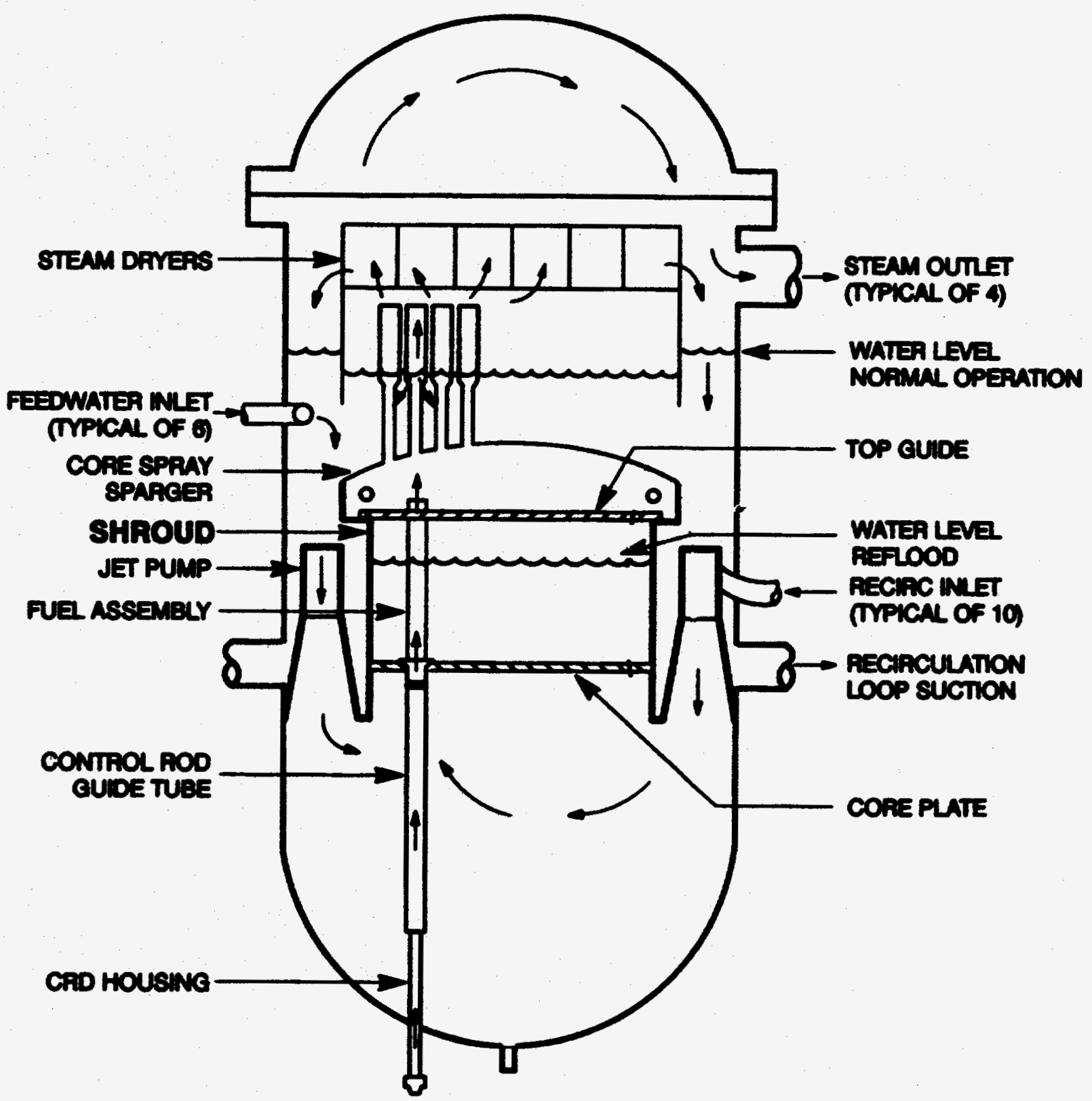

Figure 2.1-1 Reactor Vessel Flow Paths in GE BWR-3, BWR-4, BWR-5, and BWR-6 Reactor Designs 


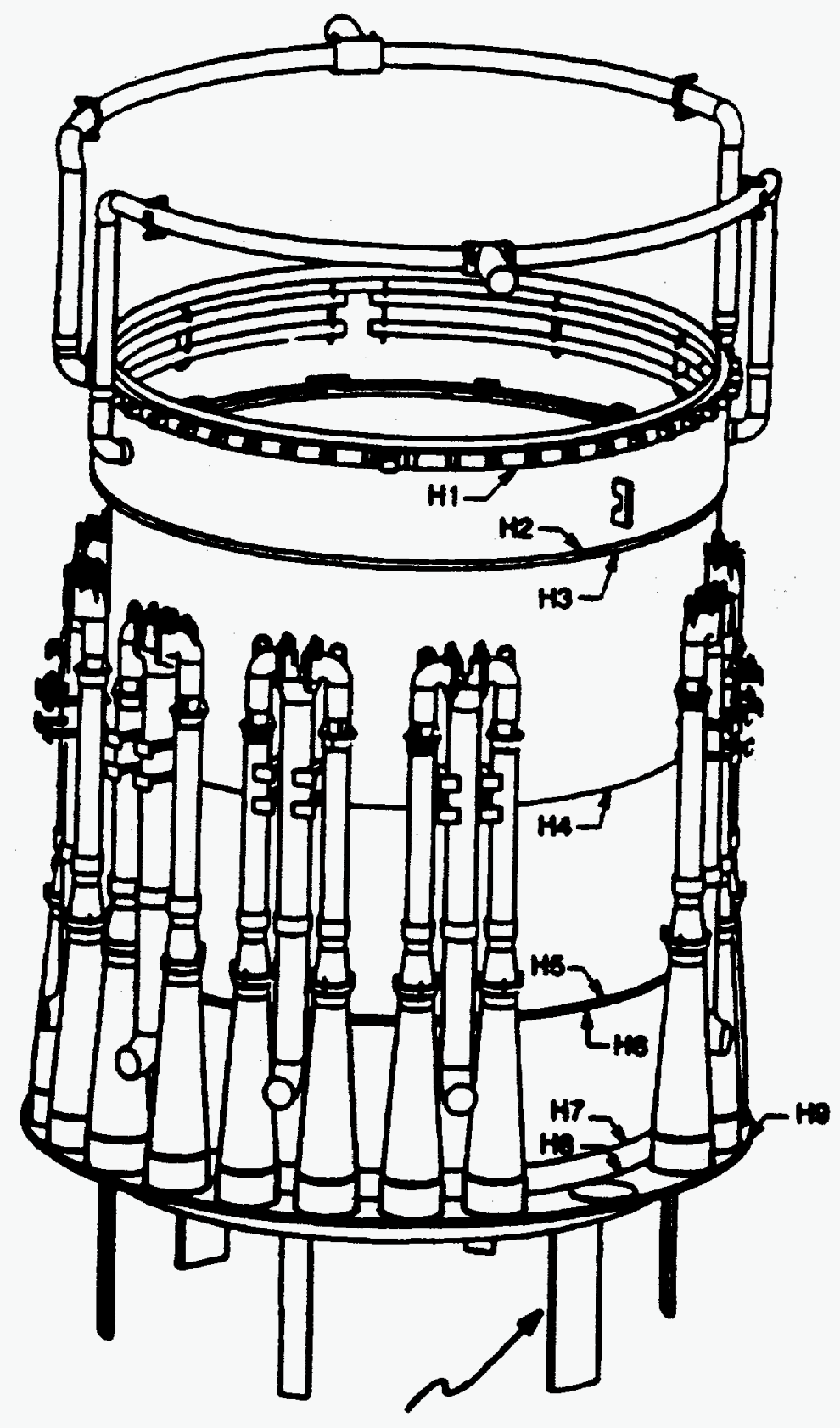

SUPPOAT CONFGURATION VARES DEPENOWN ON BWR SEMES

Figure 2.2-1 Structural Configuration Typical of GE BWR-3, BWR-4, BWR-5, and BWR-6 Core Shroud Designs 


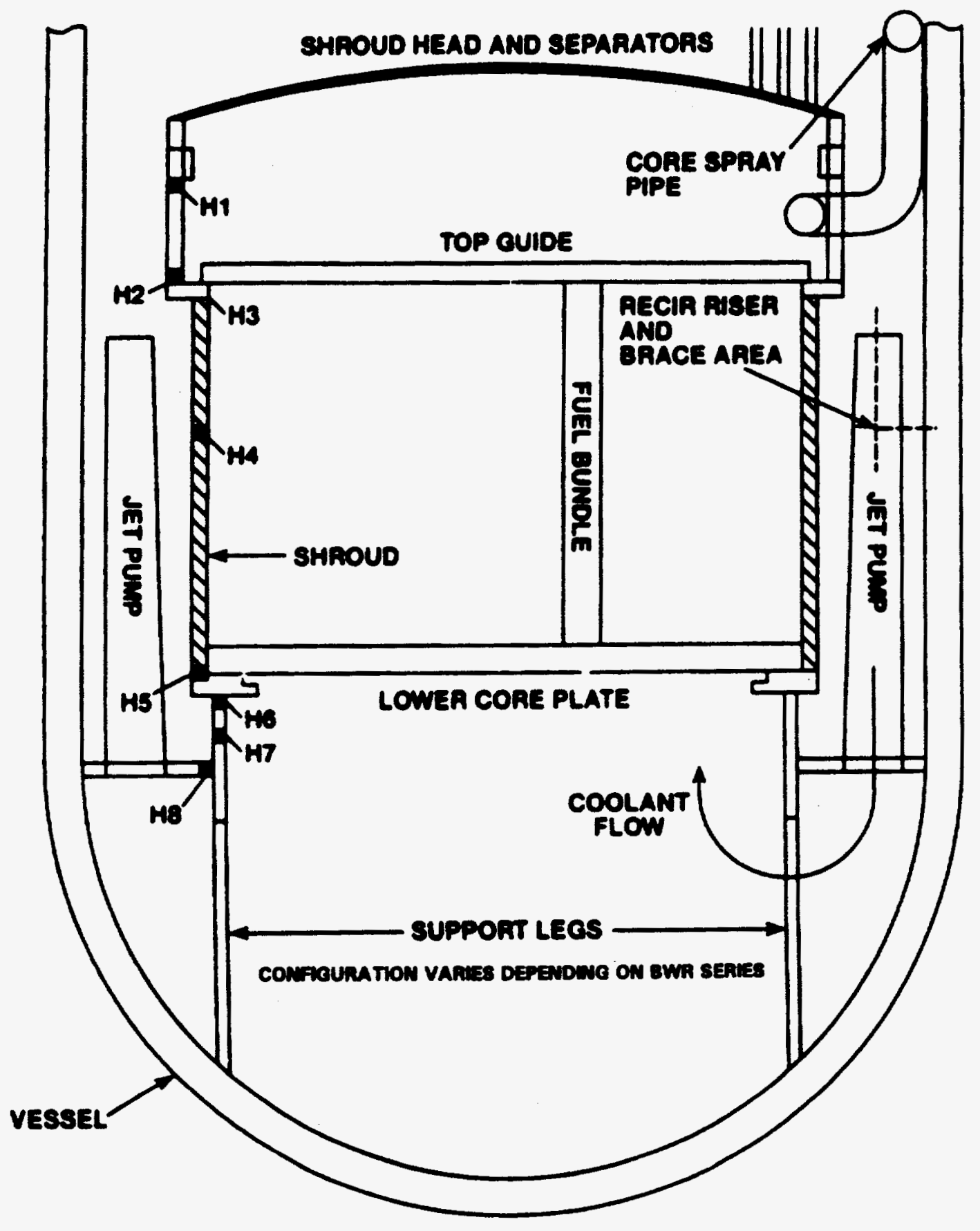

Figure 2.2-2 Core Shroud Weld Locations Typical of GE BWR-3, BWR-4, BWR-5, and BWR-6 Core Shroud Designs 


\section{INTERGRANULAR STRESS CORROSION CRACKING OF BWR INTERNAL COMPONENTS}

Many internal components of a BWR vessel are made of materials that are susceptible to IGSCC, such as stainless. steels, alloy 600 , alloy X750, and alloy 182 weld metal. Core shrouds are among the BWR internal components that have been shown to be susceptible to IGSCC. IGSCC is a time-dependent material degradation process which is known to be caused and accelerated by the presence of corrosive environments, crevices, residual stresses, material sensitization, cold work, and irradiation.

Industry experience has shown that the portions of the core shrouds most susceptible to IGSCC are commonly associated with shroud base metal located in areas immediately adjacent to the shroud welds. These base metal regions are known as the heat affected zones (HAZs) since they are known to undergo intense thermal cycling during the welding process. This thermal cycling may cause the HAZs to undergo a phenomenon known as "sensitization". During "sensitization" carbon diffuses to the grain boundaries of the HAZ base metal. This carbon precipitates out at the grain boundaries in the form of complex chromium carbides upon cooling of the weld melt. The precipitation of these carbides depletes the chromium in the steel material adjacent to the grain boundaries. Because the presence and distribution of chromium on the surfaces of the material provides corrosion resistance in stainless steels, its depletion increases the potential for the grain boundaries become crack initiation sites.

Sensitization of stainless steels typically occurs when the steels are exposed to temperatures ranging from $1000^{\circ} \mathrm{F}$ to $1500^{\circ} \mathrm{F}$. Temperatures in this range are easily achievable during welding. The degree of sensitization increases with increasing carbon content of the stainless steel materials. By contrast, material resistance to IGSCC can be increased if the carbon content is kept below $0.030 \%$. Therefore, low carbon stainless steels offer greater resistance to sensitization, and are therefore more resistant to initiation of IGSCC.

Welding processes can also increase IGSCC susceptibility by introducing high residual stresses in the stainless steel material located at the weld joint. These stresses result from thermal contraction of the weld metal during cooling and are tensile in nature. Although weld stresses are not easily quantified, previous investigations indicate that tensile stresses on the weld surface may be as high as the yield stress of the material. The stress decreases to compressive levels in the center of the welded section.

The fabrication process used for the core support and top guide rings can also play an important role in IGSCC susceptibility. Current available inspection data indicate that shrouds fabricated with forged ring segments are more resistant to IGSCC than rings constructed from welded plate sections. The difference in susceptibility relates to differences in the shroud fabrication processes. Most plants have support rings fabricated from arc segments that are cut from rolled plates and welded to form the ring. This process exposes the short transverse direction in the material to the reactor coolant. In this case, elongated grains and stringers in the material are exposed to the reactor coolant environment, thereby increasing the probability for initiation of cracking or crack-like defects. Forged rings are typically not cut in this manner, and therefore do not have the "end grains" exposed to the environment.

The degree of reactor coolant water quality also correlates strongly with the degree of IGSCC susceptibility in BWR internal components. Industry experience has shown that shrouds operated in coolants with high ionic conductivities are more likely to be highly susceptible to IGSCC than shrouds operated in coolants with low ionic conductivities'. Furthermore, industry experience has shown that reactor coolant systems (RCSs) operated at highly positive, electrochemical potentials (ECPs) are more susceptible

1 Conductivity is a measure of the anionic and cationic content of liquids. As a reference, the conductivity of pure water is $\sim 0.05 \mu \mathrm{S} / \mathrm{cm}(\sim 0.05 \mu \mathrm{mhos} / \mathrm{cm})$. Reactor coolants with conductivities below $0.20 \mu \mathrm{S} / \mathrm{cm}$ $(0.20 \mu \mathrm{mhos} / \mathrm{cm})$ are considered to be relatively ion free; reactor coolants with conductivities above 0.30 $\mu \mathrm{S} / \mathrm{cm}(0.30 \mu \mathrm{mhos} / \mathrm{cm})$ are considered to have a relatively high ion content. 
to IGSCC than RCSs operated at more negative ECPs ${ }^{2}$. The industry has made a considerable effort to improve water chemistry at nuclear facilities over the past 10 years. Industry initiatives have included introducting hydrogen water chemistry as a means of lowering ECPs (i.e., making the ECPs more negative) in the RCS, and introduction and using improved cleanup resins as a means of improving water purity in the RCS. The effectiveness of hydrogen water chemistry in reducing the susceptibility of core shrouds to IGSCC initiation has not been fully evaluated; however, its effectiveness in reducing IGSCC in recirculation piping has been demonstrated.

2 ECP is a measure of a material's susceptibility to corrosion. In the absence of an externally applied current (as is the case for reactor internal components in the RCS), the ECP is equal to the open circuit potential of the material. Industry experience has shown that crack growth rates in reactor internal components are low when the ECP $\leq \sim-0.230 \mathrm{~V}$. 


\section{BWR CORE SHROUD CRACKING - SYSTEMS EVALUATION AND SAFETY ASSESSMENT}

\subsection{Structural Integrity Assessments}

To assess the structural integrity of core shroud welds with cracks extending up to $360^{\circ}$ in the circumferential direction, an analyst must consider the effects of loading conditions, material properties, and crack geometries on the shroud. The shroud is constructed of stainless steel, which has a high degree of fracture toughness. In fact, the core shrouds were fabricated from 1.5-inch to 2-inch thick plates primarily for stiffness during transport and installation. In addition, the operational and postulated accident loads produce low stress levels in the shroud. Therefore, as previously described, adequate structural integrity for the shroud can be maintained despite extensive cracking.

The core shrouds at most U.S. BWRs were not originally designed in accordance with the design rules of the American Society of Mechanical Engineers (ASME) Boiler and Pressure Vessel Code. However, the reactor internal components have been included in plant inservice inspection programs in accordance with Section 50.55a of Title 10 of the Code of Federal Regulations (10 CFR 50.55a), and are therefore within the scope of Section XI of the ASME Code. In addition, the NRC staff and the BWROG are currently developing a draft Subsection IWG to Section XI of the ASME Code, on requirements for reactor vessel components and internal structures. Subsection IWG will augment Section XI by providing additional details concerning examination, inspection, and acceptance standards for flaws in intemal components.

The approaches in the ASME Code address both the linear elastic fracture mechanics of the limiting crack (LEFM analysis) and the potential for gross deformation and subsequent failure of the uncracked material in the vicinity of the crack (limit load or LLA analysis). To date, in reviewing these analyses for licensing purposes, the NRC has required that licensees substantiate the use of the LLA methodology by examining the stress intensification present at the crack tip through finite element modeling.

\subsection{Safety Significance of $360^{\circ}$ Through-Wall Cracks During Normal Operations and Operation Transients}

In order to provide a bounding consequence assessment for the cracking observed to date, the NRC staff postulated complete weld failures at various locations during normal power operation. The intent of this consequence assessment was to demonstrate that fuel geometry and core cooling would be maintained given the unlikely occurrence of a through-wall failure of any horizontal weld, and to identify whether horizontal weld failures would be detectable. In their responses to Generic Letter 94-03, all licensees expected that any $360^{\circ}$ through-wall crack would be detected during normal operations.

During normal operations with any horizontal weld sufficiently cracked, some upward displacement of the shroud could occur, depending on the postulated crack location, operating conditions, and plant type. A small amount of lift at the upper shroud weld locations would produce anomalies such as increased coolant temperatures and/or reduced coolant flow. These power anomalies, power/flow mismatch, are detectable during normal operations. After detection of such an anomaly, a normal shutdown is expected to be initiated until the cause of the anomaly is determined and corrected. Analogous results have been experienced at other operating reactors when the shroud head bolts were improperly engaged.

During most limiting operating conditions, $100 \%$ power and rated flow, the maximum expected vertical displacement can be postulated based on the pressure differences across the shroud head and the shroud support. Shroud lift above the top of the fuel channels has the potential to affect core geometry and control rod insertion. In most cases, the maximum postulated vertical displacement at $\mathrm{H} 3$ and $\mathrm{H} 4$ is not sufficient to disengage the top guide from the fuel channels. Shroud lift at $\mathrm{H} 2$ does not affect core geometry since $\mathrm{H} 2$ is located above the top guide. Some uncertainty remains 
as to whether shroud displacement at the lower welds, H5 through H8, would be detectable during normal operations. Postulated shroud displacement, if any, at these locations would be small and would not affect the ability to insert the control rods if necessary.

The consequences of operation during anticipated operational transients with a $360^{\circ}$ through-wall crack in the shroud are bounded by the design basis accident analysis in Section 4.3. It is expected that the following anticipated operational transients could increase shroud loads above those experienced during normal operation:

(1) pressure regulator failure - open;

(2) recirculation flow control failure - increasing to maximum flow;

(3) inadvertent actuation of the Automatic Depressurization System (ADS).

For a 3600 through-wall crack, these loads could lead to complete weld separation and/or result in higher upward displacements than normal operations. All licensee analyses concluded that during such postulated events, MCPR Safety Limit, Low Water Level, and Reactor Overpressure Limit are not violated.

\subsection{Safety Significance of $360^{\circ}$ Through-Wall Cracks During Design Basis Accidents}

In order to assess the significance of potential cracking beyond that observed to date, the staff has evaluated the safety implications of a postulated $360^{\circ}$ circumferential separation of the shroud. The staff has determined that the detectability and consequences of $360^{\circ}$ through-wall cracking relate directly to the cracked weld location. The main concern associated with cracks in the upper shroud welds arises during a postulated MSLB concurrent with a $360^{\circ}$ through-wall failure of a shroud. During such a postulated accident, the resulting differential pressures are expected to be large enough to vertically displace the remaining upper shroud assembly. These lifting forces potentially could elevate the top guide above the fuel assemblies. The resulting safety concerns would include a loss of lateral support for the fuel assemblies, potential loss of control rod insertion capability, and potential damage to the core spray piping.

The main concern associated with cracks in the lower shroud welds arises during a RLB concurrent with a postulated $360^{\circ}$ through-wall failure of the shroud. The rapid depressurization that is characteristic of this event scenario has the potential to result in loads or moments which could cause a lateral displacement or tipping of the shroud. Such a lateral displacement or tipping of the shroud may affect the ability of plant operators to insert the control rods during the event, and may result in an opening of the shroud that could allow bypass leakage through the shroud and out of the pipe break. Large bypass leakage could potentially affect the ability of the plant operators to reflood the core, maintain adequate core cooling following the pipe break, and shut down the reactor with the standby liquid control system (SLCS).

The NRC has raised additional concerns in regard to the potential for a shroud displacement to damage other vessel internal components during postulated accident conditions. In particular, a vertical shroud displacement has the potential to damage the core shroud support legs as a result of the impact loadings that would occur upon resettling of the core shroud. Displacement of a core shroud also has the potential to damage core spray lines, particularly if the core spray lines have been degraded prior to the event.

The staff has developed a probabilistic safety assessment based on assessments of potential $360^{\circ}$ through-wall failures of the circumferential shroud welds in the Dresden Unit 3 and Quad Cities Unit 1 core shrouds. The assessment estimated the potential contribution to core damage frequency resulting from the cracked shrouds. For the upper shroud welds (e.g., the $\mathrm{H} 2$ or $\mathrm{H} 3$ welds), the staff concluded that any $360^{\circ}$ throughwall failure would be expected to be detected during normal operation (e.g., either by power/flow mismatch or noise monitoring). For lower shroud welds (H5 and lower), the staff has concluded that a $360^{\circ}$ through-wall shroud failure would have to occur concurrent with a large rupture of either a main steam line or a recirculation line to be capable of achieving the loading magnitudes that could move the shroud. However, it should be noted that probabilistic risk assessments categorize such MSLBs and RLBs to be low frequency events. To date, no MSLB or RLB has ever occurred at an operating nuclear plant, and the unlikely occurrence of a $360^{\circ}$ through-wall crack concurrent with a large pipe break would be necessary to pose any incremental risk. Finally, the shroud may not move in the most adverse manner during these events, and there is a good chance that core cooling and reactor shutdown would be achieved with no adverse consequences. 
Considering these assessments, the staff concluded that core shroud cracking does not pose a high degree of risk for the short term, and that immediate plant shutdowns were not warranted for inspections. However, the staff concluded that degradation of the core shroud could impact plant safety if plants with degraded shrouds were allowed to continue to operate for extended periods. The staff therefore concluded that $360^{\circ}$ cracking of the shroud was a safety concern for the long term based on the following considerations:

(1) the potential for exceeding the ASME Code structural margins if the cracks are sufficiently deep and continue to propagate through the subsequent operating cycle;

(2) the uncertainties associated with the behavior of a $360^{\circ}$ through-wall cracked core shroud under accident conditions;

(3) elimination of a layer of defense-in-depth for plant safety.

To date, the majority of BWR industry licensees have conducted inspections, evaluations, and/or repairs of their core shrouds to address the issue of core shroud and BWR internal cracking. Such inspection, evaluation, and repair activities adequately ensure that simultaneous failure of multiple internal components will not result in adverse risk to the general public. Therefore, the staff has concluded that the current status of BWR core shrouds and internal components does not constitute a high degree of risk to the general public at this time. 


\section{BWR CORE SHROUD CRACKING - SUMMARY OF SIGNIFICANT OPERATING EXPERIENCE}

\subsection{Cracking at a Foreign BWR}

In 1990, the General Electric Company (GE) reported the occurrence of cracking in the core shroud of a foreign BWR. The shroud cracks were located in the HAZ of a circumferential core shroud weld in the reactor's beltline region. The reactor had completed approximately 190 months of power operation before the flaw indications were discovered.

As a result of this discovery, GE issued Rapid Information Communication Services Information Letter (RICSIL) 054, "Core Support Shroud Crack Indications," on October 3, 1990 (Ref. 3), to all owners of GE-designed BWRs. RICSIL 054 summarized the cracking found in the core shroud of the foreign BWR. It also recommended that nuclear utilities owning BWRs with high-carbon steel core shrouds perform a visual examination of the accessible areas of the shroud seam (circumferential) welds and associated HAZs on the inside and outside shroud surfaces.

\subsection{Cracking at Brunswick Steam Electric Plant, Unit 1}

In early July 1993, the Carolina Power and Light Company (CP\&L) performed enhanced visual testing (VT-1) examinations of the core shroud at the Brunswick Steam Electric Plant, Unit 1 (BR-1). CP\&L conducted the VT-1 examinations of the core shroud welds on the inside and outside surfaces of the shroud, in accordance with the recommendations of GE RICSIL 054. The results of the VT-1 examinations revealed the presence of numerous flaw indications in the core shroud.

GE issued RICSIL O54, Rev. 1, "Core Shroud Cracks," dated July 21, 1993 (Ref. 4), to inform the industry of the cracking in the BR-1 shroud. In addition, the NRC informed the industry of the BR-1 shroud cracking in Information Notice (IN) 93-79, "Core Shroud Cracking at Beltline Region Welds in Boiling-Water Reactors," dated September 30, 1993 (Ref. 5).

The most extensive flaw indication in the BR-1 shroud was located on the inside shroud surface of the $\mathrm{H} 3$ weld. CP\&L determined that the crack was located in the HAZ of the weld. This circumferential weld joins the top guide support ring to the middle shroud shell. Using conservative assumptions, CP\&L hypothesized that the crack could extend nearly $360^{\circ}$ around the circumference of the weld. Boat samples taken from the $\mathrm{H} 3$ weld identified IGSCC as the cracking mechanism, and indicated that the $\mathrm{H} 3$ flaws could be more than $0.036 \mathrm{~m}$ (1.4 in) deep. The VT-1 examinations also revealed circumferential cracking along significant portions of welds $\mathrm{H} 1$ and $\mathrm{H} 2$ (using conservative assumption, up to $74 \%$ and $68 \%$ of the weld circumferences, respectively). In addition, CP\&L reported minor cracking associated with the HAZs of circumferential welds H4, H5, H6a, and H6b.

GE analyses of the cracks at the $\mathrm{H} 1, \mathrm{H} 2$, and $\mathrm{H} 3$ welds indicated that structural margins would still be maintained for the next operating cycle. Nonetheless, CP\&L opted to modify the core shroud in order to ensure the structural integrity of the $\mathrm{H} 2$ and $\mathrm{H} 3$ welds during normal operating, transient and postulated accidental loading conditions. The modification involved installing a series of mechanical clamps around the $\mathrm{H} 2$ and $\mathrm{H} 3$ welds. These clamps were designed by the General Electric Company (GE) to provide an alternative load bearing capability in lieu of the $\mathrm{H} 2$ and $\mathrm{H} 3$ welds. The NRC reviewed the clamp design in the Fall of 1993 and accepted the design for implementation on January 14, 1994 (Ref. 6).

\subsection{Cracking at Commonwealth Edison Plants}

Commonwealth Edison Company (ComEd) reported cracking in the core shrouds of Dresden Unit 3 (DR-3) and Quad Cities Unit 1 (QC-1). ComEd discovered these cracks as a result of shroud examinations conducted during the DR-3 and QC-1 Spring 1994 refueling outages (RFOs). The most extensive cracking at each plant was associated with the H5 weld, which joins the mid-shroud shell to the shroud's core plate support ring. The licensee's examinations included both enhanced VT-1 and ultrasonic testing (UT) methods. Using conservative assumptions, ComEd determined that the cracks could extend nearly $360^{\circ}$ around the circumference of the welds. 
To inform the industry of the cracking at DR-3 and QC-1, the NRC issued IN 94-42, "Cracking in the Lower Region of the Core Shroud in Boiling-Water Reactors," dated June 7, 1994, and Supplement 1, dated July 19, 1994 (Refs. 7 and 8). Instead of opting to perform an immediate repair of the DR-3 and QC-1 core shrouds, ComEd proposed to operate these plants for an additional 24 months while they designed and fabricated a permanent repair.

To support the conclusion that both of these units could be operated safely, the licensee submitted a safety evaluation demonstrating the DR-3 and QC-1 core shrouds would meet the following safety criteria:

(1) The existing cracks would not propagate through the shroud wall during the next fuel cycle.

(2) The existing uncracked ligaments would continue to provide sufficient structural integrity and to meet the requirements of the ASME Code.

(3) The existing cracks would not compromise the safety function of the shroud under all postulated design-basis accident conditions.

ComEd concluded that the plants could be operated for their full cycles. The NRC reviewed the licensee's flaw evaluations and safety assessments regarding the DR-3 and QC-1 core shrouds. The NRC also performed independent analyses of the DR-3 and QC-1 core shrouds in order to validate the licensee's results and conclusions. The staff based the analyses on a bounding initial crack depth of $0.033 \mathrm{~m}$ (1.3 in) and a bounding crack growth rate of $3.5 \mathrm{E}-10 \mathrm{~m} / \mathrm{s}(5 \mathrm{E}-5 \mathrm{in} / \mathrm{hr})$. The staff did not allow for additional structural margin credit created by the inner diameter fillet weld at H5. Upon conclusion of the reviews, the staff determined that the ASME Code margins (and thereby, the requirements of 10 CFR 50.55a) would be satisfied for 15 months of hot operation commencing from the time of the DR-3 and QC-1 startups. The staff issued its Safety Evaluation Report (SER) regarding the cracking in the DR-3 and QC-1 core shrouds on July 21, 1994 (Ref. 9).

\subsection{Cracking at Oyster Creek Nuclear Generation Station}

General Public Utilities (GPU), the licensee for the Oyster Creek Nuclear Generation Station (OCNGS) inspected the OCNGS core shroud during the Fall 1994 refueling outage. GPU's examinations of the OCNGS core shroud included UT inspections of accessible areas on shroud welds $\mathrm{H} 1, \mathrm{H} 2, \mathrm{H} 4, \mathrm{H} 5$, and $\mathrm{H} 6 \mathrm{a}$, and enhanced visual examinations of welds $\mathrm{H3}, \mathrm{H} 6 \mathrm{~b}$, and H9. The results of the shroud examinations indicated significant cracking at the $\mathrm{H} 4$ weld. This weld joins the upper mid-shroud shell to the lower mid-shroud shell, and is in the vicinity of the reactor beltline region. The results of the OCNGS shroud examinations also indicated some minor cracking at the $\mathrm{H} 2$ and $\mathrm{H} 3$ welds.

After completing the UT examinations of the $\mathrm{H} 4$ weld, GPU decided that they would modify the OCNGS core shroud before restarting the unit. GPU submitted its design for the OCNGS core shroud modification on October 25, 1994 (Ref. 10). The OCNGS core shroud modification involved installing a series of tie rod assemblies symmetrically around the shroud. These tie rod assemblies are designed by MPR to restrict vertical and lateral motion of the shroud, assuming that all circumferential welds in the core shroud fail coincident with a design basis event.

The staff issued its SER regarding the OCNGS core shroud modification on Nov. 25, 1994 (Ref. 11). The staff concluded that the shroud modification design selected by GPU provides an acceptable alternative load carrying capability for the OCNGS core shroud. The staff therefore concluded that the modification design was acceptable for implementation.

\subsection{Cracking at Vermont Yankee Nuclear Power Station}

The Vermont Yankee Nuclear Power Corporation (VYNPC), the licensee for the Vermont Yankee Nuclear Power Plant (VY), has completed NDEs of the VY core shroud and feedwater nozzles. These examinations were scheduled as part of VYNPC's GL 94-03 and NUREG-0619 activities, respectively. Preliminary results of VYNPC's core shroud examinations indicated that a significant degree of cracking $\left(\approx 340^{\circ}-345^{\circ}\right.$ in circumference) existed in VY core shroud weld H5, which joins the lower mid-shroud shell to the core support ring. VYNPC also determined that cracking of a lesser degree was indicated at shroud welds $\mathrm{H} 1, \mathrm{H} 2$, $\mathrm{H3}, \mathrm{H} 4$, and H6. All feedwater nozzle examinations were negative for relevant indications.

VYNPC's flaw evaluations of indications in the $\mathrm{H1}, \mathrm{H} 2$, $\mathrm{H} 3, \mathrm{H} 4$, and $\mathrm{H} 6$ welds indicated that the welds have sufficient structural margins for at least two additional 
operating cycles. In evaluating these welds, VYNPC conservatively assumed that all relevant indications were through-wall cracks.

VYNPC's flaw evaluation of the H5 weld indicated that the H5 weld has sufficient structural margin to justify one more cycle of plant operation. In evaluating the H5 weld, VYNPC conservatively assumed that all uncracked areas and all areas with indications less than $0.013 \mathrm{~m}$ ( 0.5 in) deep contained cracks $0.013 \mathrm{~m}(0.5$ in) in depth. VYNPC also conservatively assumed that areas not inspected contained continuous through-wall cracks, and that any relevant indications with crack depths greater than $0.013 \mathrm{~m}(0.5 \mathrm{in})$ were also through-wall in nature. The flaw evaluations also included conservative allowances for crack growth and NDE uncertainties. VYNPC submitted the results of its inspections and evaluations for review by the staff on April 20, 1995 (Ref. 12). VYNPC's submittals included a consequence analysis (safety analysis) of the VY core shroud.

The staff reviewed VYNPC's examination results, flaw evaluations and consequence analyses regarding the VY core shroud. The staff determined that the VY core shroud has sufficient remaining structural margins to justify one additional cycle of operation. The staff issued its SER regarding the structural integrity of the VY core shroud on April 27, 1995 (Ref. 13). 



\section{INDUSTRY EFFORTS TO ADDRESS THE IGSCC ISSUE}

\subsection{Generic Approach Taken to Resolve the IGSCC Issue}

IGSCC in BWR internal components is a long-term problem. As BWRs begin to age, the number of IGSCC incidents in BWR internal components is expected to increase. For this reason, the NRC has encouraged the BWR industry to take a conservative, long-term approach to resolve the issue of IGSCC in BWR internal components. The approach involves the following steps:

(1) direct interaction between the NRC and the industry organizations, namely the Boiling Water Reactor Owners Group (BWROG) and the Boiling Water Reactor Vessels and Internals Project (BWRVIP)

(2) NRC assessment of generic guidelines established by the BWR industry organizations

(3) NRC assessment of plant specific actions on an individual basis

The important aspect of this approach is that it is proactive rather than reactive, since it encourages the industry to develop and implement appropriate inspections programs along with predetermined acceptance criteria and repair methods. Effective inspection programs will enable licensees to detect cracking before it becomes a safety concern, and predetermined acceptance criteria and repair methods will ensure optimal use of industry and NRC resources.

\subsection{Efforts by the Boiling Water Reactor Owners Group}

The BWROG submitted its criteria for evaluating BWR core shrouds in a letter to the NRC dated April 5, 1994 (Ref. 14). The inspection strategy detailed in the BWROG report focuses on a ranking system that bases a plant's IGSCC susceptibility according to its age, construction materials, and reactor coolant conductivity level. The BWROG then updated and refined its susceptibility rankings, which were forwarded to the NRC in a submittal dated July 13, 1994 (Ref. 15). In this submittal, the BWROG, in conjunction with GE, provided an evaluation of core shroud cracking observed in domestic BWRs that had previously been inspected.
The plants that have experienced the most extensive cracking have been operated for longer than 8 years and had histories of moderate to high coolant conductivities when averaged over the first 5 cycles of operation.

The BWROG evaluation indicated that the structural margins for the plants with the most susceptible core shrouds would be maintained for at least one additional cycle of operation at current conductivity levels. The BWROG concluded that it was unlikely that any development of cracking would fail to satisfy the safety margins specified in Section XI of the ASME Code. However, because of uncertainties in the assumptions used in the safety evaluation, such an occurrence could not be ruled out. The NRC issued GL 94-03, in part, "to ascertain the likelyhood of such an occurrence and to take appropriate corrective action(s)" as necessary. Both the BWROG and individual licensees have indicated that repairs would be implemented for cases in which it is uncertain that ASME Code margins could be met.

Revision 1 of the BWROG's submittal dated July 13, 1994, was received on August 5, 1994 (Ref. 16), along with a response (Ref. 17) to a request for additional information (RAI) that the NRC forwarded to the BWROG on May 12, 1994 (Ref. 18). The BWROG's submittal of August 5, 1994, categorized BWR core shrouds into seven IGSCC susceptibility groups for ranking purposes. These susceptibility rankings were established to aid the individual BWR utilities in their efforts to address the criteria established in GL 94-03.

\subsection{Establishment of the Boiling Water Reactor Vessel and Internals Project}

In a meeting on June 28, 1994, the BWROG informed the staff that a new industry organization, the Boiling Water Reactor Vessel and Internals Project (BWRVIP) had been established solely to address the issue of agerelated degradation of BWR internal components. The BWRVIP comprises five subcommittees: (1) Integration, (2) Inspection, (3) Assessment, (4) Mitigation, and (5) Repair. Each subcommittee is chaired by both a top executive from one of the BWROG member utilities and a engineering staff member from the industry. This organization is designed to ensure that the BWRVIP's 
efforts are reviewed on both the technical and executive levels, and to encourage widespread industry acceptance of BWRVIP guidelines, criteria, and methods. To date, individual BWROG members have shown widespread support for the BWRVIP's efforts and activities.

On September 2, 1994, the BWRVIP submitted the "BWR Core Shroud Inspection and Evaluation Guidelines" to the NRC (Ref. 19). These guidelines supplemented and superseded the information regarding core shroud inspection scopes and flaw evaluations contained in the BWROG generic safety assessment of August 5, 1994. In summary, the "BWR Core Shroud Inspection and Evaluation Guidelines" reduced the number of susceptibility categories from seven to three. The factors considered in forming the categories included hot operating time (until next refueling outage), mean reactor coolant conductivity values when averaged over the first five operating cycles, carbon contents of the core shroud construction materials (Type 304 stainless steel vs. Type 304L stainless steel), and methods of fabrication. All operating BWR plants were then grouped into one of three categories ("A," "B, " or "C") based on the potential of their internal components to develop IGSCC and on previous field inspection experience. Categories "A," "B," and "C" are described in more depth in Table 6.2-1. Plant-specific data regarding the BWRVIP rankings are provided in Appendix B of this report. However, it should be noted that plant categorizations may change as plants accrue operating time.

The BWRVIP "BWR Core Shroud Inspection and Evaluation Guidelines" also recommended inspection schedules and scopes based on the susceptibility rankings of the plants. The BWRVIP inspection guidelines provided licensees with Category "A" plants the option of postponing core shroud inspections until eight cumulative years at power had elapsed at their facilities. The BWRVIP recommended that licensees with Category "B" plants perform limited VT-1 or UT inspections of their core shrouds at the next plant refueling outage. For licensees with Category " $\mathrm{C}$ " plants, the BWRVIP recommended VT-1 or UT inspections of welds $\mathrm{H} 1$ through $\mathrm{H} 7$ (through $\mathrm{H} 8$ for BWR-2 plants) at the next refueling outage.

The BWRVIP did not initially recommend 100\% inspection of all accessible circumferential weld areas. Instead, the BWRVIP initially stated that weld coverages only had to be comprehensive to the extent they proved the existance of sufficiently long, unflawed ligaments which would ensure each weld's integrity during power operation (Ref. 19). The staff informed the BWRVIP that this "minimum ligament inspection scope" was too narrow to give an accurate indication of cracking in a core shroud (Refs. 20 and 21). In Revision 1 to the "BWR Core Shroud Inspection and Evaluation Guidelines," dated April 21, 1995 (Ref. 22), the BWRVIP amended its earlier recommendations by recommending that inspection scope for Category " $\mathrm{C}$ " core shrouds cover $100 \%$ of the accessible areas of circumferential welds $\mathrm{H} 1-\mathrm{H} 7$ (through $\mathrm{H} 8$ for BWR-2 designs). The staff concluded that the BWRVIP's alternate inspection scope recommendation for Category "C" shrouds was acceptable (Ref. 23). The NRC issued its SERs regarding the "BWR Core Shroud Inspection and Evaluation Guidelines, " Revision 0 and Revision 1, on December 28, 1994, and June 16, 1995, respectively. (Refs. 21 and 23).

The BWRVIP has committed to submit additional correspondence regarding BWR core shroud and internal components in the future. The proposed submittals will provide an integrated safety assessment of the issue, reinspection scopes and acceptance criteria, and mitigation measures, as well as changes to the core shroud repair criteria. A submittal from the BWRVIP Repair Technical Subcommittee regarding repair options was received by the staff on August 18, 1994 (Ref. 24). This submittal provided information regarding suggested criteria for the evaluation of licensee repair options. The staff issued its evaluation of the BWRVIP repair design criteria on September 29, 1994 (Ref. 25). Figure 6.3-1 provides an example of a typical core shroud modification (repair) design that has been submitted to the staff for review. The staff will continue to review core shroud modification design submittals on a case-by-case basis.

\subsection{Activities of the General Electric Company}

GE initially reported the cracking found at KKM in RICSIL 054. On October 4, 1993, GE issued Services Information Letter (SIL) 0572, Rev. 1 (Ref. 26), to incorporate domestic data on shroud cracking, and to update recommendations for inspecting BWR core shrouds.

In SIL 0572, Rev. 1, GE recommended that BWR licensees perform visual or ultrasonic inspections of their core shrouds for a statistically significant sample size of accessible welds and associated HAZs. GE also 
recommended that the inspections be performed after six effective full-power years (EFPY) if the shroud is fabricated from normal carbon content austenitic stainless steel $(0.03 \%$ to $0.08 \% \mathrm{C})$, or after $8 \mathrm{EFPY}$ if the shroud is fabricated from austenitic stainless steel of a low carbon content $(<0.03 \%$ C). GE also recommended that licensees reinspect the shrouds at every refueling outage if cracking was observed, or every two outages if cracking was not observed. No guidance was given concerning structural integrity or repair.

Metallurgical aspects of cracks in core shrouds fabricated from Type 304L stainless steels were also discussed in GE RICSIL 068, Rev. 1, dated April 14, 1994 (Ref. 27). On May 6, 1994, GE issued RICSIL 068, Rev. 2 (Ref. 28) to supplement RICSIL 068, Rev. 1, and to update the lessons learned from core shroud visual and ultrasonic examination data of low-carbon " $L$ "-grade stainless steel core shrouds. In RICSIL 068, Rev. 2, GE also provided cautions about the adequacy of visual examination procedures, and discussed whether ultrasonic examination methods are preferable to visual examination methods under certain circumstances.

\subsection{Activities of the Electric Power Research Institute}

Because core shroud examinations involve a complex, detailed set of activities, they must be planned well in advance in order to be effective. A licensee must first determine which core shroud welds must be included in the inspection scope to provide for a sufficient assessment of the core shroud, and then must determine which NDE methods are best suited for these examinations. Core shroud NDEs normally involve manipulation of complex instruments by utility NDE and engineering staff members.

The BWR industry has contracted with the Electric Power Research Institute (EPRI) to assist industry licensees in implementing NDE examinations of their BWR core shrouds and other internal components. EPRI's efforts have included the design of a series of core shroud mockups, that can be used to qualify the UT scanning equipment. These mockups are designed to contain electrodischarge machined (EDM) notches of known length and depth, and realistic IGSCC defects. Qualification of the UT examination techniques can then be accomplished by comparing the results of UT analyses to the known lengths and depths of the EDM notches and realistic IGSCC defects . Qualification of UT techniques is normally conducted at the EPRI NDE Center in Charlotte, North Carolina. EPRI is also currently investigating whether or not eddy current testing (ET) is an appropriate NDE method for BWR internal components. However, the NRC has not yet accepted ET for use on BWR internal components. 


\section{Table 6.2-1 BWRVIP Susceptibility Rankings and Core Shroud Inspection Recommendations ${ }^{1}$}

\begin{tabular}{|c|c|c|c|}
\hline CATEGORY & $\begin{array}{c}\text { INSPECTION } \\
\text { RECOMMENDATIONS }\end{array}$ & PLANT CHARACTERISTICS & PLANTS \\
\hline \multirow[t]{2}{*}{ "A" } & \multirow[t]{2}{*}{$\begin{array}{l}\text { No inspection } \\
\text { necessary at } \\
\text { this time. }\end{array}$} & $\begin{array}{l}\text { Plants with } 304 \text { SS shrouds, } \\
<6 \text { years hot operating time, and } \\
\text { avg. conductivities } \leq 0.030 \mu \mathrm{S} / \mathrm{cm} \\
(0.030 \mu \mathrm{mhos} / \mathrm{cm}) \text { during the first } \\
\text { five cycles of operation. }\end{array}$ & None \\
\hline & & $\begin{array}{l}\text { Plants with } 304 \mathrm{~L} \text { SS shrouds, } \\
<8 \text { years hot operating time, and } \\
\text { avg. conductivities } \leq 0.030 \mu \mathrm{S} / \mathrm{cm} \\
(0.030 \mu \mathrm{mhos} / \mathrm{cm}) \text { during the first } \\
\text { five cycles of operation. }\end{array}$ & $\begin{array}{l}\text { Clinton, Fermi 2, Perry, } \\
\text { Hope Creek, Limerick 2, } \\
\text { Nine Mile Point 2, } \\
\text { Washington Nuclear Plant 2, } \\
\text { River Bend }\end{array}$ \\
\hline "B" & $\begin{array}{l}\text { Limited inspection: } \\
\text { top guide support ring, } \\
\text { core support ring, and } \\
\text { mid shroud shell } \\
\text { circumferential welds; } \\
\text { also the bimetallic weld if } \\
\text { accessible. }\end{array}$ & $\begin{array}{l}\text { Plants with } 304 \mathrm{~L} \text { SS shrouds, } \\
\geq 8 \text { years hot operating time, and } \\
\text { avg. conductivities } \leq 0.030 \mu \mathrm{S} / \mathrm{cm} \\
(0.030 \mu \mathrm{mhos} / \mathrm{cm}) \text { during the first } \\
\text { five cycles of operation. }\end{array}$ & $\begin{array}{l}\text { Grand Gulf, } \\
\text { Lasalle } 1 \text { \& } 2, \\
\text { Limerick } 1, \\
\text { Susquehanna } 1 \text { \& } 2\end{array}$ \\
\hline \multirow[t]{3}{*}{ "C" } & \multirow[t]{3}{*}{$\begin{array}{l}\text { Comprehensive Inspection: } \\
\text { circumferential shroud } \\
\text { welds } \mathrm{H} 1-\mathrm{H} 7 \\
\text { (and H8 for BWR-2s) }\end{array}$} & \multirow[t]{2}{*}{$\begin{array}{l}\text { Plants with } 304 \text { SS shrouds and } \\
\geq 6 \text { years hot operating time, } \\
\text { regardless of conductivity. }\end{array}$} & $\begin{array}{l}\text { Shrouds - weld. plate rings } \\
\text { Brunswick } 1 \& 2, \\
\text { Dresden } 2 \text { \& 3, } \\
\text { FitzPatrick, Hatch 1, } \\
\text { Millstone 1, Oyster Creek, } \\
\text { Nine Mile Point 1, Pilgrim, } \\
\text { Quad Cities } 1 \& 2\end{array}$ \\
\hline & & & \begin{tabular}{|l} 
Shrouds - forged rings \\
Browns Ferry 1, 2, \& 3, \\
Peach Bottom 2 \& 3, \\
Vermont Yankee, \\
Monticello, Cooper \\
\end{tabular} \\
\hline & & $\begin{array}{l}\text { Plants with } 304 \mathrm{~L} \text { SS shrouds, } \\
\geq 8 \text { years hot operating time, and } \\
\text { avg. conductivities }>0.030 \mu \mathrm{S} / \mathrm{cm} \\
(0.030 \mu \mathrm{mhos} / \mathrm{cm}) \text { during the first } \\
\text { five cycles of operation. }\end{array}$ & Duane Arnold, Hatch 2 \\
\hline
\end{tabular}

NOTES: 1. Modified from Table 3.1, "BWR Core Shroud Inspection and Evaluation Guidelines." (Ref. 19)

ABBREVIATIONS: 304 SS - Type 304 Stainless Steel (Normal Carbon Content)

304L SS - Type 304L Stainless Steel (Low Carbon Content)

$\mu \mathrm{S} / \mathrm{cm}$ - Unit of conductivity in microSiemens per centimeter 


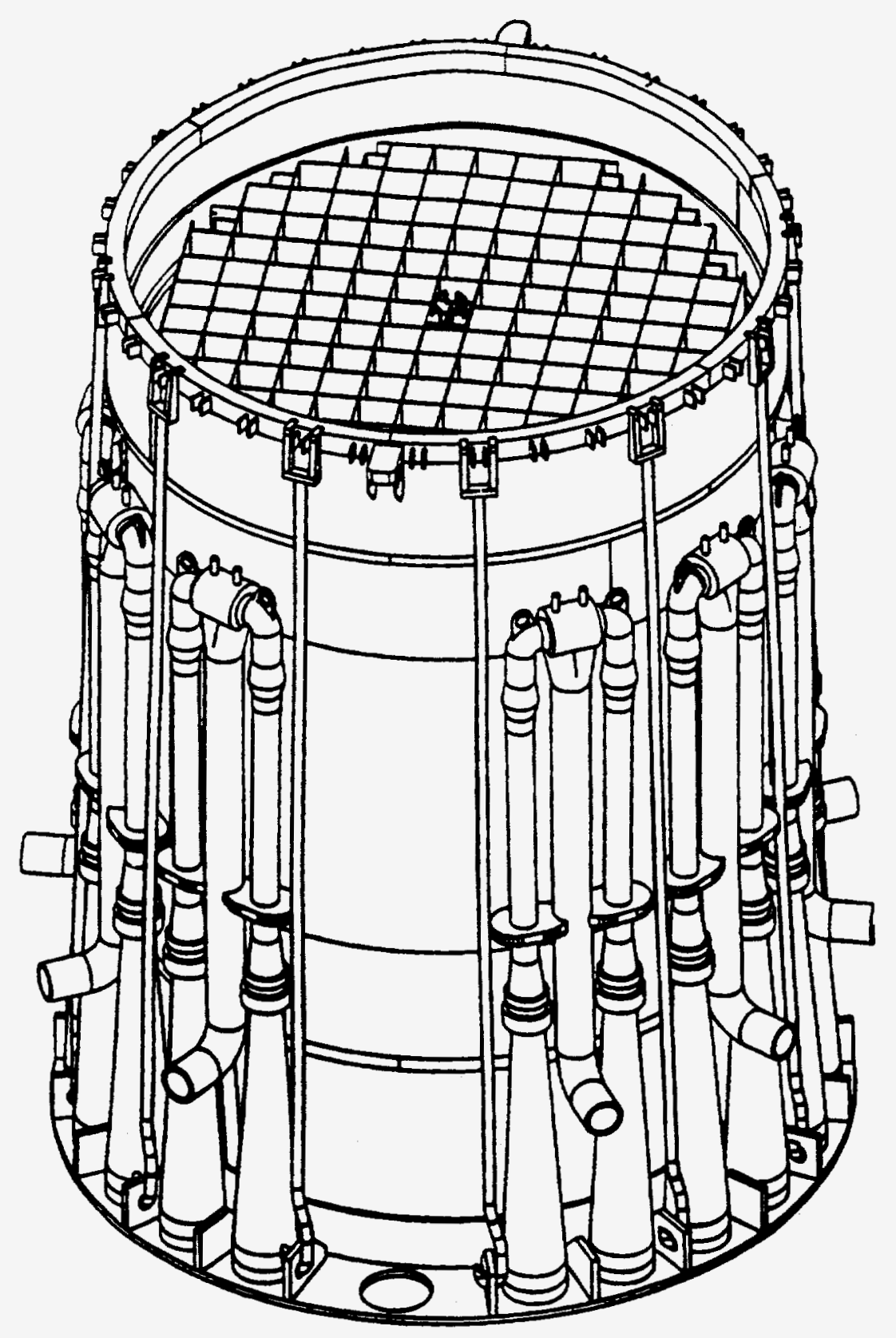

Figure 6.3-1 Typical Modification Design Proposed for Repair of BWR Core Shrouds 



\section{GL 94-03, "INTERGRANULAR STRESS CORROSION CRACKING OF CORE SHROUDS IN BOILING WATER REACTORS"}

\subsection{Content of GL $94-03$}

On July 25, 1994, the NRC issued GL 94-03, "Intergranular Stress Corrosion Cracking of Core Shrouds in Boiling Water Reactors," to all BWR licensees (with the exception of Big Rock Point, which does not have a core shroud). The NRC staff requested in GL 94-03 that licensee's take the following actions with respect to their core shrouds:

(1) Inspect BWR core shrouds no later than the plant's next refueling outage.

(2) Perform materials related and plant-specific safety analyses with respect to the core shrouds.

(3) Develop core shroud inspection plans, which address inspection of all core shroud welds and take into account the latest available technology developed by the industry for inspection of BWR internal components.

(4) Develop plans for core shroud evaluation and/or repair.

The staff also recommended in GL 94-03 that licensees work closely with the BWROG to address the issue of IGSCC of BWR internal components.

The NRC staff requested that licensees submit, under oath or affirmation, the following information in response to GL 94-03 within 30 days from the date of issuance:

(1) a core shroud inspection schedule

(2) a safety analysis supporting continued operation of the facility until inspections are conducted

(3) one or more drawings of the core shroud configurations

(4) a history of core shroud inspections completed to date
The NRC staff also requested that licensee's submit, under oath and affirmation, no later than 3 months before inspecting or repairing of their core shrouds, the scope of the planned core shroud inspections and their plans for evaluating and/or repairing their core shrouds based on inspection results. The NRC staff further requested that licensee's submit, under oath or affirmation, their core shroud inspection results within 30 days of completing their shroud examinations.

\subsection{Generic Assessment of the Industry's Responses to GL 94-03}

The NRC's reviews covered the following items in the plant-specific responses to GL 94-03:

(1) schedules for inspection or repair of BWR core shrouds

(2) safety assessments based on postulated core shroud failures

(3) scopes of BWR core shroud inspections

(4) plant-specific inspection results

(5) core shroud flaw evaluations, as appropriate

(6) core shroud repairs, as appropriate

To facilitate its reviews, the NRC grouped the industry core shrouds according to their relative susceptibility to IGSCC, as ranked by the BWRVIP Technical Subcommittee on Inspection. (The BWRVIP rankings have been discussed in more depth in Section 6.3 of this report.) The NRC then issued safety evaluation reports (SERs) for all BWRs in the industry, with the exception of Big Rock Point, which does not have a core shroud.

In order to simplify its task of determining whether or not individual BWR licensees could justify operation of their units to the respective RFOs, the NRC performed a generic assessment of the results of core shroud inspections conducted before July 1995 . The staff 
determined that no cases of $360^{\circ}$ through-wall cracks occurred in any core shroud inspected before July 1995, and no BWR had exhibited any symptoms (power-toflow mismatch) that would be indicative of bypass leakage from a $360^{\circ}$ through-wall crack. Furthermore, the staff determined that, in all cases, sufficient ligaments remained in the core shrouds to provide a reasonable assurance that the structural integrity of the shrouds would be maintained during the current plant operating cycles. The staff also determined that, in all cases, the frequency of an initiating event which could challenge the structural integrity of a core shroud was low. In addition, the staff noted that only a short time remained before the scheduled RFOs when the licensees would inspect or repair their respective core shrouds. The NRC therefore concluded that, in all cases, the licensees provided sufficient technical bases to justify operation of their units to their next respective RFOs. 


\section{PLANT-SPECIFIC ASSESSMENTS AND RESULTS OF CORE SHROUD INSPECTIONS OR REPAIRS}

\subsection{Overview}

This chapter provides the staff's assessments regarding the plant-specific responses to GL 94-03 and a discussion of the industry's inspection and repair activities to date. Appendix B augments this discussion by summarizing the plant-specific core shroud data, and providing an overview of pertinent information requested from licensees, concerning core shroud materials, operation, and fabrication. The NRC found this information essential to its assessments of the susceptibility of industry core shrouds to IGSCC. The plant-specific core shroud summaries also include discussions of the plant-specific inspections and repairs performed by the industry through the end of September 1995, and a list of the corresponding SERs and acknowledgement letters issued by the NRC in response to the industry's submittals to GL 94-03.

\subsection{Boston Edison Company}

\subsubsection{Assessment of the Response to GL 94-03 for the Pilgrim Nuclear Power Station}

Boston Edison Company (BECo), the licensee for the Pilgrim Nuclear Power Station (PNPS), responded to GL 94-03 on August 27, 1994 (Ref. 29). The licensee's response included a schedule for inspection of the PNPS core shroud and a safety assessment to support continued operation of PNPS until the April 1995 RFO. In a public meeting on October 4, 1994, and in submittals dated October 13, 1994 (Ref. 30), and October 28, 1994 (Ref. 31), BECo provided additional information to support its justification for continued operation (JCO) of PNPS until the April 1995 RFO.

BECo reviewed the plant-specific susceptibility factors regarding the PNPS core shroud. In submitting its findings to the staff in its plant-specific response to GL 94-03, BECo informed the NRC that the PNPS core shroud was fabricated from type 304 plate materials with carbon content typically in the range of $0.040-0.065 \%$. BECo also stated that PNPS had operated in excess of 15 years, and that average reactor coolant conductivity over the first five years of operation was in excess of $0.300 \mu \mathrm{S} / \mathrm{cm}$. BECo therefore concluded that the PNPS core shroud was highly susceptible to IGSCC. In considering the plant-specific susceptibility factors for PNPS, as well as the industry-wide inspection experience and the uncertainties in the residual stress profile for the PNPS shroud, the staff concurred with BECo's susceptibility assessment of the PNPS core shroud. The staff therefore concluded that significant cracking in the PNPS core shroud could not be ruled out.

BECO performed a preliminary plant-specific flaw evaluation of the PNPS core shroud as part of its JCO. The results of the flaw evaluation showed that only a $5 \%$ remaining ligament of the PNPS shroud wall was needed to maintain the structural integrity of the core shroud under all design conditions. This evaluation was based on a limit load analysis (LLA) of the PNPS core shroud. BECo also used the GE PLEDGE model to calculate a hypothetical crack growth rate for any postulated crack in the PNPS core shroud during the remaining time in the PNPS 1994-1995 operating cycle. However, since the initial flaw size was not known, BECo used the results of the BWROG's generic crack growth analysis as a bounding analysis for the PNPS core shroud.

The BWROG's generic crack growth analysis was benchmarked using the worst crack depth measurements associated with shroud inspections performed at Brunswick Steam Electric Plant, Unit 1 (BR-1). The results of the analysis predicted that the structural integrity of the shroud wall would be maintained even with a postulated $360^{\circ}$ crack extending up to a depth of $80 \%$ of the shroud wall thickness. In addition, since hydrogen water chemistry was implemented at PNPS, BECo assumed that postulated cracks in the shroud would grow less than $2.54 \times 10^{-4} \mathrm{~m}(0.01$ inch) during the remainder of the 1994-1995 operating cycle, even if a factor of 10 was applied to account for the uncertainties in the growth rate. BECo therefore concluded that a sufficient structural margin would be maintained in the PNPS shroud to justify operation of PNPS until the April 1995 RFO.

BECO also performed a plant-specific safety assessment of the PNPS core shroud. BECo's intent was to demonstrate that fuel geometry and core cooling would be maintained given the occurrence of a through-wall 
circumferential weld failure concurrent with postulated main steam line break (MSLB) or recirculation line break (RLB) conditions. BECo also performed the safety assessment to determine whether any circumferential weld failures would be detectable by control room operators during normal operations.

BECo used the GE TRAC-G Model as the basic model for determining the differential pressures across the shroud head and shroud support during MSLB or RLB conditions. BECo concluded that any leakage through a weld separation of 0.05 or more meters (two or more inches) would be detectable during normal operations. BECo also stated that the ability to maintain reactivity control, fuel geometry, core cooling, and a refloodable volume was ensured with substantial margin, even though degraded performance was assumed in the design-basis event evaluations. On the basis of this assessment, BECo concluded that core shroud separation and/or displacement occurring during normal operations or anticipated events would have no effect on the primary safety functions of reactivity control and core cooling, which are required to mitigate design basis events.

The NRC staff used the results of the safety margin analyses of the BR-1 core shroud as its basis for evaluating the BECo safety assessment. The staff considered the BR-1 core shroud to be as susceptible to IGSCC as the shroud at PNPS. Although significant shroud cracking was identified at BR-1, the NRC staff determined that all welds had sufficient remaining ligaments to ensure adequate structural integrity of the shroud during normal operating, transient, and postulated design-basis accident conditions. The staff therefore concluded that any postulated IGSCC in the PNPS core shroud should be bounded by that detected at other BWRs of similar design. Therefore, considering that only a small remaining ligament is necessary to ensure core shroud structural integrity, and considering industry experience regarding shroud cracking, the staff concluded that the PNPS core shroud should have sufficient remaining ligament for the remainder of the operating cycle leading to the PNPS RFO in April 1995.

The NRC also performed a qualitative assessment of BECo's consequence assessment for the PNPS shroud. The staff found BECo's submittal to be a relatively complete assessment behavior expected from the PNPS core shroud in response to a postulated MSLB, RLB (including acoustic and blowdown loads), MSLB plus seismic event, and RLB plus seismic event, given a postulated through-wall failure of one of the shroud's circumferential welds. During postulated MSLB conditions, BECo's calculations demonstrated that the top guide would not lift above the fuel, indicating that no lateral movement of the fuel would occur. The NRC staff concluded that this was reasonable; however, because of inherent uncertainties in BECo's analysis methods, the staff concluded that there was a small likelihood that the top guide would lift above the fuel assemblies during a postulated MSLB concurrent with a failure of one of the upper circumferential welds. Even if this were to occur, however, the staff concluded that safe shutdown of the reactor would be achieved by manual initiation of the standby liquid control system (SLCS).

For postulated through-wall failures of circumferential shroud welds, the other initiating event of concern would be the RLB. BECo's calculations indicated that, during a postulated failure of a lower circumferential weld concurrent with an RLB, the resulting blowdown forces would induce a momentary tipping of the shroud, but no permanent lateral movement. For such shroud response, the staff agreed that little core/annulus bypass would occur during the RLB, and that adequate core flooding would be maintained during the event. Modeling the behavior of shroud with a through-wall crack in response to a postulated RLB is quite complex. Such modeling involves making assumptions regarding crack surface frictional forces and competing forces in the vertical and lateral directions. The staff therefore concluded that lateral motion of the shroud following an RLB could not be precluded.

The staff concluded that a lateral displacement of the shroud less than the magnitude of the shroud thickness would result only in small bypass leakages. However, the staff also concluded that any large lateral movement of the PNPS shroud had the potential to open a significant leakage path through the shroud wall. In this case, the staff reached the following determinations:

(1) No $360^{\circ}$ through-wall core shroud cracking had been observed to date in any U.S. BWR that had performed a shroud inspection. 
(2) All analyses performed by the licensee for PNPS showed that even if cracking did exist in its shroud, sufficient ligaments would remain in the shroud to ensure its structural integrity during normal operating conditions, operational transients, and postulated design basis events.

(3) PNPS had not exhibited any of the symptoms (power-to-flow mismatch) caused by leakage through a $360^{\circ}$ through-wall shroud crack.

(4) MSLB and RLB are low frequency events.

(5) Only a short time remained until a repair would be implemented at PNPS.

In addition, the staff noted that BECo replaced recirculation line piping, and operates the PNPS RCS with hydrogen water chemistry. These practices substantially lower the frequency of an RLB and somewhat mitigate the potential for IGSCC to occur in the core shroud. Therefore, based on these determinations, and the operational availability of the SLCS, the staff concluded that there was no undue risk to the public health and safety for the approximate four month period remaining in the PNPS 1994-1995 operating cycle, and that PNPS could safely continue to be operated until the April 1995 RFO. The NRC issued its SER regarding BECo's response to GL 94-03 on November 28, 1994 (Ref. 32)

\subsubsection{Repair of the Pilgrim Core Shroud}

BECo opted to install a pre-emptive repair (modification) of the PNPS core shroud during the April 1995 RFO. BECo's core shroud modification design was submitted to the NRC for review on January 16, 1995 (Ref. 33), and was later supplemented with additional information on February 24, 1995, March 14, 1995, and April 17, 1995 (Refs. 34-36). The NRC reviewed BECo's core shroud modification design, accepted the design in April of 1995, and issued its SER regarding the Pilgrim core shroud modification on May 12, 1995 (Ref. 37).

\subsection{Carolina Power and Light Company}

\subsubsection{Assessment of the Response to GL 94-03 for Brunswick Unit 1}

The Carolina Power and Light Company (CP\&L), the licensee for the Brunswick Steam Electric Plant, Unit 1
(BR-1), responded to GL 94-03 on August 24, 1994 (Ref. 38). The licensee's response included CP\&L's justification for continued operation (JCO) of the BR-1 reactor until RFO B110R1, which was scheduled to commence in March 1995.

CP\&L response also included the licensee's review of the materials, fabrication, and operational histories of the BR-1 core shroud. CP\&L originally inspected the BR-1 core shroud during RFO B109R1 in the summer of 1993, and submitted its inspection results and flaw evaluations to the staff in November 1993. The licensee's submittal indicated that CP\&L performed UT inspections on accessible areas of welds H1-H6b. CP\&L also performed VT-1 inspections on the accessible areas of welds H7, H8, and H9. (Section 5.2 summarizes the results of examinations performed on the BR-1 core shroud during the Summer 1993 RFO. Of particular note was the report of a $360^{\circ}$ crack at the H3 weld.)

CP\&L implemented a permanent repair of welds $\mathrm{H} 2$ and H3 in the BR-1 core shroud to ensure the structural integrity of the $\mathrm{H} 2$ and $\mathrm{H} 3$ welds during subsequent operating cycles. This repair design, which involved installing a series of clamps encompassing the $\mathrm{H} 2$ and H3 welds, was submitted to the staff in November 1993. On January 14, 1994, the staff issued a safety evaluation (Ref. 6), concluding that the structural integrity of the BR-1 core shroud would be maintained for the remainder of operating cycle leading to RFO B110R1 (Spring 1995).

\subsubsection{Reinspection of the Brunswick Unit 1} Core Shroud

During RFO B110R1, CP\&L reinspected the BR-1 core shroud to determine how much additional cracking of the BR-1 core shroud occurred during the plant's 10th operating cycle. On April 28, 1995, CP\&L submitted the results of the RFO B110R1 shroud examinations (Ref. 39). The staff will issue its SER regarding the reinspections of the BR-1 core shroud after finalizing its review of the BWRVIP's generic guidance regarding core shroud reinspections.

\subsubsection{Assessment of the Response to GL 94-03 for Brunswick Unit 2}

CP\&L, the licensee for the Brunswick Steam Electric Plant, Unit 2 (BR-2), responded to GL 94-03 on August 24, 1994 (Ref. 38). This response included 
CP\&L's justification for continued operation of BR-2 until RFO B212R1, as well as CP\&L's review of materials, fabrication, and operational histories of the BR-2 core shroud. The staff assessed the materials, fabrication, and operational histories of the BR-2 core shroud and found them to be similar to those of BR-1. The NRC staff therefore concurred with CP\&L's assessment that the BR-2 core shroud is highly susceptible to IGSCC.

CP\&L originally inspected the BR-2 core shroud during RFO B211R1 in the Spring of 1994. CP\&L did not include the $\mathrm{H} 3$ weld in its inspection scope during the outage. Instead, CP\&L implemented a permanent repair of shroud welds $\mathrm{H} 2$ and $\mathrm{H} 3$ in the same manner used at BR-1 during RFO B109R1. CP\&L also performed a 40to 50-percent inspection of the $\mathrm{H} 2$ weld before the repair to confirm some indications at $\mathrm{H} 2$ that were recorded during an earlier maintenance outage. Other inspections of the BR-2 shroud included (a) visual inspection (VT-1) of 18 percent of the $\mathrm{H} 1$ weld, (b) ultrasonic testing (UT) of 78 percent of the $\mathrm{H} 4$ weld from the outside diameter (OD) of the shroud, (c) VT-1 of 93 percent of weld H5 from the inner diameter (ID) and 30 percent from the OD, and (d) VT-1 of 11 percent of welds H6a, H6b, and $H 7$ from the $O D$ (all percentages relative to the total circumferential length of the welds). CP\&L did not inspect welds $\mathrm{H} 8$ and $\mathrm{H} 9$ based on the acceptable results of the VT-1 examinations of the corresponding welds in the BR-1 core shroud.

The BR-2 core shroud inspection results identified 23 circumferential indications at weld $\mathrm{H} 4$, seven circumferential indications at weld $\mathrm{H} 5$, and one circumferential indication at weld H6a. The longest indications were $0.35 \mathrm{~m}$ (13.6 in) in length at weld $\mathrm{H} 4$, $0.30 \mathrm{~m}(11 \mathrm{in})$ in length at weld $\mathrm{H} 5$, and $0.038 \mathrm{~m}$ (1.5 in) in length at weld H6a. These inspection results confirm that the BR-2 core shroud is highly susceptible to IGSCC.

CP\&L's previous inspections of the BR-2 core shroud were not as comprehensive as the inspections of the BR-1 shroud in 1993. However, the BR-2 core shroud inspections were performed before the issuance of GL 94-03. The inspection scope was sufficient to assess the current status of the BR-2 core shroud with regard to the presence of IGSCC. Although the BR-2 core shroud is considered highly susceptible to IGSCC, CP\&L had gathered considerable inspection data regarding the current condition of the core shroud. The licensee completed evaluations of the flaws in the $\mathrm{H} 4, \mathrm{H} 5$, and
H6a welds, and included these flaw evaluations in its response to GL 94-03. The evaluations of these shroud welds indicated that the shroud would meet structural margins for all circumferential welds for the remainder of operating cycle No. 12. The NRC staff concluded that CP\&L's previous inspection results and evaluations justified continued operation of BR-2 for the current operating cycle (Ref. 40). Reinspection of the BR-2 core shroud is scheduled for RFO B212R1 in the Summer of 1996.

\subsection{Commonwealth Edison Category " $\mathrm{C}$ " Plants}

\subsubsection{Assessment of the Response to GL 94-03 for Dresden Unit 3 and Quad Cities Unit 1}

ComEd performed comprehensive examinations of the core shrouds at Dresden Unit 3 (DR-3) and Quad Cities Unit 1 (QC-1) during May of 1994 (Ref. 41). The licensee's UT results indicated the presence of significant cracking at the H5 locations of the DR-3 and QC-1 core shrouds. ComEd's inspection results confirmed that the DR-3 and QC-1 core shrouds are highly susceptible to IGSCC. ComEd performed flaw evaluations and integrated safety assessments of the DR-3 and QC-1 core shrouds, and submitted them to the staff for review (Refs. 42 and 43).

ComEd performed its flaw evaluations of the DR-3 and QC-1 core shrouds in accordance with the flaw evaluation guidelines and acceptance criteria specified in Section XI of the ASME Code. Section 5.3 of this report discusses the ComEd inspection results and flaw evaluations in greater depth. The staff reviewed the ComEd flaw evaluations and safety assessments, and concluded that sufficient ligaments remained in the DR-3 and QC-1 core shrouds to ensure their integrity for an additional 15 months of service. The NRC issued its SER regarding the operability of the DR-3 and QC-1 core shrouds on July 21, 1994 (Ref. 9).

\subsubsection{Assessment of the Responses to GL 94-03 for Dresden Unit 2 and Quad Cities Unit 2}

In its response to GL 94-03 (Ref. 41), ComEd submitted its review of the materials, fabrication and operational histories of the core shrouds at Dresden Unit 2 (DR-2) and the Quad Cities Unit 2 (QC-2). After reviewing this information, the NRC concluded that the DR-2 and QC-2 core shrouds are susceptible to IGSCC, and that significant cracking of the DR-2 and QC-2 core shrouds 
could not be ruled out.

ComEd performed plant-specific safety assessments of the DR-2 and QC-2 core shrouds in order to justify continued operation of the DR-2 and QC- 2 plants until their respective 1995 RFOs. ComEd assumed that cracks could potentially initiate in the DR-2 and QC-2 core shrouds after three effective full power years (EFPY) of operation. ComEd's structural integrity calculation for the DR-2 core shroud resulted in a bounding crack depth of $0.016 \mathrm{~m}$ (0.64 in) for the DR-2 core shroud. ComEd's calculation also indicated that $\sim 9 \%$ remaining shroud ligament would be necessary to maintain the structural integrity of the DR-2 core shroud, even under faulted conditions (the most severe operating conditions for the plant). In performing these calculations, ComEd used what they considered realistic crack growth rates, as determined from results of the GE PLEDGE model. ComEd concluded that the remaining ligaments projected for the DR-2 shroud welds would provide considerably greater margin than that required by Section XI of the ASME Code.

ComEd also stated that the worst crack depths measured at QC-1 during the recent inspections performed during the Spring RFO would be bounding for any postulated cracking in the QC-2 core shroud. ComEd based this conclusion on the observations that the water chemistry conditions over the first 5 years of operation were similar for the QC-1 and QC-2 units, and that QC-2 has operated at power for 2 years less time than QC-1.

The DR-2 and QC-2 core shrouds are of a construction similar to that of DR-3 and QC-1 core shrouds, which were both inspected in the spring of 1994. Consequently, the NRC assessed the DR-2 and QC-2 core shrouds by benchmarking the plant-specific data against data which was previously obtained through evaluations of the DR-3 and QC- 1 core shrouds. The inspection results of the DR-3 and QC-1 core shrouds confirmed the existence of significant, circumferential cracks associated with the H5 welds of the DR-3 and QC-1 core shrouds. The NRC staff noted that the DR-2 unit had operated 2 years longer than the DR-3 reactor. However, based on plant-specific susceptibility criteria, the NRC staff concluded that the DR-2 core shroud appears less susceptible to IGSCC than the DR-3 shroud. The staff based this conclusion on the fact that the DR-2 reactor has been operating with hydrogen water chemistry for the past several operating cycles, and that ComEd had reported more incidents of cracking in safety related components at DR-3 than at DR-2.
With regard to the QC-2 core shroud, the NRC determined that $\mathrm{QC}-2$ had been on-line for approximately the same amount of time as has QC-1, and had a reactor coolant water chemistry history similar to that of QC-1. The NRC therefore concluded that the as-found conditions and determinations given in the staff's SER regarding the cracking found at QC-1 and DR-3 (Ref. 9) would bound any cracking that could potentially occur in the QC-2 and DR-2 core shrouds. In addition, the NRC concluded that the DR-2 and QC-2 core shrouds should have sufficient remaining ligaments to justify continued operation of the DR-2 and QC-2 units to their respective summer and spring 1995 RFOs, and that operation of these units to the 1995 RFOs should not adversely affect to the health and safety of the public (Ref. 44).

\subsubsection{Repairs of the Dresden, Units 2 and 3, and Quad Cities, Units 2 and 3, Core Shrouds}

On January 16, 1995 and May 24, 1995, ComEd submitted its modification designs for the QC-1 \& QC-2, and DR-2 \& DR-3 core shrouds, respectively (Refs. 45 and 46). ComEd's design modification for the core shrouds involves installation of a series of GE designed tie rod assemblies around the OD of the shrouds. The tie rod assemblies are designed to provide an alternative load bearing capability during the most severe normal operating, transient and postulated design basis accident conditions for the plants, given the occurrence of a $360^{\circ}$ through-wall failure of a circumferential shroud weld. The NRC reviewed and approved the modification design for the QC-1 and QC-2 core shrouds on June 8, 1995 (Ref. 47). The NRC evaluated and approved the core shroud modification design for DR-2 and DR-3 in the fall of 1995 (Oct. 10, 1995). ${ }^{3}$

\subsection{General Public Utilities}

\subsubsection{Assessment of the Response to GL 94-03 for the Oyster Creek Nuclear Generation Station}

General Public Utilities (GPU) submitted their response to GL 94-03 on August 24, 1994 (Ref. 48). The BWRVIP categorized the OCNGS shroud as being

3 Although the date of the staff's SER regarding the Dresden Core Shroud Modification Design is outside the time frame scope of this report, the date is listed here to indicate that the staff did approve the design for installation at the site. 
highly susceptible to IGSCC, and rated the OCNGS shroud as a Category " $\mathrm{C}$ " shroud, based on shroudmaterials and fabrication data, the number of plant years on-line, and the plant specific reactor coolant chemistry history. Upon reviewing the materials, fabrication, and operational data regarding the OCNGS core shroud, the staff concluded that the BWRVIP's assessment of the OCNGS core shroud was appropriate (Ref. 49).

\subsubsection{Inspections and Repair of the Oyster Creek Core Shroud}

GPU inspected the OCNGS core shroud during RFO 15R which commenced on September 10, 1994. The examinations of the OCNGS core shroud revealed significant cracking in the $\mathrm{H} 4$ weld. After completing the UT examinations of the H4 weld, GPU decided to modify the OCNGS core shroud (Ref. 10). (Section 5.4 discusses the OCNGS core shroud examination results and repair design in greater detail.) The staff reviewed GPU's core shroud modification design and accepted the modification on Nov. 25, 1994 (Ref. 11).

\subsection{Georgia Power Company}

\subsubsection{Assessment of the Response to GL 94-03 for Edwin I. Hatch Unit 1}

Georgia Power Company (GPC), the licensee for Edwin I. Hatch Nuclear Plant Unit 1 (HAT-1), responded to GL 94-03 on August 24, 1994 (Ref. 50). This response included GPC's review of the materials, fabrication, and operational histories (water chemistry and on-line years) of the HAT-1 core shroud.

The BWRVIP determined that the HAT-1 shroud is highly susceptible to IGSCC, and rated it as a Category " $\mathrm{C}$ " shroud. The staff determined that the BWRVIP assessment of the HAT-1 shroud was appropriate, and concluded that significant cracking of the HAT-1 core shroud could not be ruled out (Ref. 51).

\subsubsection{Repair of the Edwin I. Hatch Unit 1 Core Shroud}

On September 2, 1994, GPC submitted a design modification for the HAT-1 core shroud (Ref. 52). In its SER of September 30, 1994 (Ref. 53), the staff concluded that the HAT-1 core shroud design modification would ensure the structural integrity of the core shroud during normal, transient, and postulated design basis accident conditions, given the occurrence of a through-wall failure of a circumferential weld in the HAT-1 core shroud. GPC installed the proposed modification to the HAT-1 core shroud during the 1994 RFO, which commenced on September 15, 1994. (The core shroud modification was implemented in lieu of comprehensive core shroud examinations.) The modification involved the installation of a number of GE-designed tie rod assemblies placed symmetrically into the annulus between the reactor vessel wall and the core shroud wall.

\subsubsection{Assessment of the Response to GL 94-03 for Edwin I. Hatch Unit 2}

Georgia Power Company (GPC), the licensee for the Edwin 1. Hatch Nuclear Plant Unit 2 (HAT-2), responded to GL 94-03 on August 24, 1994 (Ref. 50). The licensee has indicated that they have scheduled a modification of the HAT-2 core shroud during the fall 1995 refueling outage (RFO) in the same manner that was used to modify the HAT-1 shroud during the fall 1994 RFO.

The BWRVIP categorized the HAT-2 shroud as a Category " $C$ " shroud. The NRC staff concluded that the BWRVIP assessment of the HAT-2 shroud was appropriate (Ref. 51).

GPC originally examined the HAT-2 core shroud during the spring 1994 RFO. These inspections were performed prior to issuance of GL 94-03. GPC performed the UT examinations of the HAT-2 core shroud using the GE O.D. Tracker UT Scanner, the GE SMART 2000 Data Acquisition/Analysis System, and a GE designed motion control system. GPC also performed enhanced VT-1 examinations in accordance with the recommendations found in GE SIL 0572, Revision 1, using a high-resolution camera capable of resolving a $2.54 \times 10^{-5} \mathrm{~m}(0.001 \mathrm{in})$ wire on a gray background. The scope of GPC's examinations included 100-percent UT examinations (from the OD surface) of the accessible areas of welds $\mathrm{H} 1-\mathrm{H} 4$, and partial enhanced VT-1 inspections from the OD surface of shroud welds $\mathrm{H} 5, \mathrm{H} 6 \mathrm{a}, \mathrm{H} 6 \mathrm{~b}, \mathrm{H} 7$, and $\mathrm{H} 8$, commencing at the $0^{\circ}$ and $180^{\circ}$ azimuthal locations.

GPC identified IGSCC indications at several of the circumferential welds, including: (1) five indications at shroud weld $\mathrm{H} 1$, the longest being $0.23 \mathrm{~m}(9 \mathrm{in})$ in length; (2) nine indications at shroud weld $\mathrm{H} 2$, the longest being $4.04 \mathrm{~m}(159 \mathrm{in})$ in length $(\approx 1 / 4$ around 
the circumference of the shroud at this location); (3) eight indications at shroud weld $\mathrm{H} 1$, the longest being $0.43 \mathrm{~m} \mathrm{(17} \mathrm{in)} \mathrm{in} \mathrm{length;} \mathrm{and} \mathrm{(4)} \mathrm{fifteen}$ indications at shroud weld $\mathrm{H} 4$, the longest indication being $0.30 \mathrm{~m}(11 \mathrm{in})$ in length. No relevant IGSCC indications were discovered by GPC in the areas inspected on the $\mathrm{H} 5-\mathrm{H} 8$ welds.

GPC performed a flaw evaluation of the $\mathrm{H} 1-\mathrm{H} 4$ weld indications in order to show that the HAT-2 core shroud would maintain its structural margins for the next HAT-2 operating cycle (Ref. 50). GPC included this flaw evaluation as part their response to GL 94-03. GPC's flaw evaluation was used to calculate the maximum allowable flaw lengths based on the most conservative stress magnitudes in the core shroud. Both LLA and LEFM methods were used for the analysis of the $\mathrm{H} 4$ weld indications. Only LLA was performed for evaluation of the $\mathrm{H} 1, \mathrm{H} 2$, and $\mathrm{H} 3$ welds, where the neutron fluence levels are lower. GPC's flaw evaluations included adjustments to account for crack proximities, crack growth, and NDE examination uncertainties.

The staff reviewed GPC's flaw evaluation of the HAT-2 core shroud and determined that the evaluation used conservative methods to determine safety margins remaining in the HAT-2 shroud. The staff also determined that the calculated safety margins were within the required values as specified in Section XI of the ASME Code. The staff therefore concluded that the HAT-2 core shroud had sufficient ligament to justify operation of the HAT-2 reactor for the remainder of the operating cycle (Ref. 51).

\subsubsection{Repair of the Edwin I. Hatch Unit 2 Core Shroud}

On July 3, 1995, GPC submitted a proposed design modification for the HAT-2 core shroud (Ref. 54). The design modification involved installing a number of GEdesigned tie rod assemblies symmetrically about the OD of the core shroud wall. In its SER dated September 25, 1995 (Ref. 55), the staff concluded that the HAT-2 core shroud modification would ensure the structural integrity of the core shroud during normal, transient, and postulated design basis accident conditions, given the occurrence of a through-wall failure of a circumferential weld in the HAT-2 core shroud. GPC installed the HAT-2 tie rod assemblies during the RFO in October 1995.

\subsection{IES Utilities, Inc.}

\subsubsection{Assessment of the Response to GL 94-03 for the Duane Arnold Energy Center}

IES Utilities (IES), the licensee for the Duane Arnold Energy Center (DAEC), responded to GL 94-03 on August 24, 1994 (Ref. 56). The IES response included a schedule for inspecting the DAEC core shroud, justification supporting continued operation (JCO) of the plant, a description of the shroud, and a discussion of past core shroud inspection results. IES based its JCO on the susceptibility of core shroud material to IGSCC, and on the absence of observed cracking in previous limited inspections of the shroud.

The core shroud at DAEC is constructed from type 304L stainless steel. The higher resistance to IGSCC of this material compared with type 304 stainless steel decreases the likelihood that extensive cracking will be observed in the DAEC core shroud. The average conductivity value of the DAEC reactor coolant during the first 5 years of operation was in the moderate range of conductivities for the industry. Although the NRC anticipated that some cracks may have initiated during the early years of operation, the staff concluded that the low carbon content of the DAEC shroud materials would tend to inhibit early IGSCC initiation.

During RFO No. 11 in 1990, IES performed limited inspections of the DAEC core shroud at accessible portions of several vertical shroud welds and at a single horizontal weld in the beltline region of the core. These inspections did not identify any indications of cracking in the DAEC core shroud. IES performed additional inspections of horizontal and vertical shroud welds in 1993 (RFO No. 12). These inspections again did not identify any flaw indications in the DAEC core shroud. However, because of the limited scope of past inspections, the NRC concluded that the possibility of significant cracks in the shroud could not be discounted.

In order to assess the IES JCO further, the staff applied its generic core shroud assessment (i.e., the assessment of core shrouds that were inspected before GL 94-03 was issued, as discussed in Section 7.2). In this case, the staff determined that its conclusions in the generic safety assessment were applicable to the DAEC core shroud. 
In its generic core shroud assessment, the staff concluded that the most highly susceptible core shrouds could contain cracks up to 80-percent of the shroud wall thickness, and still satisfy the applicable safety margin requirements of Section XI of the ASME Code. The NRC concluded that the conditions needed for initiation and growth of IGSCC in the DAEC core shroud would be bounded by the conditions at the most highly susceptible BWRs. Consequently, any postulated IGSCC in the DAEC core shroud should be bounded by the most severe cracking identified at those BWRs. The staff therefore concluded that, while significant cracking could not be entirely ruled out, the DAEC core shroud should retain adequate structural margin to justify safe operation of DAEC until the February 1995 RFO (Ref. 56).

\subsubsection{Inspection of the Duane Arnold Core Shroud}

IES performed comprehensive inspections of the DAEC core shroud during the winter 1995 RFO. The scope of IES's examinations of the DAEC core shroud covered welds H1 - H7. IES performed the examinations using the GE OD Tracker System. This system includes $45^{\circ}$ shear wave and $60^{\circ}$ longitudinal wave transducers. IES also used UT creeping wave methods for additional surface examinations of core shroud welds H1 - H6A. All examinations of the DAEC core shroud were negative for relevant indications. The results of the DAEC shroud inspections justify operation of the DAEC core shroud for the current operating cycle.

\subsection{Nebraska Public Power District}

\subsubsection{Assessment of the Response to GL 94-03 for the Cooper Nuclear Station}

Nebraska Public Power District (NPPD), the licensee for Cooper Nuclear Station (CNS), responded to GL 94-03 on August 26, 1994 (Ref. 57). NPPD's response included its review of the materials, fabrication processes and operational histories (water chemistry and on-line years) of the CNS core shroud. The BWRVIP categorized the CNS core shroud as a Category " $\mathrm{C}^{\text {" }}$ shroud. The NRC staff reviewed the materials, fabrication, and operational history information provided by NPPD, and determined that the BWRVIP's susceptibility assessment of the CNS core shroud was appropriate. The staff therefore concluded that cracking in the CNS core shroud could not be ruled out.
NPPD performed a crack growth analysis using the GE PLEDGE Model to justify operation of the CNS unit until the October 1995 RFO. NPPD's analysis indicated that most of the growth of an IGSCC-initiated crack would occur during the early portions of plant life, but would be significantly reduced after the first five cycles. NPPD's analysis also indicated that only a 7-percent shroud ligament was necessary to ensure the structural integrity of the shroud.

The NRC did not accept the results of NPPD's crack growth analysis based on GE PLEDGE Model. Instead, based on the information provided by NPPD, the staff concluded that the material and water chemistry evaluations indicate that IGSCC initiation in the horizontal welds could occur in the CNS shroud welds. Since the initial depth of a postulated crack at CNS could not definitely be established, staff determined that its generic core shroud assessment was appropriate for its evaluation of the CNS core shroud. The staff concluded in its generic core shroud assessment that the most highly susceptible core shrouds could contain cracks extending up to 80-percent into the shroud wall thickness, and still satisfy the minimum required safety margins (as specified in Section XI of the ASME Core) during the operating cycle.

The staff concluded that a generically determined crack depth of this size was conservative in relation to the thickness of the CNS shroud because the water chemistry at CNS was significantly better than that assumed in the generic evaluation. Even if this limiting crack depth value was assumed, the staff determined that sufficient structural margin would be maintained for the remainder of the current CNS operating cycle since the predicted crack growth for the current cycle was expected to be small. Based on these assessments, the staff determined that the proposed schedule for inspection or pre-emptive repair of the CNS core shroud was acceptable, and that CNS could safely continue.to be operated until the October 1995 RFO (Ref. 59).

\subsubsection{Inspection Scope for the Cooper Core Shroud}

By letter dated July 14, 1995, NPPD submitted its inspection plan for the CNS core shroud (Ref. 60). NPPD's inspection scope includes UT examinations of the accessible portions of circumferential welds $\mathrm{H} 1-\mathrm{H} 7$. This scope is consistent with the latest inspection criteria established by the BWRVIP for Category " $C$ " core shrouds (Ref. 22). The staff accepted NPPD's 
inspection scope for the CNS core shroud on September 20, 1995 (Ref. 61).

\subsection{Niagara Mohawk Power Corporation Category " $\mathrm{C}^{\text {" Plants }}$}

\subsubsection{Assessment of the Response to GL 94-03 for Nine Mile Point Unit 1}

The Niagara Mohawk Power Corporation (NMPC), the licensee for Nine Mile Point Unit 1 (NMP-1), responded to GL 94-03 on August 23, 1994 (Ref. 62). NMPC's response included a safety assessment to justify continued operation of NMP-1 until the core shroud inspection scheduled for the February 1995 RFO. On October 14, 1994, NMPC presented additional information to the staff during a meeting at the NRC headquarters regarding their structural integrity assessment of weld H8. During the meeting, NMPC also showed the staff portions of their videotape of previous inspections of weld H8. In its SER of January 13, 1995 (Ref. 63), the staff determined that its conclusions in the staff's generic assessment, as previously discussed in Section 7.2 of this report, were applicable to the NMP-1 core shroud. The staff therefore concluded that the presence of a remaining ligament in the NMP-1 core shroud, coupled with a low frequency of an initiating design-basis event and the availability of the NMP-1 SLCS, provided a reasonable assurance that the NMP-1 core shroud would meet the applicable safety margins (specified in Section XI of the ASME Code) for the remainder of the operating cycle leading to the Spring 1995 RFO.

\subsubsection{Repair of the Nine Mile Point \\ Unit 1 Core Shroud}

NMPC submitted the NMP-1 core shroud modification design to the NRC on January 6, 1995 (Ref. 64). Initially, NMPC's scope for this modification proposed the installation of MPR-designed tie rod assemblies to assume the loads acting on welds $\mathrm{H} 1-\mathrm{H} 7$, and a number of MPR-designed brackets to assume the vertical load acting on weld H8. NMPC intended to examine the $\mathrm{H1}-\mathrm{H} 8$ shroud welds in accordance with the BWRVIP inspection criteria and to install the tie-rod assemblies and/or the brackets only if the inspections revealed that the remaining ligaments in the shroud were not sufficient to meet the required ASME Code (Section XI) safety margins.
However, upon final review, NMPC decided to install the tie-rod assemblies in lieu of performing comprehensive core shroud examinations. NMPC did not install the brackets. NMPC's omission of the brackets in the design was based on the UT results of the $\mathrm{H} 8$ weld, which did not indicate the presence of any flaws in the weld. The tie rod assemblies were designed to provide a redundant load carrying capability for the NMP-1 shroud welds H1-H7. The staff reviewed the shroud modification hardware, considering structural, systems, materials, and fabrication factors. On the bases of that review, the staff concluded that the proposed modification of the NMP-1 core shroud was acceptable for implementation, and should ensure the integrity of the NMP-1 core shroud during subsequent operating cycles. The NRC issued its SER regarding the NMP-1 core shroud modification on March 31, 1995 (Ref. 65).

\subsection{Northeast Nuclear Energy Company}

\subsubsection{Assessment of the Response to GL 94-03 for the Millstone Unit 1 Core Shroud}

Northeast Nuclear Energy Company (NNECO, a subsidiary of Northeast Utilities), the licensee for the Millstone Unit 1 (MS-1), responded to GL 94-03 on August 24, 1994 (Ref. 66). However, this response omitted the detailed materials and fabrication history of the MS- 1 core shroud and an operational history of the MS-1 reactor. The licensee's basis for omitting this information was that such information was not needed to justify operation of the unit during the current operating cycle (Cycle 15). Instead, NNECO provided the results of the core shroud inspections and flaw evaluations performed during the Cycle 14 RFO (Winter 1994) as its basis for justifying continued operation of the MS-1 unit during Operating Cycle 15. The staff agreed that this was an acceptable basis for omitting the fabrication and operational history in the response to GL 94-03.

Based on the staff's review of applicable plant specific data provided by the BWRVIP, the staff determined that the MS-1 core shroud is fabricated from a material known to be susceptible to IGSCC. However, the staff also determined that NNECO has typically kept the impurities in MS-1 reactor coolant at levels well below the industry norm. The staff therefore concluded that BWRVIP's categorization of the MS-1 core shroud as a moderately susceptible Category " $\mathrm{C}$ " shroud was appropriate. 
NNECO examined the MS-1 core shroud in accordance with the recommendations of GE SIL 572, Rev. 1 (Ref. 4), which contained the most up-to-date recommendations for performing shroud examinations at the time of the examinations. The MS-1 core shroud VT-1 examinations were performed from both the OD and ID of all accessible shroud weld surfaces. NNECO performed the VT-1 examinations to a resolution of at least a $2.54 \times 10^{-5} \mathrm{~m}(0.001$ in or $1 \mathrm{mil})$ wire. NNECO cleaned the weld surface areas by manual brushing before performing the examinations. In addition, NNECO used a Westinghouse Model ETV-1250 blackand-white camera to inspect the welds and Westinghouse twin quartz tungsten lamp assemblies to illuminate the welds. All of these choices were in accordance with GE's recommendations for performing enhanced VT-1 examinations of core shroud welds.

The staff noted that NNECO inspected the MS-1 core shroud before GL 94-03 was issued. With the exception of omitting the inspection of the H5A weld, the licensee's inspection scope for the Cycle 14 RFO shroud examinations agreed with the staff's position recommending examination of $100 \%$ of the accessible weld area of core shroud welds $\mathrm{H1}-\mathrm{H} 7$ (through weld H8 for GE BWR-2 designs).

NNECO indicated that all flaw indications in the MS-1 core shroud were evaluated per Plant Nonconformance Report \# NCR 194-097. The licensee determined that all indications were acceptable for service during the current operating cycle. The staff did not formally review the licensee's method of evaluating the flaw indications in the MS-1 core shroud. Nontheless, upon reviewing the licensee's inspection results, the staff determined that the size of the flaws found by the licensee during the MS-1 shroud inspections were within the screening criteria previously established by the BWROG. These evaluation methods are consistent with the methods used to evaluate the structural integrity of the Brunswick Unit 1 core shroud, and are acceptable for use by the industry. The staff therefore concluded that sufficient structural margin exists in the MS-1 core shroud to justify operation of the MS-1 reactor during Operating Cycle 15 (Ref. 67).

\subsubsection{Reinspection Scope for the Millstone Unit 1 Core Shroud}

By letter dated July 14, 1995 (Ref. 68), NNECO submitted its scope for the MS-1 core shroud examinations scheduled for the Operating Cycle 15 RFO
(October 1995). NNECO's inspection scope includes UT examinations of the accessible portions of the accessible portions of circumferential welds $\mathrm{H} 1-\mathrm{H} 7$. This scope in consistent with the latest inspection criteria established by the BWRVIP for Category " $\mathrm{C}$ " core shrouds (Ref. 22). The staff accepted NNECO's inspection scope for the MS-1 core shroud on August 11, 1995 (Ref. 69).

\subsection{Northern States Power Company}

8.10.1 Assessment of the Response to GL 94-03 for the Monticello Nuclear Generation Plant

Northern States Power Company (NSP), the licensee for the Monticello Nuclear Generation Plant (MNGP), responded to GL 94-03 on August 23, 1994 (Ref. 70). NSP's response included its review of the materials, fabrication and operational histories (water chemistry and on-line years) of the MNGP core shroud.

The BWRVIP has categorized the MNGP core shroud as a moderately susceptible Category " $C$ " shroud. The NRC staff concluded that the BWRVIP's ranking of the MNGP core shroud was appropriate because NSP used forged fabrication methods for manufacture of the core shroud rings, and because NSP was able to maintain the MNGP reactor coolant impurities at levels slightly lower than the industry averages ( $\operatorname{Ref} 71$ ).

\subsubsection{Inspection of the Monticello Core Shroud}

NSP completed comprehensive inspections of the MNGP core shroud during the September 1994 RFO. NSP inspected 100 percent of the accessible areas of shroud welds $\mathrm{H} 1-\mathrm{H} 5$ using qualified UT examination methods, and shroud welds $\mathrm{H} 6, \mathrm{H} 8$, and $\mathrm{H} 9$ using approved enhanced VT-1 examination methods. NSP also performed enhanced VT-1 examinations of the $\mathrm{H} 4$ and H5 welds to augment the UT examinations of those welds. These inspection were done in accordance with the guidance provided by the BWRVIP.

NSP did not examine the $\mathrm{H} 7$ shroud weld, as this weld area was inaccessible to both the UT tracker equipment (as a result of obstruction from the jet pump assemblies) and to the enhanced VT-1 camera (as a result of a weld backing bar). NSP also did not inspect the vertical welds in the MNGP core shroud on the basis that vertical welds were not necessary to maintain the structural integrity of the core shroud. The staff agreed 
with the position that an inspection of vertical core shroud welds is unnecessary for core shrouds not modified by repairs. Therefore, the licensee's decision not to include these welds in the scope of the MNGP core shroud inspection was acceptable to the staff.

On October 25, 1994, NSP submitted the results of the MNGP shroud inspections performed during the fall 1994 RFO (Ref. 72). NSP indicated that the flaw evaluations of the MNGP core shroud were performed in accordance with the criteria of the ASME Code Section XI and the flaw evaluation guidance developed by the BWRVIP. NSP's examinations of the MNGP core shroud revealed minor indications at welds H2-H5. The maximum number of indications (five relevant flaw indications) occurred at weld H5. NSP's inspection results revealed that all flaw indications were less than $0.25 \mathrm{~m}$ (10 in) in length, even after adjusting crack lengths to account for crack proximity relationships. All other UT and enhanced VT-1 examinations performed by NSP were negative for relevant indications.

The staff determined that NSP's inspection results were within the screening criteria previously established by the BWR Owners Group, and that NSP's evaluation methods were consistent with the methods used to evaluate the structural integrity of the Brunswick Unit 1 (BR-1) core shroud (Ref. 6). The staff determined that these flaw evaluation methods were acceptable for use by the industry. The staff also concluded that, based on the licensee's evaluation of identified cracking, sufficient structural margin remained in the MNGP core shroud to justify operation of the MNGP reactor for the operating cycle following the fall 1994 RFO (Ref. 71).

\subsection{Philadelphia Electric Company Category " $\mathrm{C}$ " Plants}

8.11.1 Assessment of the Response to GL 94-03 for the Peach Bottom Atomic Power Station Unit 2

The Philadelphia Electric Company (PECo), the licensee for the Peach Bottom Atomic Power Station Unit 2 (PB-2), responded to GL 94-03 on August 24, 1994 (Ref. 73). PECo used the results of previous inspections of the Peach Bottom Atomic Power Station Unit 3 (PB-3) as its basis for justifying operation of PB-2 until the RFO 2R10 (September 1994). PECo has operated the $\mathrm{PB}-2$ and $\mathrm{PB}-3$ reactors for approximately the same number of years at power, and with similar reactor coolant conductivities when averaged the initial 5 years of power operation.

From a materials standpoint, the PB-2 and PB-3 core shrouds were each constructed with ring segments fabricated from forged type 304 stainless steel, and shell segments fabricated from type 304 stainless steel plates. Previous inspections of circumferential and vertical welds in the PB-3 core shroud revealed a crack of moderate size $(2.67 \mathrm{~m}$ or $\sim 105$ inches in length) in the lower HAZ of the shroud's H3 weld, and some less significant cracking at the $\mathrm{H} 1$ and $\mathrm{H} 4$ weld locations. PECo therefore stated that any potential cracking of the PB-2 core shroud would be bounded by the amount of cracking in the PB-3 core shroud.

The BWRVIP classified the PB-2 core shroud as a susceptible Category " $C$ " shroud. The staff concluded that the BWRVIP's categorization of the PB-2 core shroud was appropriate, and that the PB-2 core shroud should not be any more susceptible to IGSCC than the core shroud at PB-3 (Ref. 74).

\subsubsection{Inspection of the Peach Bottom Unit 2 Core Shroud}

By letter dated November 7, 1994 (Ref. 75), PECo resummarized the scope of the $\mathrm{PB}-2$ core shroud inspections, and submitted the results of core shroud examinations performed during the RFO 2R10. PECo performed the PB-2 shroud examinations using GE's Smart-2000 Data Acquisition System, OD Tracker and suction cup scanners. The UT examinations used three types of transducers: a $45^{\circ}$ shear wave transducer, a $60^{\circ}$ longitudinal wave transducer, and a creeping wave transducer used to pick up surface indications. The creeping wave transducer was not used on the $\mathrm{H} 3$ weld because of equipment failure.

The scope of the UT examinations included all accessible portions of shroud welds $\mathrm{H} 1-\mathrm{H} 7$. This corresponded to approximately 33-percent coverage of weld $\mathrm{H} 1,84 \%$ to $89 \%$ coverage of welds $\mathrm{H} 2-\mathrm{H} 5$, and $9 \%$ to $10 \%$ coverage of welds H6 and H7. PECo's inspections of welds $\mathrm{H} 6$ (the core support ring-to-lower shroud weld) and $\mathrm{H7}$ (the lower shroud-to-shroud support cylinder weld) were conducted through accessible areas of the access hole covers (AHCs). Interference from jet pump assemblies, the reactor core, and other internal components located at lower vessel elevations limited access of the UT equipment to these welds. PECo performed some additional enhanced VT-1 
examinations of shroud weld $\mathrm{H} 6(\sim 13$ percent of the weld) to achieve some additional coverage.

PECo identified the following relevant indications using $45^{\circ} \mathrm{S} / 60^{\circ} \mathrm{L}$ UT transducers:

. 11 indications at the $\mathrm{H} 1$ weld, totalling $0.86 \mathrm{~m}$ (34 in), with the maximum length and maximum depth being $0.12 \mathrm{~m} \mathrm{(4.8} \mathrm{in)} \mathrm{and} 0.019 \mathrm{~m}$ $(0.74 \mathrm{in})$, respectively (both at Indication $\# 7$ )

- 19 indications at the $\mathrm{H3}$ weld, totalling $1.74 \mathrm{~m}$ $(68.5 \mathrm{in})$, with the maximum length being $0.22 \mathrm{~m}$ (8.75 in) at Indication \#16

. 8 indications at the $\mathrm{H} 4$ weld, totalling $0.292 \mathrm{~m}$ (11.5 in), with the maximum length being $0.146 \mathrm{~m}(5.76 \mathrm{in})$ at Indication \#4

. 1 indication at the $\mathrm{H} 6$ weld, $0.12 \mathrm{~m}$ (4.73 in) in length and $0.11 \mathrm{~m}(0.45 \mathrm{in})$ in depth

PECo identified a minor amount of cracking at the $\mathrm{H} 4$ and H5 welds using UT creeping wave methods. Examinations of core shroud welds $\mathrm{H} 2$ and $\mathrm{H} 7$ were negative for relevant indications.

PECo's inspection results were compared to the initial screening criteria established in GENE 523-176-1293, "Evaluation and Screening Criteria for the Peach Bottom Unit 2 Shroud" (Ref. 76). If unacceptable, these results were evaluated for safety margins using the LLA methodology found in the "BWR Core Shroud Inspection and Flaw Evaluation Guidelines" (Ref. 19). This methodology applies the most conservative loading conditions as the basis for performing flaw evaluations. This equated to using faulted condition loadings for evaluations of welds $\mathrm{H} 1-\mathrm{H} 5$, and upset condition loadings for evaluations of welds $\mathrm{H} 6$ and H7. PECo's LLAs of the $\mathrm{H} 1-\mathrm{H} 7$ welds indicated that the welds would meet the safety margin criteria specificed in Section XI of the ASME Code for all postulated loading conditions. The remaining ligaments of the $\mathrm{H} 3$ and $\mathrm{H} 4$ welds were also subject to evaluation using LEFM methods to account for the high-neutron fluences that are typical at these weld elevations. The LEFM analyses of the $\mathrm{H} 3$ and $\mathrm{H} 4$ welds also indicated that the welds would have sufficient structural margin to justify operation of PB-2 for the cycle.

The staff reviewed PECo's methodology for performing flaw evaluations of the PB-2 core shroud welds, and determined that it was acceptable. The staff therefore concluded that PECo's evaluations of the PB-2 core shroud provided a reasonable assurance that the structural integrity of the PB-2 shroud would be with the ASME Code safety margins and that PB-2 could be safely operated for Operating Cycle No. 11 (Ref 74).

\subsubsection{Assessment of the Response to GL 94-03 for the Peach Bottom Atomic Power Station Unit 3}

The Philadelphia Electric Company (PECo), the licensee for the Peach Bottom Atomic Power Station Unit 3 (PB-3), responded to GL 94-03 on August 24, 1994 (Ref. 73). PECo completed an inspection of the PB-3 core shroud during the previous Fall 1993 refueling outage (RFO 3R9). PECo submitted the examination results and assessment of the PB-3 core shroud to the NRC by letter dated March 14, 1994 (Ref. 77).

PECo reviewed the materials, fabrication and operational histories of the PB-3 core shroud and included this information in its response to GL 94-03. PECo determined that the mean initial 5 year conductivity of the PB-3 reactor coolant was greater than the corresponding mean 5 year conductivity value for the industry. In addition, PECo determined that the shell portions of the PB-3 core shroud are fabricated from high carbon content Type 304 stainless steel plates. On these bases, both PECo and the BWRVIP has classified the PB-3 core shroud as a susceptible Category "C" shroud. The staff concluded that the BWRVIP's susceptibility assessment was appropriate. This conclusion was supported by the identification of moderate cracking during the previous core shroud inspections.

PECo's inspections of the PB-3 core shroud (completed during RFO 3R9) were performed in accordance with recommendations of SIL-572, Revision 1 (Ref. 26), and included enhanced VT-1 examinations at eight (8) cell locations in each of the H1-H5 welds. PECo expanded the inspection scope after discovering relevant flaw indications at the $\mathrm{H} 3$ and $\mathrm{H} 4$ welds. The expanded scope included the following enhanced VT-1 examinations:

100-percent examination of accessible portions of the $\mathrm{H} 3$ and $\mathrm{H} 4$ welds from the ID

100-percent examination of accessible areas of weld $\mathrm{H} 4$ from the $\mathrm{OD}$ 
- examinations of the $\mathrm{H} 3$ weld from the $\mathrm{OD}$ in areas where cracking was not indicated on the ID

- an examination of the $\mathrm{H} 3$ weld from the $\mathrm{OD}$ in areas where cracking was indicated on the ID

- examinations at six locations of the $\mathrm{H} 6$ weld

- examinations at two locations of the respective $\mathrm{H7}$ and $\mathrm{H} 8$ welds

- examination of a vertical weld between the $\mathrm{H3}$ and H4 welds

- examination of one of the mid shroud plates.

The licensee's VT-1 examinations identified a significant (2.67 $\mathrm{m}$ or $105 \mathrm{in}$ ) crack in the $\mathrm{H} 3$ weld (the weld joining the top guide support ring to the upper midshroud shell). Less extensive cracking was also found at the $\mathrm{H} 4$ weld ( $<0.76 \mathrm{~m}$ or 30 in total). Minor cracking was determined to exist at weld $\mathrm{H} 1$ and at one of the vertical shroud welds.

PECo performed flaw evaluations of the PB-3 shroud in accordance with the structural margin criteria found GENE-523-141-1093, Rev. 1 (Ref. 78). These criteria conform to the structural margin criteria found in Section XI of the ASME Code. The evaluations of the PB-3 core shroud indications, which included adjustments to account for crack proximities, crack growth and NDE uncertainties, indicated that the PB-3 core shroud would meet the safety margin criteria specified in Section XI of the ASME Code to justify operation during the current operating cycle (Operating Cycle 10). The staff reviewed PECo's inspection results and flaw evaluation methods, and concluded that they were acceptable to justify continued operation of PB-3 for Operating Cycle 10 (Ref. 74).

\subsubsection{Reinspection Scope for the Peach Bottom Unit 3 Core Shroud}

By letter dated June 16, 1995, PECo provided the NRC with its supplemental response to GL 94-03 (Ref. 79). This submittal provided PECo's scope for performing UT examinations of the PB-3 core shroud during RFO 3R10, in September/October of 1995. The NRC determined that PECo's proposed inspection scope was consistent with the guidelines of the BWRVIP "BWR Core Shroud Inspection and Flaw Evaluation
Guidelines," Rev. 1, dated April 21, 1995 (Ref. 22), and with the inspection scope previously approved for the PB-2 core shroud, which was inspected in the Fall of 1994. The NRC therefore concluded that PECo's proposed scope for inspection of the PB-3 core shroud was acceptable for implementation during RFO 3R10. The NRC accepted PECo's proposal for the UT inspection scope on September 25, 1995 (Ref. 80).

\subsubsection{Peach Bottom Core Shroud Repair Designs}

By letter dated September 16, 1994, PECO Energy Company (PECO) submitted the design details of a proposed core shroud stabilizer design for PB2 and PB3 (Ref. 81). The Peach Bottom core shroud repair involves the installation of GE-designed tie rod assemblies symmetrically around the circumference of the shroud. These tie-rod assemblies were designed to provide an alternative load carrying capability for the shroud in lieu of shroud welds $\mathrm{H} 1-\mathrm{H} 7$ during normal operating, transient, and postulated design basis accident and seismic conditions. The Peach Bottom repair design was submitted as an alternative to the requirements of the American Society of Mechanical Engineers (ASME) Boiler and Pressure Vessel (B\&PV) Code, pursuant to 10 CFR 50.55a(a)(3)(i). The staff is currently in the process of reviewing PECo's submittal.

\subsection{Power Authority of the State of New York}

8.12.1 Assessment of the Response to GL 94-03 for the James A. FitzPatrick Nuclear Power Plant

The Power Authority of the State of New York (NYPA), the licensee for the James A. FitzPatrick Nuclear Power Plant (FITZ), responded to GL 94-03 on August 24, 1994 (Ref. 82), as supplemented with responses on October 18, 1994, and November 30, 1994 (Refs. 83 and 84). The NRC staff considered the FITZ core shroud to be highly susceptible to IGSCC based on the following determinations:

(1) The average reactor coolant conductivity at FITZ during the first five years of plant operation was high in comparison to the industry norm.

(2) The FITZ core shroud was fabricated from Type 304 cut and rolled plate materials, which are considered to be more susceptible to IGSCC than forged Type 304 or Type 304L stainless steels. 
(3) Weld residual stress levels resulting from fabrication of the shroud were considered to be high.

Therefore, the staff concluded that the BWRVIP's ranking of the FITZ core shroud as a highly susceptible Category " $\mathrm{C}$ " shroud was appropriate (Ref. 85).

\subsubsection{Repair of the James A. FitzPatrick Core Shroud}

NYPA originally indicated that inspections of the FITZ core shroud would involve $100 \%$ UT inspections of all accessible areas on shroud welds $\mathrm{H} 1-\mathrm{H} 5$, UT and enhanced VT-1 examinations of welds H6a and H6b, and enhanced VT-1 inspections of welds $\mathrm{H} 7, \mathrm{H8}$, and H9. On October 21, 1994, NYPA informed the staff that it would perform a pre-emptive modification of the FITZ shroud instead of a comprehensive shroud inspection (Ref. 86). The shroud modification was designed by MPR for the purpose of providing an alternative load path for the reactor core in lieu of the core shroud during normal operating, transient and postulated design basis accident conditions.

The licensee also informed the staff that the inspection scope for the FITZ core shroud would be revised to support implementation of the core shroud modification design. The revised inspection scope included, as a minimum, VT-1 inspections of the welds joining those gusset plates used in the repair design to the jet pump support plate and the reactor pressure vessel; UT inspection of at least one vertical seam weld below the $\mathrm{H} 4$ weld; and inspections of the H3, H6a, and H6b welds to gauge the extent of cracking in the shroud support rings. In the staff's SER dated January 5, 1995, the staff concluded that both NYPA's core shroud repair design and reduced core sbroud inspection scope were acceptable for implementation at the plant site (Ref. 87).

\subsection{Tennessee Valley Authority Core Shrouds}

\subsubsection{Assessment of the Response to GL 94-03 for} Browns Ferry Nuclear Plant Units 1, 2, and 3

Tennessee Valley Authority (TVA), the licensee for Browns Ferry Nuclear Plant Units 1, 2, and 3 (BF-1, BF-2 and BF-3, respectively), responded to GL 94-03 on August 24, 1994 (Ref. 88). In the report "BWR Core Shroud Inspection and Flaw Evaluation Guidelines," (Ref. 19), the BWRVIP classified the Browns Ferry shrouds as being highly susceptible
Category " $\mathrm{C}$ " shrouds. The BWRVIP also recommended that TVA perform comprehensive inspections of the BF-1, BF-2, and BF-3 core shrouds. The staff concluded that the BWRVIP's assessment of the BF-1, BF-2 and BF-3 core shrouds was appropriate (Ref. 89). However, based on a review of the plantspecific IGSCC susceptibility factors, the staff concluded that, while the BF1, BF-2 and BF-3 core shrouds were likely to contain some cracking, the extent of any IGSCC would be less than that identified at other highly susceptible BWRs. The results of the BF-2 and BF-3 core shroud examinations confirm this conclusion for Units 2 and 3.

\subsubsection{Inspections of the Browns Ferry Units 1, 2, and 3 Core Shrouds}

In its response to GL 94-03, TVA stated that BF-1 has been in an prolonged defueled condition since 1985, and that no scheduled restart date has been scheduled for the reactor. TVA indicated, however, that should a decision be made to restart BF-1, the core shroud would be inspected before the unit was restarted. The inspection results would then be evaluated to justify operation of the unit for the upcoming cycle.

TVA stated that BF-3 has also been in a prolonged defueled condition. However, TVA completed an inspection of the BF-3 core shroud on July 14, 1994. The results of the BF-3 shroud inspections were presented to the NRC during a meeting held on August 11, 1994, and were submitted as an enclosure to the licensee's GL 94-03 response. The inspection identified cracking at three weld locations on the BF-3 core shroud. However, TVA determined that the extent of cracking in the BF-3 core shroud was limited. TVA, in conjunction with $\mathrm{GE}$, completed an analysis which demonstrated that the BF-3 core shroud had adequate margin to justify operation of the unit. The staff reviewed the inspection results and flaw evaluation regarding the BF-3 core shroud, and found TVA's determination to be acceptable. Since both BF-1 and BF-3 have been idle since 1985, TVA did not submit a justification for continued operation (JCO) for these units.

TVA informed the NRC that it had scheduled inspections of the BF-2 unit for the September 1994 RFO. TVA completed the inspections of the BF-2 core shroud in October 1994, and submitted the results to theNRC on November 18, 1994 (Ref. 90). The scope of TVA's inspection of the BF- 2 core shroud covered portions of

NUREG-1544 
welds $\mathrm{H} 1-\mathrm{H} 7$. TVA performed the UT inspections using $45^{\circ}$ shear wave and $60^{\circ}$ longitudinal wave transducers. TVA also used UT creeping wave methods to determine near side surface conditions. TVA identified cracking in or adjacent to welds $\mathrm{H} 2, \mathrm{H} 3$, and H5. The indications, however, were minor. The largest linear crack was located at weld $\mathrm{H} 3$ and was less than $0.13 \mathrm{~m}$ ( $5 \mathrm{in})$ in length. The deepest indication was measured to be $0.024 \mathrm{~m}$ (0.96 in).

Cracks identified during the inspections were initially compared to plant-specific screening criteria. Thescreening criteria were consistent with the evaluation guidelines established by the BWROG in the "BWR Core Shroud Evaluation," GENE-523-148-1193, dated April 5, 1994 (Ref. 14). Thess criteria are similar to those approved for use in the flaw evaluations of cracking in the Brunswick Nuclear Plant Unit 1 core shroud. All indications in the BF-2 core shroud were determined to be below the inspection screening limits of the evaluation guidelines. The staff therefore concluded that the BF-2 reactor could safely operate for the current operating cycle without requiring a modification of its core shroud (Ref. 89).

\subsection{Vermont Yankee Nuclear Power Corporation}

8.14.1 Assessment of the Response to GL 94-03 for the Vermont Yankee Nuclear Power Station

Vermont Yankee Nuclear Power Corporation (VYNPC), the licensee for the Vermont Yankee Nuclear Power Station (VY), responded to GL 94-03 on August 17, 1994 (Ref. 91). The staff issued its SER regarding VYNPC's response to GL 94-03 on January 5, 1995 (Ref. 92)

VYNPC inspected the VY core shroud during the Spring 1995 RFO, which commenced on March 18, 1995. (Section 5.5 of this report discusses the scope and results of the VY core shroud examinations.) The staff reviewed the VY core shroud inspection results and flaw evaluations in April 1995, and issued its SER regarding these submittals on May 5, 1995 (Ref. 13). In that SER, the staff concluded that the VY core shroud had sufficient structural margin to justify one additional cycle of operation for the plant.

\subsection{Plants with Category "B" Core Shrouds}

In late August 1994, Commonwealth Edison Co. (ComEd), Philadelphia Electric Co. (PECo), Pennsylvania Power \& Light Co. (PP\&L), and Entergy Operations, Inc. (EOI) submitted their responses regarding the core shrouds at Lasalle Units 1 and 2 (LA-1 and LA-2), Limerick Unit 1 (LIM-1), Susquehanna Units 1 and 2 (SSES-1 and SSES-2), and Grand Gulf Unit 1 (GG-1), respectively (Refs. 41, 73, 93 and 94). The staff issued its SERs regarding these submittals on February 16, 1995, March 7, 1995, March 23, 1995, and March 29, 1995, respectively (Refs. 93-96).

In order to assist these licensees with their submittals to the staff, the BWRVIP performed a susceptibility assessment of these shrouds, and concluded these shrouds were not as highly susceptible to IGSCC as the core shrouds of Category "C" plants. The BWRVIP based its assessment of these shrouds on the following factors:

(1) The construction material for fabrication of these shrouds was low carbon content Type 304L stainless steel (a more IGSCC resistant material than Type 304 stainless steel).

(2) The reactor coolant chemistry impurity levels at these facilities were typically maintained at lower levels than at the norm for the industry.

The BWRVIP concluded, however, that some potential existed for cracking to initiate in these shrouds based on the amount of time that these plants had operated at power ( $>8$ years of power operation). As a result, the BWRVIP categorized these shrouds as Category "B" shrouds and recommended that the licensees owning these facilities inspect the circumferential welds associated with the top guide support ring, core support plate ring and mid-shroud shell at the next available RFO. (Table 6.2-1 summarizes the BWRVIP's susceptibility rankings and inspection recommendations.)

Since July 1994, the licensees owning these Category "B" shrouds have performed limited inspections of the LA-1, LA-2, LIM-1, SSES-1, and GG-1 shrouds. PP\&L has scheduled inspections of the SSES- 2 core 
shroud for the Fall 1995 (Ref. 93). By letter dated May 22, 1995, PP\&L submitted its scope for performing UT inspections of the SSES-2 core shroud (Ref. 99). The staff determined that PP\&L's inspection scope for SSES-2 was consistent with the BWRVIP's inspection criteria for Category "B" shrouds. The staff accepted the inspection scope for the SSES-2 core shroud on August 7, 1995 (Ref. 100).

Of the inspections performed on these core shrouds to date, only the inspections of the SSES-1 core shroud have resulted in the identification of any IGSCC-related cracking in excess of $2.54 \mathrm{~m}$ (100 in). PP\&L submitted the results of the SSES-1 core shroud UT examinations on April 21, 1995 and May 25, 1995 (Refs. 101 and 102). Of particular note were the reports of indications located in the SSES-1 H-4 and H-5 shroud welds. The flaw lengths at these welds totaled $4.75 \mathrm{~m}$ (187 in) and $4.80 \mathrm{~m}(189 \mathrm{in})$, respectively. This cracking is significant in that it was the first report of moderate cracking in Category "B" core shrouds to date. PP\&L provided its flaw evaluation of the SSES-1 core shroud in its submittals to the NRC (Refs. 101 and 102). The results of PP\&L's flaw evaluation indicate that the SSES-1 core shroud will meet the ASME Code, Section XI safety margins for the current cycle. On May 3, 1995, the NRC accepted the results of PP\&L's flaw evaluation and approved the restart of SSES-1 (Ref. 103).

\subsection{Plants with Category "A" Core Shrouds}

In August 1995, the Philadelphia Electric Co. (PECo), Public Services Electric and Gas Company (PSE\&G), Niagara Mohawk Power Corp. (NMPC), Entergy Operations, Inc. (EOI), Detroit Edison Company (DECo), Illinois Power Co. (IPC), Centerior Energy, Inc. (CEI) and Washington Public Power Supply System (WPPSS) submitted their responses regarding the core shrouds at Limerick Unit 2 (LIM-2), Hope Creek Station Unit 1 (HC-1), Nine Mile Point Unit 2 (NMP-2), River Bend Unit 1 (RVR-1), Fermi Unit 2 (FRM-2), Clinton Power Station (CPS), Perry Nuclear Power Plant (PRY) and Washington Nuclear Plant Unit 2 (WNP-2), respectively (Refs. 73, 104-110). In order to assist these licensees in their submittals to the staff, the BWRVIP performed a susceptibility assessment of these shrouds, and concluded that, of all core shrouds in the industry, these shrouds were least susceptible to IGSCC.
The BWRVIP based its assessments of these shrouds on the following factors:

(1) The construction material for fabrication of these shrouds was low carbon content Type 304L stainless steel (a more IGSCC resistant material of construction).

(2) The reactor coolant water chemistries at these plants, when averaged over the first five years of operation, were typically better than the norm for the industry.

(3) These reactors had been operated for only a limited amount of time at power, in comparison to other BWRs in the industry $(<8$ years total time at power).

The BWRVIP therefore grouped the core shrouds of these plants as Category " $A$ " type shrouds, and suggested that licensees owning these facilities could defer examinations of their core shrouds until the first RFO commencing after their plants had surpassed 8 years of time at power. Upon reaching that point, the BWRVIP recommended that the licensees for these plants conduct examinations of these core shroud in accordance with the BWRVIP's recommendations for Category " $B$ " shrouds (Refer to Section 7.2.15 and Table 6.2-1 of this report.).

The NRC reviewed the BWRVIP's assessment of these shrouds, and concluded that the assessments were appropriate based on the factors cited in the BWRVIP assessment. The staff therefore concluded that the licensees owning these plants could safely defer inspection of their shrouds until they had surpassed 8 years at power (Refs. 111-118).

To date, PECo (the licensee for LIM-2), PSE\&G (the licensee for HC-1), IPC (the licensee for the CPS), and EOI (the licensee for the RVR-1), have deferred examinating their core shrouds at this time. DECo, NMPC, and WPPSS (the licensees for FRM-2, NMP-2, WNP-2, respectively) performed limited examinations of their core shrouds during the last RFOs for their nuclear facilities. No IGSCC-related cracking indications have been identified as a result of the limited examinations performed by these licensees. 


\section{IGSCC IN OTHER BWR INTERNAL COMPONENTS}

\subsection{Core Plate and Top Guide Cracking}

In November 1994, IGSCC was reported in the top guide and core plate rings of a foreign BWR. On Novemeber 22, 1994, GE issued RICSIL 071 to inform the U.S. nuclear industry of this cracking (Ref. 119). In RICSIL 071, GE concluded that, while the design of the foreign BWR was not a GE design, there were enough similarities between the design of the foreign BWR and those of U.S. BWRs to warrant an investigation to determine whether domestic BWR top guides and core plates would similarly be susceptible to IGSCC. GE, however, did not provide any recommendations in RICSIL 071 in regard to performing inspections of BWR top guides and core plates.

In December 1994, the NRC requested that the BWRVIP provide them with the details of top guide and core plate configurations in domestic BWR designs, and assess the safety significance of the top guide and core plate cracking at U.S. BWR facilities. A preliminary response from the BWRVIP was received on December 23, 1994, and a revised response was received on January 3, 1995 (Refs. 120 and 121). GE subsequently issued SIL 588 (February 17, 1995) to update their position on safety significance and provide specific recommendations for inspections of BWR top guides and core plates (Refs. 122). The NRC reviewed the information submitted by the BWRVIP and GE regarding top guide and core plate cracking. Upon completion of thier review, the staff came to the following conclusions (Ref. 123):

(1) With regard to IGSCC susceptibility, it is reasonable to expect that U.S. BWRs (BWR-2 through BWR-5) operating with conditions similar to those found at Wuergassen (13 years operating time, moderate conductivity water chemistry) may experience cracking in the top guide and core plate rim ring welds.

(2) All U.S. BWRs have core plates with 36 to 70 hold-down bolts. With the hold-down bolts intact, core plate ring cracking has an insignificant impact on core plate displacements under design basis loading. If complete separation of all hold-down bolts is postulated in conjunction with a seismic event, the potential exists for lateral motion of the core plate to occur, inhibiting control rod insertion. In this event, SLC would be required for reactor shutdown. However, simultaneous failure of all of the core plate hold-down bolts is highly improbable.

(3) Lateral motions is also prevented in plants with hold-down bolts and four horizontal aligner pin assemblies.

(4) Vertical displacement of the core plate during design basis loading is limited to $0.013 \mathrm{~m}$ $(0.5$ in) due to the clearance between the core support plate and the fuel support structures. Vertical displacements of this magnitude were evaluated by the staff during the core shroud assessments and were not found to inhibit control rod insertion.

(5) Vertical displacement of the top guide during a LOCA with postulated through-wall cracking of the top guide ring weld is bounded by analyses performed during the core shroud assessments.

(6) A variety of designs exist for lateral and vertical restraint of top guides. Certain configurations are more susceptible than others to lateral displacements under design-basis loading. Specifically, for top guide designs which do not incorporate wedges or reinforcement blocks, failure of the pin/aligner supports due to IGSCC could result in lateral displacement of the top guide during seismic loading. The lateral displacement could inhibit control rod insertion and SLC would be required for safe shutdown. However, staff evaluations performed for GL 9403 have indicated that full control rod insertion would likely occur under these conditions.

(7) Due to the potential consequences of the lateral displacement of top guide assemblies which do not incorporate wedges, SIL 588 recommends an enhanced VT-1 inspection of the members which provide the load path between the alignment pins, the top guide and the shroud during the next scheduled refueling outage. The staff agrees with this recommendation. For the core shroud bolts, the SIL recommends only an inspection to confirm 
that the bolting is in place. While this is most likely sufficient based on the redundancy of the structure, the staff recommends that consideration be given to a more comprehensive inspection of a limited sampling of the core plate bolts. This recommendation has been communicated to the BWRVIP, and the staff expects that their revised report on top guide/core plate cracking will address this issue.

(8) With the SIL No. 588 recommended inspections, the NRC staff concurs with the BWRVIP and GE assessments that the potential cracking of the top guide and core plate rings does not have a significant impact on safety (Ref. 123).

\subsection{Jet Pump Hold-Down Beams}

Jet pump hold-down beams (JPHDBs) provide lateral support for the jet pump assemblies at the rams head diffuser elevations. In February 1980, a JPHDB failed at Dresden 3 (DR-3), resulting in disassembly of one of the plant's jet pump assemblies. As a result of the jet pump flow anomalies, Commonwealth Edison (ComEd, the licensee for the Dresden, Quad City, and Lasalle BWRs) commenced an orderly shutdown of the DR-3 unit. Subsequent visual and ultrasonic inspections, conducted at the direction of GE, disclosed that holddown beams on other jet pumps at DR-3, Quad Cities Unit 2 (QC-2, March 15-16, 1980) and Pilgrim (PNPS, March 28, 1980) contained cracks in the ligament zone at the center of the beams. Investigations determined that these cracks were caused by IGSCC, which in the case of the JPHDB failures progressed very slowly over a period of years.

The NRC issued Inspection and Enforcement Bulletin (IEB) 80-07 "BWR Jet Pump Assembly Failure" in April 1980 to inform the industry of the JPHDB cracking at DR-3 (Ref. 124). In IEB 80-07, the NRC requested that licensees owning BWR-3 and BWR-4 facilities inspect their JPHDB assemblies and begin operability surveillances to justify further operation of their units.

Failure of a JPHDB assembly and subsequent disassembly of a jet pump could potentially result in an increased flow area through the jet pump and lower the flooding elevation of the core during postulated LOCAs (Ref. 125). Such effects could adversely impact the water level in the core during a postulated LOCA, as well as the assumed blowdown loads (Ref. 125). As a result, IGSCC of JPHDB assemblies has the potential to reduce safety margins during postulated LOCAs. Failure of a JPHDB assemblies can also result in loose parts, although events to date have not resulted in any damage to safety-related systems or equipment. However, failure of a JPHDB can be detected during power operation, thereby assuring prompt corrective action. BWR licensees are performing inspections of their JPHDBs and/or core flow balance tests, as required by Technical Specifications, to confirm the operability of their jet pumps.

In June 1980, GE issued a SIL No. 330, "Jet Pump Beam Cracks" to highlight the problem of JPHDB cracking (Ref. 126). As a result of the inspections performed at the request of the $\mathrm{NRC}$, several other licensees reported cracking of JPHDBs at their facilities. These plants include DR-2, MS-1, PB-3, PNPS, QC-1 and VY. IEB 80-07 was closed out with the issuance of NUREG/CR-3052 (November 1984), which summarized the findings and actions taken to resolve the issue of JPHDB cracking in BWRs (Ref. 127).

On September 13, 1993, Entergy Operations, Incorporated (EOI), reported the occurrence of cracking in a JPHDB at the Grand Gulf Nuclear Power Station, Unit 1 (GG-1), during the 1993 RFO for the plant. EOI opted to replace all JPHDBs at the plant during the RFO. The JPHDB failure at GG-1 is unlike the earlier JPHDB failure at DR-3, in that the cracking at GG-1 occurred in the transition area between the main body of the beam and the beam end, while the failure at DR-3 involved IGSCC cracks initiated at the bolt hole in the center portion of the JPHDB.

EOI expanded the inspection scope to other JPHDBs, and determined that a second JPHDB was degraded in the center bolt-hole region (in the same portion of the JPHDB as the failure at DR-3). The JPHDB failures at GG-1 are the first JPHDB failures at a GE-designed BWR-6 facility. Grand Gulf decided to replace all of their beams during their ongoing refueling outage. On December 17, 1993, the NRC issued IN 93-101, "Jet Pump Hold-down Beam Failure," to inform the industry of the cracking discovered at GG-1 (Ref. 125).

During UT inspection of the hold-down beams in October 1993, the Illinois Power Company (IPC), the licensee for the Clinton Nuclear Station (CNS, a BWR-6 design) determined that one of the beams (No. 7) had crack indications around the center hole region. 
IPC replaced the cracked component before returning the unit to service. In addition, on November 22, 1993, Pennsylvania Power and Light Company (PP\&L) notified the NRC that they would be replacing all of the jet pump beams at the Susquehanna Steam Electric Station Unit 1 (SSES-1). This action was being taken after GE informed the licensee that they could not adequately predict, at this time, the crack initiation and crack growth rate of the beams, given the new failure mode of the Grand Gulf beam. The old method relied on predictable crack growth rates of IGSCC and cracks appearing at the center bolt hole region.

GE has recommended that licensees replace their JPHDBs at the earliest opportunity if the JPHDBs are of a design similar to that used at GG-1, and if the JPHDBs have a history of being in service for more than 8 years as of the next RFO. Although there are no requirements governing inspections of JPHDBs, licensees have been inspecting their JPHDBs at their own initiative.

\subsection{Access Hole Covers}

BWRs are designed with two access hole covers (AHCs) in the shroud support plates. These AHCs are located at the bottom of the annulus region between the reactor vessel wall and the core shroud, $180^{\circ}$ apart from each other, where they provided access to the lower plenum areas during construction phases. AHC are mainly fabricated from Alloy 600 , and were welded to the shroud support plate with Alloy 82 or 182 weld material before initial startup of the plants. Like Type 304 and 316 stainless steels, these alloys are known to be susceptible to IGSCC.

On January 21, 1988, PECo reported the occurrence of significant circumferential cracking in the welds joining the AHCs to the shroud support plate of the PB-3 nuclear plant. PECo discovered these cracks using a remotely operated ultrasonic inspection method. PECo's inspection results indicated that the cracks had initiated as a result of vertical crevices at the welds, and had propagated along the weld fusion lines. Other cases of AHC weld cracking were reported as a result of inspections performed at the QC-2 nuclear plant.
Three concerns have been identified with regard to a postulated failure of an access hole cover due to IGSCC.

1. Loose parts - In the event of complete failure of an AHC weld during normal operation, the slightly higher bottom head area pressure would lift the cover out of its recess. It would most likely fall to one side, but the potential exists for it to be swept into the re-circulation pump suction line and cause severe pump damage.

2. Core flow bypass (normal operation) - Loss of one or both cover plates would allow some recirculation system flow to bypass the core, from the jet pump discharge through the open hole to the recirculation pump suction. This flow transient would be readily detectable and would require reactor shutdown.

3. Core flow bypass (LOCA) - If an AHC weld were to fail as a result of a RLB, the bypass path would prevent the emergency core cooling system from reflooding the core to the two-thirds level. However, the core spray system would be capable of maintaining adequate core cooling.

GE issued SIL 462, including Supplement 1, Supplement 2, Supplement 2, Rev. 1, and Supplement 3, provided the industry with information regarding AHC cracking (Refs. 128-132). GE recommended that BWR licensees inspect the AHC welds at the next available RFO if the AHC weld areas had not been previously inspected. GE also recommended that licensees who had examined their AHC welds review the inspection results. Furthermore, GE recommended that licensees perform suitable repairs of the flaws if IGSCC is detected in AHC welds. In addition, the NRC also issued IN 88-03, "Cracks in Shroud Support Access Hole Cover Welds" (Ref. 133), and IN 92-57, "Radial Cracking of Shroud Support Access Hole Cover Welds" (Ref. 134), to inform the industry of the event at PB-3. Although there are no requirements governing inspections of AHCs, licensees have been inspecting their AHCs at their own initiative. 


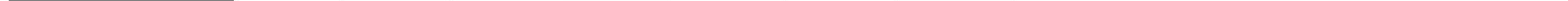




\section{CONCLUSIONS AND FUTURE ACTIONS}

The NRC staff has reviewed the licensee-specific responses to GL 94-03. In all cases, the staff has concluded that the BWR licensees have provided sufficient evidence to support continued operation of their BWR units until the refueling outages during which shroud inspections or repairs have been scheduled. The results of inspections performed by the industry indicate that IGSCC can occur in BWR core shrouds fabricated from Type 304 stainless steel rolled plate materials.

Prior to issuance of GL 94-03, the NRC analyzed the results of inspections and flaw evaluations performed at Brunswick Unit 1, Dresden Unit 3, and Quad Cities Unit 1 because of the severity of the flaw indications at these plants. In light of the extent of cracking observed at these plants, the staff evaluated potential safety concerns associated with the possibility of a $360^{\circ}$ circumferential separation of the shroud following a postulated LOCA. The staff's evaluation considered the potential for separation of the shroud during postulated accidents to either prevent full insertion of the control rods, or open a gap large enough to preclude the ECCS from fulfilling their intended safety functions. The bounding case accident scenarios are the MSLB and the RLB. Of these postulated accidents, the MSLB is the more serious event associated with cracks in the upper shroud welds (e.g., H2, H3), and the RLB is the more serious event associated with cracks in the lower elevations of the core shroud.

In consideration of the consequences of a $360^{\circ}$ throughwall failure of the shroud coincident with a LOCA, the NRC has conservatively estimated the risk contribution from shroud cracking and determined that it does not pose a high degree of risk at this time. However, the NRC has also determined that ASME Code structural margins could potentially be exceeded if the cracks were sufficiently deep and were to continue propagating through the shroud during normal operating, transient, or accident conditions, which could result in a loss of a layer of the defense-in-depth strategy. Therefore, in order to verify compliance with the inservice inspection requirements of $10 \mathrm{CFR} 50.55 \mathrm{a}$, and to ensure that the risk associated with core shroud cracking remains low, the staff has concluded that it was appropriate for BWR licensees to implement timely inspections and/or repairs of their core shrouds.
As of early September 1994, the NRC staff received all of the BWR licensee submittals in response to GL 94-03. The staff has completed its evaluations of the licensee responses to GL 94-03, and has transmitted the SERs to the appropriate BWR licensees. For all cases, the staff concluded that BWR licensee's have provided sufficient justification to operate their facilities until core shroud inspections or repairs could be implemented. The staff based its conclusions on the following factors:

(1) To date, no 3600 through-wall core shroud cracking has been observed in any U.S. BWR that has performed a shroud inspection.

(2) All analyses performed by U.S. licensees to date indicate that, even if cracking did exist in a particular BWR core shroud, sufficient ligaments would remain in the shroud such that structural integrity of the shroud would be ensured for the remainder of the plant's operating cycle.

(3) No U.S. BWR has exhibited any of the symptoms (power-to-flow mismatch) that would indicate leakage through a 3600 through-wall shroud crack.

(4) MSLBs or RLBs are both considered to be low frequency events.

(5) Only short durations remained until core shroud inspections or repairs would be implemented by the individual BWR licensees.

Since January 1994, the staff has reviewed and accepted the design modifications submitted in regard to repair of the core shrouds at Brunswick Units 1 and 2, Hatch Units 1 \& 2, FitzPatrick, Oyster Creek, Quad Cities Units 1 \& 2, Nine Mile Point Unit 1, and Pilgrim. The staff is currently reviewing the design modifications submitted by the Commonwealth Edison Company (ComEd) and Philadelphia Electric Company (PECo) in regard to repair of the core shrouds at Dresden Units 2 and 3, and Peach Bottom Units 2 and 3 . Additional design modifications will be submitted if licensees determine that their shrouds are highly susceptible to IGSCC, or if inspection results indicate that large-scale cracking of circumferential shroud welds has occurred. These repairs or modifications are designed to ensure the structural integrity of the core shrouds in the long term, 
and are being reviewed by the NRC staff on a case-bycase basis. The staff will continue to assess the scopes that have yet to be submitted by licensees concerning inspections or reinspections of their core shrouds. The staff will also continue to assess core shroud inspection results and any appropriate core shroud repair designs on a case-by-case basis. The staff will issue separate SERs regarding the acceptability of core shroud inspection results and core shroud repair designs.

The BWROG has formed an independent organization, the BWRVIP, for the purpose of providing recommendations and guidelines in regard to inspections, evaluations, and repairs of BWR internal components. The BWRVIP has submitted its initial guidelines regarding inspections, evaluations, and repairs of BWR core shrouds, and its guidelines regarding qualification of NDE techniques, to the staff. These guidelines have been reviewed and accepted by the staff. The BWRVIP has also submitted its revised criteria regarding qualifications of NDE techniques for inspection of BWR internal components, standardized repair submittal formats, and generic safety assessment regarding BWR internal components. These dacuments are currently under review by the staff. The BWRVIP has committed to submit in 1996 its recommended guidelines for performing reinspections of BWR core shrouds, and its recommended guidelines for performing augmented inspections of BWR core shroud repair assemblies. The staff will review these documents following their receipt.

The staff will continue to request timely submittals and responses by the BWRVIP Technical Subcommittees and individual licensees to meet the established schedules for plant startups. The staff has interacted with the BWRVIP and individual licensees on a request basis to achieve this goal. The staff will continue to interact with the industry in the future to encourage them in their efforts to address IGSCC and other forms of age-related degradation in BWR internal components. 


\section{REFERENCES}

Memorandum from James M. Taylor, Executive Director of Operations to the NRC dated January 4, 1994, "Emerging Technical Issue: Cracking of BWR Vessel Internals."

NRC Generic Letter 94-03, dated July 25, 1994, "Intergranular Stress Corrosion Cracking of Core Shrouds in Boiling Water Reactors."

General Electric Company RICSIL 054, dated October 3, 1994, "Core Support Shroud Crack Indications."

General Electric Company RICSIL 054, Rev. 1, dated July 21, 1993, "Core Shroud Cracks."

NRC Information Notice 93-79, dated September 30, 1993, "Core Shroud Cracking at Beltline Region Welds in Boiling-Water Reactors." and Light Company, dated January 14, 1994, "Evaluation and Repair of the Core Shroud Cracks, Brunswick Steam Electric Plant, Unit 1 (TAC No. M87270)."

NRC Information Notice 94-42, dated June 7, 1994, "Cracking in the Lower Region of the Core Shroud in Boiling-Water Reactors."

NRC Information Notice 94-42, Supplement 1, dated July 19, 1994, "Cracking in the Lower Region of the Core Shroud in Boiling-Water Reactors."

Letter from the NRC to D. L. Ferrar, Manager, Nuclear Regulatory Services, Commonwealth Edison Company, dated July 21, 1994, "Evaluation of Core Shroud Cracking at Dresden, Unit 3, and Quad Cities, Unit 1 (TAC Nos. M89871 and M89493)."

Letter from R. W. Keaten, Vice President and Director of Technical Functions, GPU Nuclear Corporation, to the NRC, dated October 25, 1994, "Oyster Creek Nuclear Generation Station Core Shroud Repair - Design Report," Rev. 0.

Letter from the NRC to J. J. Barton, Vice President and Director, GPU Nuclear Corporation, dated November 25, 1994, "Safety Evaluation Regarding the Oyster Creek Core Shroud Repair (TAC No. M90104)."

12 Letter from Vermont Yankee Nuclear Power Corporation to the NRC forwarding the Memorandum from S. R. Miller, Yankee Atomic Electric Company to R. D. Pagodin, Vermont Yankee Nuclear Power Corporation, dated April 20, 1995, "Vermont Yankee Core Shroud Inspection and Flaw Evaluations."

3 Letter from the NRC to D. A. Reid, Vice President of Operations, Vermont Yankee Nuclear Power Corporation, dated April 27, 1995, "Core Shroud Inspection and Flaw Evaluation, Vermont Yankee Nuclear Power Station (TAC No. M92050)."

14 Letter from L. A. England, Chairman, BWROG, to the NRC, dated April 5, 1994, "BWR Core Shroud Evaluation (GENE-523-148-1193)." 

Assessment (GENE-523-A107-0794)."

Letter from R. A. Pinelli, Chairman BWROG, to the NRC, dated Aug. 5, 1994, "BWR Shroud Cracking Generic Safety Assessment," Rev. 1.

Letter from R. A. Pinelli, Chairman BWROG, to the NRC, dated Aug. 5, 1994, "Responses to NRC Questions on Core Shroud and Reactor Internals."

Letter from the NRC to S. LaBruna, Chairman, BWROG Executive Oversight Committee, dated May 12, 1994, "Generic Questions Regarding Core Shroud Cracking."

Letter from C. Terry, Executive Chairman, Assessment Subcommittee, BWR Vessels and Internals Project, to the NRC, dated Sept. 2, 1994, "BWR Core Shroud Inspection and Evaluation Guidelines."

Letter from Brian W. Sheron, Director - Division of Engineering, Office of Nuclear Reactor Regulation, NRC, to J. T. Beckham, Chairman, BWRVIP, dated September 13, 1994, "Evaluation of BWR-VIP Report Entitled 'BWR Core Shroud Inspection and Evaluation Guidelines,'

GENE-523-113-0894, September 2, 1994."

Letter from the NRC to J. T. Beckham, Chairman, BWRVIP, dated Dec. 28, 1994, "Evaluation of 'BWR Shroud Cracking Generic Safety Assessment, Revision 1,' GENE-523-A107P-0794, August 5, 1994 and 'BWR Core Shroud Inspection and Evaluation Guidelines,' GENE-523-113-0894, September 2, 1994."

Letter from C.D. Terry, Executive Chairman - Assessment Subcommittee, BWR Vessel and Internals Project, to the NRC, dated April 21, 1995, "BWR Core Shroud Inspection and Evaluation Guidelines, Revision 1."

Letter from the NRC to J. T. Beckham, Chairman - BWRVIP, dated June 16, 1995, "Evaluation of 'BWR Core Shroud Inspection and Evaluation Guidelines,' GENE-523-113-0894, Revision 1, dated March 1995, and 'BWRVIP Core Shroud NDE Uncertainty and Procedure Standard,' dated November 22, 1994.

Letter from B. McCleod, Technical Chairman, BWRVIP Repair Technical Subcommittee, to the NRC, dated Aug. 18, 1994, "BWR Core Shroud Repair Design Criteria."

Letter from the NRC to B. McCleod, Technical Chairman, BWRVIP Repair Technical Subcommittee, dated Sept. 29, 1994, "Safety Evaluation on Boiling Water Reactor (BWR) Core Shroud Repair Design Criteria."

GE SIL 0572, Rev. 1, dated October 4, 1993, "Core Shroud Cracks."

GE RICSIL 068, Rev. 1, dated April 14, 1994, "Update on Core Shroud Cracking."

GE RICSIL 068, Rev. 2., dated May 6, 1994, "Update on Core Shroud Cracking."

Letter from L. J. Olivier, Vice President of Nuclear Operations, Boston Edison Company (BECo), to the NRC, dated August 27, 1994, "Response to Generic Letter 94-03, Integranular Stress Corrosion Cracking of Core Shrouds." 

(BECo), to the NRC, dated October 13, 1994, "Pilgrim Shroud Analysis."

31 Letter from L. J. Olivier, Vice President of Nuclear Operations, Boston Edison Company (BECo), to the NRC, dated Oct. 28, 1994, "NRC Request for Additional Information, Pilgrim Shroud Analysis." (Response to RAI)

NRC letter to E. T. Boulette, Ph.D., Senior Vice President - Nuclear, Boston Edison Company, dated November 28, 1994, "Safety Evaluation Report for Pilgrim Nuclear Station Regarding Generic Letter 94-03: 'Integranular Stress Corrosion Cracking of Core Shrouds in Boiling Water Reactors' (TAC No. M90108)."

Letter from E. T. Boulette, Ph.D., Senior Vice President - Nuclear, Boston Edison Company (BECo), to the NRC, dated January 16 1995, "Pilgrim Nuclear Power Station Core Shroud Stabilizer Design."

34 Letter from E. T. Boulette, Ph.D., Senior Vice President - Nuclear, Boston Edison Company (BECo), to the NRC, dated February 24, 1995, "PNPS Response to the NRC Staff Request for Additional Information Concerning the Proposed Repair of the Pilgrim Core Shroud."

Letter from E. T. Boulette, Ph.D., Senior Vice President - Nuclear, Boston Edison Company (BECo), to the NRC, dated March 21, 1995, "PNPS Response to the NRC Staff Request for Additional Information Concerning the Proposed Repair of the Pilgrim Core Shroud."

Letter from E. T. Boulette, Ph.D., Senior Vice President - Nuclear, Boston Edison Company (BECo), to the NRC, dated April 14, 1995, "Additional Information Concerning Our Planned Modification of the Pilgrim Core Shroud."

Letter from the NRC to E. T. Boulette, Ph.D., Senior Vice President - Nuclear, Boston Edison Company, dated May 12, 1995, "Safety Evaluation Regarding the Pilgrim Nuclear Power Station Core Shroud Repair (TAC No. M91305)."

38 Letter from R. A. Anderson, Vice President, Carolina Power \& Light Company, to the NRC, dated August 24, 1995, "Brunswick Steam Electric Plant, Unit Nos. 1 and 2, Docket Nos. 50-325 and 50324/License Nos. DPR-71 and DPR-62, NRC Generic Letter 94-03, 'Intergranular Stress Corrosion Cracking of Core Shrouds in Boiling Water Reactors." (Response to GL 94-03)

39 Letter from R. A. Anderson, Vice President, Carolina Power \& Light Company, to the NRC, dated April 28, 1995, "Brunswick Steam Electric Plant, Unit No. 1, Docket Nos. 50-325/License Nos. DPR71, NRC Generic Letter 94-03, 'Intergranular Stress Corrosion Cracking of Core Shrouds in Boiling Water Reactors" (re-inspection results).

Letter from the NRC to R. A. Anderson, Vice President - Carolina Power and Light Company, dated January 3, 1995, "Generic Letter 94-03, 'Intergranular Stress Corrosion Cracking of Core Shrouds in Boiling Water Reactors,' Brunswick Steam Electric Plant, Units 1 and 2 (TAC Nos. M90084 and M90085."

41 Letter from G. G. Benes, Nuclear Licensing Administrator, Commonwealth Edison, to the NRC, dated August 23, 1994, "Dresden Nuclear Power Station Units 2 and 3, Quad Cities Nuclear Power Station Units 1 and 2, Lasalle County Nuclear Power Station Units 1 and 2, Commonwealth Edison (ComEd) Response to NRC Generic Letter (GL) 94-03, 'Integranular Stress Corrosion Cracking of Core Shrouds in Boiling Water Reactors,' NRC Docket Nos. 50-237/249, 50-254/249, 50-373/374." 
42 Letter from M. D. Lyster, Site Vice-President - Dresden Station, to Mr. William T. Russell, Director Office of Nuclear Reactor Regulation, NRC, dated June 13, 1995, "Analytical Evaluation of Cracking Identified at Dresden Nuclear Power Station Unit 3, NRC Docket No. 50-249."

43 Letter from R. J. Walsh, Core Shroud Project Manager - Quad Cities Station, to Mr. William T. Russell, Director Office of Nuclear Reactor Regulation, NRC, dated June 13, 1995, "Analytical Evaluation of Cracking Identified at Quad Cities Nuclear Power Station Unit 1, NRC Docket No. 50-254."

44 Letter from the NRC to D. L. Farrar, Manager - Nuclear Regulatory Services, Commonwealth Edison Company, dated January 31, 1995, "Resolution of Generic Letter 94-03, 'Intergranular Stress Corrosion Cracking of Core Shrouds in Boiling Water Reactors,' at Dresden, Units 2 and 3, and Quad Cities, Units 1 and 2 (TAC Nos. M90088, M90089, M90109 and M90110)."

Letter from J. L. Schrage, Nuclear Licensing Administrator, Commonwealth Edison, to the NRC, dated January 16, 1995, "Quad Cities Nuclear Station Units 1 and 2, Core Shroud Modification Documents and Unit 2 Core Shroud Inspection Plan, NRC Docket Nos. 50-254 and 50-265."

Letter from J. L. Schrage, Nuclear Licensing Administrator, Commonwealth Edison, to the NRC, dated May 24, 1995, "Design Documents for the Dresden Station Core Shroud Repair, NRC Docket No.s 50-237 and 50-249."

47 Letter from the NRC to D. L. Farrar, Manager - Nuclear Regulatory Services, Commonwealth Edison Company, dated June 8, 1995, "Quad Cities Nuclear Power Station, Units 1 and 2, Safety Evaluation Regarding Core Shroud Repair (TAC Nos. M91301 and M91302)."

Letter from R. W. Keaten, Vice President and Director of Technical Functions, General Public Utilities (GPU), to the NRC, dated Aug. 24, 1994, "Oyster Creek Nuclear Generating Station (OCNGS), Docket No. 50-219, NRC Generic Letter 94-03, 'Intergranular Stress Corrosion Cracking of Core Shrouds in Boiling Water Reactors."' (Response to Generic Letter 94-03)

Letter from the NRC to J. J. Barton, Vice President and Director, GPU Nuclear Corp., dated November 25, 1994," Safety Evaluation Regarding the Oyster Creek Core Shroud Repair (TAC No. M90104)."

Letter from J. T. Beckham, Vice President - Plant Hatch, Georgia Power Company (GPC), to the NRC, dated August 24, 1994, "Edwin I. Hatch Nuclear Plant, BWR Core Shroud Cracking, Response to Generic Letter 94-03."

51 Letter from the NRC to J. T. Beckham, Vice President - Plant Hatch, Georgia Power Company (GCP), dated Feb. 23, 1995, SER regarding "Generic Letter 94-03, 'Intergranular Stress Corrosion Cracking of Core Shrouds in BWRs - Edwin I. Hatch Nuclear Plant, Units 1 and 2 (TAC Nos. M90094 and M99095)."

52 Letter from J. T. Beckham, Vice President - Plant Hatch, Georgia Power Company (GPC), to the NRC, dated September 2, 1994, "Edwin I. Hatch Nuclear Plant Unit 1, Installation of Core Shroud Stabilizers for Core Shroud Stabilizer Design Submittal."

53 Letter from the NRC to J. T. Beckham, Vice President - Plant Hatch, Georgia Power Company (GCP), dated September 30, 1994, "Safety Evaluation Report for Core Shroud Stabilizer Design, Edwin I. Hatch Nuclear Plant, Unit 1 (TAC No. M90270)." 

NRC, dated July 3, 1995, "Edwin I. Hatch Nuclear Plant - Unit 2, Core Shroud Stabilizer Design Submittal."

Letter from the NRC to J. T. Beckham, Vice President - Plant Hatch, Georgia Power Company, dated September 25, 1995, "Safety Evaluation for Core Shroud Stabilizer Design, Edwin I. Hatch Nuclear Plant, Unit 2 (TAC No. M92783)."

Letter from J. F. Franz, Vice President - Nuclear, IES Utilities Inc., to the NRC, dated August 24, 1994, "Duane Arnold Energy Center, Docket No. 50-331, Op. License No. DPR-49, Response to NRC Generic Letter 94-03, Integranular Stress Corrosion Cracking of Core Shrouds in Boiling Water Reactors, dated July 25, 1994."

NRC letter to Mr. Lee Liu, Chairman of the Board and Chief Executive Officer, IES Utilities Inc., dated March 1, 1995, SER regarding the "Duane Arnold Energy Center - Response to Generic Letter (GL) 94-03, "Intergranular Stress Corrosion Cracking of Core Shroud in BWRs (TAC No. M90090)."

Letter from G. R. Horn, Vice President - Nuclear, Nebraska Public Power District (NPPD), to the NRC, dated Aug. 26, 1994, "Response to Generic Letter 94-03 - Core Shroud Cracking, Cooper Nuclear Station, Docket No. 50-298, DPR-46."

Letter from the NRC to G. R. Horn, Vice President - Nuclear, Nebraska Public Power District, dated April 12, 1995, SER regarding "Generic Letter (GL) 94-03, 'Intergranular Stress Corrosion Cracking of Core Shrouds in BWRs' - Cooper Nuclear Station (TAC No. M90087)."

Letter from G. R. Horn, Vice President - Nuclear, Nebraska Public Power District, to the NRC, dated July 14, 1995, "Core Shroud Inspection Plan, Cooper Nuclear Station, NRC Docket 50-298, DPR-46."

61 Letter from the NRC to G. R. Horn, Vice President - Nuclear, Nebraska Public Power District, dated September 20, 1995, "Cooper Nuclear Station - Generic Letter 94-03, Core Shroud Inspection Plan (TAC No. M93007)."

Letter from C. D. Terry, Vice President - Nuclear Engineering, Niagara Mohawk Power Corporation, to the NRC, dated August 23, 1994, "Response to Generic Letter 94-03, 'Intergranular Stress Corrosion Cracking of Core Shrouds in Boiling Water Reactors," for Nine Mile Point Unit 1.

Letter from the NRC to B. R. Sylvia, Executive Vice President - Nuclear, Niagara Mohawk Power Corporation, dated January 13, 1995, SER regarding the "Response to Generic Letter (GL) 94-03, 'Intergranular Stress Corrosion Cracking of Core Shrouds in BWRs,' for Nine Mile Point Nuclear Station Unit No. 1 (TAC No. M90102)."

Letter from C. D. Terry, Vice President - Nuclear Engineering, Niagara Mohawk Power Corporation, to the NRC, dated January 6, 1995, supplemental response to "Generic Letter 94-03, 'Integranular Stress Corrosion Cracking of Core Shrouds in Boiling Water Reactors (TAC No. M90102)," Nine Mile Point Unit 1 core shroud repair design.

65 Letter from the NRC to B. R. Sylvia, Executive Vice President - Nuclear, dated March 31, 1995, "Nine Mile Point Nuclear Station Unit No. 1 (NMP1), Evaluation of Core Shroud Stabilizer Design (TAC No. M91273)." 

(NNECO), to the NRC, dated August 24, 1994, "Millstone Nuclear Power Station, Unit No. 1, Response to Generic Letter 94-03."

67 Letter from the NRC to J. F. Opeka, Executive Vice President - Nuclear, Northeast Nuclear Energy Company, dated January 4, 1995, SER regarding the "Millstone Nuclear Power Station, Unit 1 Generic Letter 94-03, 'Intergranular Stress Corrosion Cracking of Core Shrouds in BWRs' (TAC No. M90246)."

68 Letter from J. F. Opeka, Executive Vice President, Northeast Nuclear Energy Company, to the NRC, dated July 14, 1995, "Millstone Nuclear Power Station, Unit 1, Supplemental Response to Generic Letter 94-03."

69 Letter from the NRC to J. F. Opeka, Executive Vice President - Nuclear, Northeast Nuclear Energy Company, dated August 11, 1995, "Generic Letter 94-03, 'Intergranular Stress Corrosion Cracking of Core Shrouds in Boiling Water Reactors, Millstone Nuclear Power Station, Unit 1, Supplemental Response (TAC No. M92925)."

70 Letter from L. H. Waldinger, General Manager, Monticello Nuclear Site, to the NRC, dated August 23, 1994, "Monticello Nuclear Generating Plant, Docket No. 50-263, License No. DPR-22, Initial (30-Day) Response to NRC Generic Letter 94-03, 'Intergranular Stress Corrosion Cracking of Core Shrouds in Boiling Water Reactors."

71 Letter from the NRC to R. O. Anderson, Director Licensing and Management Issues, Northern States Power Company, dated January 20, 1995, SER regarding "Generic Letter (GL) 94-03, 'Integranular Stress Corrosion Cracking of Core Shrouds in Boiling Water Reactors,' Northern States Power Company (NSP), Monticello Nuclear Generation Plant (MNGP) (TAC No. M90101)."

72 Letter from W. J. Hill, Plant Manager, Monticello Nuclear Generating Plant, to the NRC, dated October 25, 1994, "Monticello Nuclear Generating Plant, Docket No. 50-263, License No. DPR-22, Supplemental Response to NRC Generic Letter 94-03, 'Intergranular Stress Corrosion Cracking of Core Shrouds in Boiling Water Reactors."

73 Letter from M. C. Kray, Acting Director - Licensing, Philadelphia Electric Company, to the NRC, dated August 24, 1994, "Peach Bottom Atomic Power Station, Units 1 and 2, Limerick Generating Station, Units 1 and 2, Response to Generic Letter 94-03, 'Intergranular Stress Corrosion Cracking of Core Shrouds in Boiling Water Reactors."

74 Letter from the NRC to G. A. Hunger, Jr., Director - Licensing, PECo Energy Company, dated February 6, 1995, Safety Evaluation Report regarding "Generic Letter (GL) 94-03,-·'Intergranular Stress Corrosion Cracking of Core Shrouds in BWRs,' Peach Bottom Atomic Power Station, Unit Nos. 2 and 3 (TAC Nos. M90105 and M90106)."

75 Letter from G. A. Hunger, Jr., Director - Licensing, Philadelphia Electric Company, to the NRC, dated November 7, 1994, "Peach Bottom Atomic Power Station, Unit 2, Supplemental Response to Generic Letter 94-03, Summary of Core Shroud Inspection Results." 
77 Letter from G. A. Hunger, Jr., Director - Licensing, PECo Energy Company, to the NRC, dated March 14, 1994, "Peach Bottom Atomic Power Station, Unit 3, Evaluation of Core Shroud Indications."

78 GENE-523-141-1093, Rev. 1, "Evaluation and Screening Criteria for the Peach Bottom Unit-3 Shroud Indications," dated December 13, 1993."

79 Letter M. C. Kray, Acting for G. A. Hunger, Jr., Director - Licensing, Philadelphia Electric Company, to the NRC, dated June 16, 1995, "Peach Bottom Atomic Power Station, Unit 3, Submittal of Inspection Plan in Response to Generic Letter 94-03, 'Intergranular Stress Corrosion Cracking of Core Shrouds in Boiling Water Reactors'."

80 Internal NRC Memorandum from R. A. Hermann to J. F. Stolz, dated September 25, 1995, "Staff Acknowledgement in Regard to Philadelphia Electric Company's Supplemental Response to Generic Letter 94-03."

81 Letter from G. A. Hunger, Director - Licensing, Philadelphia Electric Company, to the NRC, dated September 16, 1994, "Peach Bottom Atomic Power Station, Unit 2, Submittal of Proposed Alternative Repair Plan in Accordance with 10 CFR 50.55a(a)(3)."

82 Letter from W. A. Josiger, Acting Executive Vice President, New York Power Authority, to the NRC, dated August 24, 1994, "James A. FitzPatrick Nuclear Power Plant, Docket No. 50-333, Response to Generic Letter 94-03, 'Intergranular Stress Corrosion Cracking of Core Shrouds in BWRs'."

83 Letter from W. J. Cahill, Jr., Executive Vice President - Nuclear Generation, New York Power Authority, to the NRC, dated October 18, 1994, "Supplemental Response to Generic Letter 94-03, 'Intergranular Stress Corrosion Cracking of Core Shrouds in BWRs'."

84 Letter from William J. Cahill, Jr., Executive Vice President - Nuclear Generation, New York Power Authority, to the NRC, dated November 30, 1994, "Revision to Core Shroud Safety Assessment Report."

85 Letter from the NRC to W. J. Cahill, Jr., Executive Vice President - Nuclear Generation, New York Power Authority, dated February 5, 1995, Safety Evaluation regarding the "Response to Generic Letter 94-03 for the James A. FitzPatrick Nuclear Power Plant (TAC No. M90092)."

Letter from W. J. Cahill, Jr., Executive Vice President - Nuclear Generation, New York Power Authority, to the NRC, dated October 21, 1994, "Request for NRC Approval of the Fitzpatrick Core Shroud Repair."

87 Letter from the NRC to W. J. Cahill, Jr., Executive Vice President - Nuclear Generation, New York Power Authority, dated January 5, 1995, "Safety Evaluation Regarding the Core Shroud Repair for the James A. FitzPatrick Nuclear Power Plant (TAC No. M90964)."

88 Letter from R. D. Machon, Site Vice President, Browns Ferry Nuclear Plant, to the NRC, dated August 23, 1994, "Browns Ferry Nuclear Plant (BFN) - Units 1, 2, and 3 - Response to Generic Letter (GL) 94-03 - Intergranular Stress Corrosion Cracking (IGSCC) of Shrouds In Boiling Water Reactors."

89 Letter from the NRC to O. D. Kingsley, Jr., President and Chief Nuclear Officer, Tennessee Valley Authority, dated January 13, 1995, "Browns Ferry Nuclear Plant Units 1, 2, and 3, Safety Evaluation of Response to Generic Letter 94-03, (TAC Nos. M90081, M90082, and M90083)." 
Letter from P. S. Salas, Site Licensing Manager, Browns Ferry Nuclear Plant, to the NRC, dated November 18, 1994, "Browns Ferry Nuclear Plant (BFN) - Unit 2 - Results of Core Shroud Inspection (TAC No. M90082)."

91 Letter from J. P. Pelletier, Vice President - Engineering, Vermont Yankee Nuclear Power Corporation, to the NRC, dated August 17, 1994, "Response to USNRC Generic Letter 94-03, 'Intergranular Stress Corrosion Cracking of Core Shrouds in BWRs'."

Letter from the NRC to D. A. Reid, Vice President of Operations, Vermont Yankee Nuclear Power Corporation, dated January 5, 1995, "Safety Evaluation for Vermont Yankee Nuclear Power Station Regarding Generic Letter 94-03, 'Intergranular Stress Corrosion Cracking of Core Shrouds in Boiling Water Reactors' (TAC No. M90114)."

Letter from R. G. Byram, Senior Vice President - Nuclear, Pennsylvania Power \& Light Company, to the NRC, date August 24, 1994, "Susquehanna Steam Electric Station, Initial Response to Generic Letter 94-03, Docket Nos. 50-387 and 50-388.".

Letter from C. R. Hutchinson, Vice President - Operations, Grand Gulf Nuclear Station, to the NRC, dated August 19, 1994, "Grand Gulf Nuclear Station Unit 1, Docket No. 50-416, License No. NPF-29, Response to Generic Letter 94-03."

Letter from the NRC to D. L. Farrar, Manager - Nuclear Regulatory Services, Commonwealth Edison Company, dated February 16, 1995, Safety Evaluation regarding "Lasalle County Station, Units 1 and 2 - Response to Generic Letter 94-03, (TAC Nos. M90097 and M90098)."

Letter from the NRC to G. A. Hunger, Jr., Director - Licensing, PECo Energy Company, dated March 7, 1995, Safety Evaluation regarding "Generic Letter (GL) 94-03, "Intergranular Stress Corrosion Cracking of Core Shrouds in BWRs,' Philadelphia Electric Company (PECo), Limerick Unit 1 (TAC No. M90099)."

Letter from the NRC to R. G. Byram, Senior Vice President Nuclear, Pennsylvania Power and Light Company, dated March 23, 1995, Safety Evaluation regarding "Generic Letter (GL) 94-03, 'Intergranular Stress Corrosion Cracking of Core Shrouds in BWRs,' Pennsylvania Power and Light Company, Susquehanna Steam Electric Station, Units 1 and 2 (TAC Nos. M90112 and M90113)."

Letter from the NRC to C. R. Hutchinson, Vice President of Operations - Grand Gulf Nuclear Station, Entergy Operations, Inc., dated March 29, 1995, Safety Evaluation regarding "Generic Letter (GL) 94-03, "Intergranular Stress Corrosion Cracking of Core Shrouds in BWRs,' Entergy Operations, Inc., Grand Gulf Nuclear Station, Unit 1 (TAC No. M90093)."

Letter from R. G. Byram, Senior Vice President - Nuclear, Pennsylvania Power and Light Company, to the NRC, dated December 19, 1994, "Susquehanna Steam Electric Station Interim Response to Generic Letter 94-03."

100 Letter from the NRC to R. G. Byram, Senior Vice President - Nuclear, Pennsylvania Power and Light Company, dated April 10, 1995, "Susquehanna Steam Electric Station, Units 1 and 2, Interim Response to Generic Letter 94-03, 'Intergranular Stress Corrosion Cracking of Core Shrouds in BWRs (TAC No. M90112 and M90113)."

101 Letter from R. G. Byram, Senior Vice President - Nuclear, Pennsylvania Power and Light Company, to the NRC, dated April 4, 1995, "Susquehanna Steam Electric Station, Generic Letter 94-03 Interim Inspection Report." (Docket 50-387) 
Letter from R. G. Byram, Senior Vice President - Nuclear, Pennsylvania Power and Light Co., to the NRC, dated May 25, 1995, "Susquehanna Steam Electric Station, Generic Letter 94-03 Final Inspection Results for Unit 1 Core Shroud." (Docket 50-387)

103 Letter from the NRC to R. G. Byram, Senior Vice President - Nuclear, Pennsylvania Power and Light Company, dated May 3, 1995, "Susquehanna Steam Electric Station, Unit 1, Staff Acknowledgement in regard to Pennsylvania Power and Light Company's (PP\&L) Supplemental Response to Generic Letter (GL) 94-03 (TAC No. M92098)."

104 Letter from S. LaBruna, Vice President - Nuclear Engineering, Public Service Electric and Gas Company, to the NRC, dated August 24, 1994, "Response to Generic Letter 94-03, 'Intergranular Stress Corrosion Cracking of Core Shrouds in Boiling Water Reactors, Hope Creek Generating Station, Docket No. 50-354."

105 Letter from C. D. Terry, Vice President - Nuclear Engineering, Niagara Mohawk Power Corporation, to the NRC, dated August 23, 1994, regarding the Nine Mile Unit 2 "Response to Generic Letter 94-03, 'Intergranular Stress Corrosion Cracking of Core Shrouds at Boiling Water Reactors."

106 Letter from J. J. Fisicaro, Director - Nuclear Safety, Entergy Operations, Incorporated, to the NRC, dated August 24, 1995, "Response to Generic Letter 94-03, River Bend Station Unit 1/Docket No. 50-458."

107 Letter from D. R. Gibson, Senior Vice President - Nuclear Generation, Detroit Edison Company, to the NRC, dated August 24, 1994, "Detroit Edison Response to NRC Generic Letter 94-03."

108 Letter from J. G. Cook, Vice President, Illinois Power Company, to the NRC, dated August 24, 1994, "Illinois Power's (IP's), Clinton Power Station's (CPS's) Response to Generic Letter (GL) 94-03, "Intergranular Stress Corrosion Cracking of Core Shrouds in Boiling Water Reactors."

109 Letter from R. A. Stratman, Vice President - Nuclear Perry Station, Centerior Service Company, to the NRC, dated August 24, 1994, "Perry Nuclear Power Plant, Docket No. 50-440, Response to Generic Letter 94-03."

110 Letter from J. W. Baker, Acting Assistance Managing Director of Operations, Washington Public Power Supply System, to the NRC, dated August 24, 1994, "WNP-2, Operating License NPF-21, Response to Generic Letter 94-03, 'Intergranular Stress Corrosion Cracking of Core Shrouds'."

111 Letter from the NRC to G. A. Hunger, Jr., Director - Licensing, Philadelphia Electric Company, dated March 13, 1995, Safety Evaluation regarding "Generic Letter (GL) 94-03, 'Intergranular Stress Corrosion Cracking of Core Shrouds in BWRs,' Limerick Generation Station, Unit 2 (TAC No. M90100)."

112 Internal NRC Memorandum, dated December 13, 1994, "Safety Evaluation Reports for Licensee Responses to Generic Letter 94-03." Note that the actual Safety Evaluation Report regarding the response to GL 94-03 for Hope Creek Station was issued to Public Service Electric and Gas Company after September 30, 1995, which is beyond the time scope of this NUREG. 
113 Letter from the NRC to B. R. Sylvia, Executive Vice President - Nuclear, Niagara Mohawk Corporation, dated February 2, 1995, Safety Evaluation regarding "Generic Letter (GL) 94-03, 'Intergranular Stress Corrosion Cracking of Core Shrouds in BWRs,' Nine Mile Point Station, Unit 2 (NMP-2) (TAC No. M90103)."

114 Letter from the NRC to J. R. McGaha, Jr., Vice President, Entergy Operations, Incorporated, dated February 3, 1995, Safety Evaluation regarding "Generic Letter (GL) 94-03, 'Intergranular Stress Corrosion Cracking of Core Shrouds in BWRs,' Entergy Operations, Inc., River Bend Station (TAC No. M90111)."

115 Letter from the NRC to D. R. Gipson, Senior Vice President - Nuclear Generation, Detroit Edison Company, dated January 24, 1995, Safety Evaluation regarding "Generic Letter (GL) 94-03, 'Intergranular Stress Corrosion Cracking of Core Shrouds in BWRs,' Detroit Edison Company, Fermi 2 (TAC No. M90091)."

116 Letter from the NRC to R. F. Phares, Director - Licensing, Clinton Power Station, dated February 10, 1995, Safety Evaluation regarding "Response to Generic Letter (GL) 94-03, 'Intergranular Stress Corrosion Cracking of Core Shrouds in BWRs,' - Clinton Power Station (TAC No. M90086)."

117 Letter from the NRC to D. C. Shelton, Acting Vice President Nuclear - Perry, Centerior Service Company, dated February 10, 1995, Safety Evaluation regarding "Generic Letter (GL) 94-03, 'Intergranular Stress Corrosion Cracking of Core Shrouds in BWRs,' Perry Nuclear Plant, Unit No. 1 (TAC No. M90107)."

118 Letter from the NRC to J. V. Parrish, Vice President - Nuclear Operations, Washington Public Power Supply System, dated May 8, 1995, "Closeout of Generic Letter 94-03, 'Intergranular Stress Corrosion Cracking of Core Shrouds in BWRs,' for the Washington Public Power Supply System Nuclear Project No. 2 (TAC No. M90115)."

119 General Electric Company RICSIL 071, dated November 22, 1994, "Top Guide and Core Plate Cracking."

120 Letter from C. Terry, Executive Chairman, BWRVIP Assessment Committee, to the NRC, dated December 23, 1994, "Request for Information Regarding the Impact of BWR Core Plate and Top Guide Ring Cracking."

121 Letter from C. Terry, Executive Chairman, BWRVIP Assessment Committee, to the NRC, dated January 3, 1995, "Request for Information Regarding the Impact of BWR Core Plate and Top Guide Ring Cracking."

122 General Electric Company SIL 588, dated February 17, 1995, "Top Guide and Core Plate Cracking."

123 Internal NRC Memorandum, from B. W. Sheron, Director Division of Engineering, NRR, to A. C. Thadani, Associate Director for Technology, dated April 25, 1995, "Safety Assessment of BWR Core Plate Ring and Top Guide Ring Cracking."

124 NRC Inspection and Enforcement Bulletin (IEB) 80-07, dated April 4, 1980, "BWR Jet Pump Assembly Failure." 
127 NRC NUREG/CR-3052, dated November 30, 1984, "Closeout of IE Bulletin 80-07: BWR Jet Pump Assembly Failure."

128 GE SIL No. 462, dated February 1, 1988, "Shroud Support Access Hole Cracks."

129 GE SIL No. 462, Supplement 1, dated February 22, 1989, "Shroud Support Access Hole Cracks."

130 GE SIL No. 462, Supplement 2, dated August 1990, "Shroud Support Access Hole Cracks."

131 GE SIL No. 462, Supplement 2, Revision 1, dated December 31, 1990, "Shroud Support Access Hole Cracks."

132 GE SIL No. 462, Supplement 3, dated June 8, 1992, "Radial Cracking in Creviced Inconel 600 AHC Weldments."

133 NRC Information Notice 88-03, dated February 2, 1988, "Cracks in Shroud Support Access Hole Covers."

134 NRC Information Notice 92-57, dated August 11, 1992, "Radial Cracking of Shroud Support Access Hole Cover Welds." 



\section{APPENDIX A \\ LIST OF BWROG MEMBERS AND BWRVIP SUBCOMMITTEES}

\section{BWROG Members}

Boston Edison Company

Carolina Power \& Light Company

Centerior Energy, Incorporated

Commonwealth Edison Company

Detroit Edison Company

Entergy Operation, Incorporated

Georgia Power Company

General Public Utilities

Illinois Power Company

IES Utilities, Inc.

Nebraska Public Power District

Niagara Mohawk Power Corporation

Northeast Nuclear Energy Company

Northern States Power Company

Pennsylvania Power \& Light Company

Philadelphia Electric Company

Power Authority of the State of New York

Public Services Electric and Gas Company

Tennessee Valley Authority

Vermont Yankee Nuclear Power Corporation

Washington Public Power Supply System
BWRVIP Subcommittees *

\author{
BWRVIP Chairman \\ Thomas Beckham \\ Southern Nuclear Operating Corp. \\ BWRVIP Vice Chairman \\ Carl Terry \\ Niagara Mohawk Power Company \\ Integration Subcommittee \\ Executive Chairman \\ John Hosmer \\ Commonwealth Edison \\ Technical Chairman \\ Vaughn Wagner \\ CP\&L
}

Inspection Subcommittee

Executive Chairman
Robert Keaten
General Public Utilities

Technical Chairman Steve Leonard

Niagara Mohawk

Assessment Subcommittee

Executive Chairman

Carl Terry

Technical Chairman

Robin Dyle

Niagara Mohawk Power Co.

Southern Nuclear

Mitigation Subcommittee

$$
\begin{aligned}
& \text { Executive Chairman } \\
& \text { Vacant }
\end{aligned}
$$

Technical Chairman John Wilson PSE\&G

Repair Subcommittee

$\begin{array}{ll}\text { Executive Chairman } & \text { Technical Chairman } \\ \text { William Campbell } & \text { Bruce McLeod } \\ \text { Carolina Power \& Light } & \text { Georgia Power Co. }\end{array}$

* As of January 3, 1996 


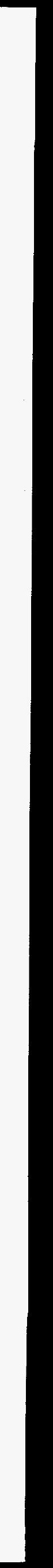




\section{APPENDIX B \\ PLANT-SPECIFIC BWR \\ CORE SHROUD SUMMARIES}




\section{PILGRIM NUCLEAR POWER PLANT DATA SHEET}

LICENSEE: Boston Edison Company (BECo)

PLANT NAME: Pilgrim Nuclear Power Station (PNPS)

DOCKET NO.: $50-293$

LICENSE NO.: DPR-35

BWRVIP CATEGORY GROUPING:_Category "C"

\section{SHROUD FABRICATION DATA:}

SHROUD MANUFACTURER:P.F. Avery Corp.

SHROUD SHELL CONSTRUCTION MATERIALS: ASTM A240-63 Type 304 stainless steel plate

CARBON CONTENT RANGE SHELL SECTIONS: $0.045 \% \mathrm{C}-0.54 \% \mathrm{C}$

SHROUD RING CONSTRUCTION MATERIALS: ASTM A240-63 Type 304 stainless steel plate

CARBON CONTENT RANGE SHROUD RINGS: $0.054 \% \mathrm{C}-0.056 \% \mathrm{C}$

\section{WELDING DATA:}

INITIAL PASS TECHNIQUE: Flange welds by SMAW; other shroud vert. \& circ. welds by SAW

INITIAL PASS WELD MATERIAL:_E-308 electrodes for SMAW; ER-308L filler for SAW

SUBSEQUENT PASS TECHNIQUE: Flange welds by SMAW; other shroud vert. \& circ. welds by SAW

SUBSEQUENT PASS WELD MATERIAL: E-308 electrodes for SMAW; ER-308L filler for SAW

OPERATIONAL DATA:

AVERAGE CONDUCTIVITY VALUE OVER

THE FIRST FIVE YEARS OF OPERATION: $0.53 \mu \mathrm{S} / \mathrm{cm}$

ELAPSED TIME AT POWER OPERATION: $>12.6$ EFPY by F1994

\section{GENERIC LETTER INFORMATION:}

DATE GL 94-03 RESPONSE: August 27, 1994

BASIS FOR ACCEPTING JCO: Generic Safety Assessment

DATE OF CORE SHROUD INSPECTION/REPAIR: RFO No. 10, April 1995

NRC SERs: (1) SER regarding BECo's response to GL 94-03, November 28, 1994

(2) SER regarding BECo modification of the PNPP core shroud, May 12, 1995

REMARKS: BECo opted to implement a modification of the PNPP core shroud in lieu of performing comprehensive core shroud examinations. Modification uses the GE tie rod assembly design. This design provides a redundant load path for the shroud under normal operating, transient and postulated design basis accident conditions given the occurrence of a $360^{\circ}$ throughwall failure of a circumferential weld. Modification of the PNPP core shroud is designed to maintain the structural integrity of the PNPP core shroud during subsequent operating cycles. Staff approved the PNPP core shroud modification design in May 1995. 


\section{BRUNSWICK UNIT 1 DATA SHEET}

LICENSEE:_Carolina Power and Light Company (CP\&L)

PLANT NAME: Brunswick Steam Electric Plant, Unit 1 (BR-1)

DOCKET NO.: $50-325$

LICENSE NO.: DPR-71

BWRVIP CATEGORY GROUPING: Category " $\mathrm{C}$ "

SHROUD FABRICATION DATA:

SHROUD MANUFACTURER: Sun Ship Building and Dry Dock Co.

SHROUD SHELL CONSTRUCTION MATERIAL: A/SA 240 Type 304 stainless steel rolled plates

CARBON CONTENT RANGE SHELL SECTIONS: $0.048 \% \mathrm{C}-0.064 \% \mathrm{C}$

SHROUD RING CONSTRUCTION MATERIAL: A/SA 240 Type 304 stainless steel rolled plates

CARBON CONTENT RANGE SHROUD RINGS: $0.063 \% \mathrm{C}-0.078 \% \mathrm{C}$

\section{WELDING DATA:}

INITIAL PASS TECHNIQUE: SMAW or SAW methods

INITIAL PASS WELD MATERIAL: E308

SUBSEQUENT PASS TECHNIQUE: SMAW or SAW methods

SUBSEQUENT PASS WELD MATERIAL:_E308

OPERATIONAL DATA:

AVERAGE CONDUCTIVITY VALUE OVER

THE FIRST FIVE YEARS OF OPERATION: $0.578 \mu \mathrm{S} / \mathrm{cm}$

ELAPSED TIME AT POWER OPERATION: $>9.8$ EFPY by F1994

\section{GENERIC LETTER INFORMATION:}

DATE GL 94-03 RESPONSE: August 24, 1994

BASIS FOR ACCEPTING JCO: Results of F1993 flaw evaluation and implementation of shroud repair

DATE OF CORE SHROUD INSPECTION/REPAIR:Inspect. S1993. Repair W1993/1994. Reinspection SP1995

NRC SERs: (1) SER regarding BR-1 core shroud repair January 14, 1994

(2) SER regarding CP\&L's response to GL 94-03, January 3, 1995

REMARKS: Initial VT-1 and UT examination of BR-1 core shroud in S1993, in accordance with recommendations in GE RICSIL 054. Results of examinations indicated large scale $\left(360^{\circ}\right)$ cracking at the $\mathrm{H} 3$ weld. Results also indicated a significant amount of cracking at welds $\mathrm{H1}$ and $\mathrm{H} 2$, and minor cracking at weld H4. CP\&L implemented a modification of the BR-1 shroud using a series of mechanical clamps around the $\mathrm{H} 2$ and $\mathrm{H} 3$ welds. The clamps are designed to provide a redundant load path around the $\mathrm{H} 2$ and $\mathrm{H} 3$ welds. Modification design approved by staff in January 1994. CP\&L performed a second inspection (UT) of the BR-1 shroud in April 1995. No new crack initiation discovered; growth of existing indications minimal. 


\section{BRUNSWICK UNIT 2 DATA SHEET}

LICENSEE: Carolina Power and Light Company (CP\&L)

PLANT NAME: Brunswick Steam Electric Plant, Unit 2 (BR-2)

DOCKET NO.: $50-324$

LICENSE NO.: DPR-62

BWRVIP CATEGORY GROUPING: Category "C"

SHROUD FABRICATION DATA:

SHROUD MANUFACTURER: Sun Ship Building and Dry Dock Co. SHROUD SHELL CONSTRUCTION MATERIAL: A/SA 240 Type 304 rolled plates

CARBON CONTENT RANGE SHELL SECTIONS: $0.046 \% \mathrm{C}-0.061 \% \mathrm{C}$

SHROUD RING CONSTRUCTION MATERIAL:A/SA 240 Type 304 rolled plates

CARBON CONTENT RANGE SHROUD RINGS: $0.047 \% \mathrm{C}-0.067 \% \mathrm{C}$

WELDING DATA:

INITIAL PASS TECHNIQUE: SMAW or SAW methods

INITIAL PASS WELD MATERIAL: E308L electrode or ER308L filler as appropriate

SUBSEQUENT PASS TECHNIQUE: SMAW or SAW methods

SUBSEQUENT PASS WELD MATERIAL: E308L electrode or ER308L filler as appropriate

OPERATIONAL DATA:

AVERAGE CONDUCTIVITY VALUE OVER

THE FIRST FIVE YEARS OF OPERATION: $0.714 \mu \mathrm{S} / \mathrm{cm}$

ELAPSED TIME AT POWER OPERATION: $>10.1$ EFPY by F1994

\section{GENERIC LETTER INFORMATION:}

DATE GL 94-03 RESPONSE: August 24, 1994

BASIS FOR ACCEPTING JCO: Results of BR-1 S1993 shroud exams bounding for BR-2, also generic assessment

DATE OF CORE SHROUD INSPECTION/REPAIR: S1994; Next inspection scheduled for S1996

NRC SERs: SER regarding response to GL 94-03, January 3, 1995

REMAIRKS: CP\&L implemented a repair of the BR-2 core shroud during the SP1994 RFO. Repair design encompassed circumferential welds H2 and H3. Repair design was the same one as was used to modify the BR-1 core shroud in the W1994/1995. CP\&L also performed examinations of BR-2 shroud welds that were not covered by the design modification. These examinations included enhanced VT-1 inspections of the H1, H2, H4, H5, H6a H6b, and H7 circumferential welds, and a UT inspection of the H4 weld. Only minor cracking was detected as a result of the examinations. Maximum circumferential crack length was $0.35 \mathrm{~m}(13.6 \mathrm{in}$ ) at weld $\mathrm{H} 4$ (an $0.28-\mathrm{m}$

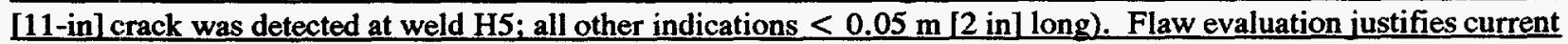
operation. 


\section{DRESDEN UNIT 3 DATA SHEET}

LICENSEE: Commonwealth Edison Company (ComEd)

PLANT NAME: Dresden Nuclear Power Plant, Unit 3 (DR-3)

DOCKET NO.: $50-249$

LICENSE NO.: DPR-25

BWRVIP CATEGORY GROUPING: Category " $\mathrm{C}$ "

SHROUD FABRICATION DATA:

SHROUD MANUFACTURER: Bingham Williamette

SHROUD SHELL CONSTRUCTION MATERIAL: A 240 Type 304 SS rolled plate

CARBON CONTENT RANGE SHELL SECTIONS: $0.044 \% \mathrm{C}-0.063 \% \mathrm{C}$ (range for whole shroud)

SHROUD RING CONSTRUCTION MATERIAL: A 240 Type 304 SS rolled plate

CARBON CONTENT RANGE SHROUD RINGS: $0.044 \% \mathrm{C}-0.063 \% \mathrm{C}$ (range for whole shroud)

WELDING DATA:

INITIAL PASS TECHNIQUE: Technique not specified in the repsponse to GL 94-03

INITIAL PASS WELD MATERIAL: ASTM Type E308 electrode or ER308 filler material

SUBSEQUENT PASS TECHNIQUE: Technique not specified in the response to GL 94-03

SUBSEQUENT PASS WELD MATERIAL: ASTM Type E308 electrode or ER308 filler material

OPERATIONAL DATA:

AVERAGE CONDUCTIVITY VALUE OVER

THE FIRST FIVE YEARS OF OPERATION: $0.399 \mu \mathrm{S} / \mathrm{cm}$

ELAPSED TIME AT POWER OPERATION: $>\approx 15$ EFPY by F1994

\section{GENERIC LETTER INFORMATION:}

DATE GL 94-03 RESPONSE:_August 23, 1994

BASIS FOR ACCEPTING JCO: Flaw evaluation of DR-3/QC-1 core shrouds

DATE OF CORE SHROUD INSPECTION/REPAIR: Repair scheduled for F1996

NRC SERs: (1) SER regarding DR-3/OC-1 core shrouds, July 21, 1994

(2) SER regarding response to GL 94-03, January 31, 1995

(3) SER regarding confirmation of DR-3/OC-1 flaw evaluation, August 16, 1995

REMARKS: ComEd performed a comprehensive inspection of the DR-3 core shroud in SP1994. Inspections included enhanced VT-1 examinations of welds H1 - H7 and UT examinations of welds H2, H5, H6, and H7. Results of ComEd's examinations indicated the presence of extensive circumferential cracking in the H5 weld. Cracks treated as extending $360^{\circ}$ around the weld. The NRC performed an independent flaw evaluation of the $\mathrm{H} 5$ weld. NRC determined that the H5 weld should have sufficient remaining ligaments in the weld to justify an additional 15 months of hot operation of the DR-3 unit. The NRC also determined that any cracking detected at other circumferential welds would be bounded by that at the H5 weld. 


\section{QUAD CITIES UNIT 1 DATA SHEET}

LICENSEE: Commonwealth Edison Company (ComEd)

PLANT NAME: Quad Cities Nuclear Power Plant, Unit 1 (OC-1)

DOCKET NO.: $50-254$

LICENSE NO.: DPR-29

BWRVIP CATEGORY GROUPING:_Category "C"

SHROUD FABRICATION DATA:

SHROUD MANUFACTURER: Bingham Williamette

SHROUD SHELL CONSTRUCTION MATERIAL: A 240 Type 304 SS rolled plate

CARBON CONTENT RANGE SHELL SECTIONS: $0.044 \%$ C $-0.063 \%$ C (range for whole shroud)

SHROUD RING CONSTRUCTION MATERIAL: A 240 Type 304 SS rolled plate

CARBON CONTENT RANGE SHROUD RINGS: $0.044 \% \mathrm{C}-0.063 \% \mathrm{C}$ (range for whole shroud)

WELDING DATA:

INITIAL PASS TECHNIQUE: Technique not specified in the response to GL 94-03

INITIAL PASS WELD MATERIAL: ASTM Type E308 electrode or ER308 filler material

SUBSEQUENT PASS TECHNIQUE: Technique not specified in the response to GL 94-03

SUBSEQUENT PASS WELD MATERIAL: ASTM Type E308 electrode or ER308 filler material

OPERATIONAL DATA:

AVERAGE CONDUCTIVITY VALUE OVER

THE FIRST FIVE YEARS OF OPERATION: $0.377 \mu S / \mathrm{cm}$

ELAPSED TIME AT POWER OPERATION: $>16.0$ EFPY by F1994

GENERIC LETTER INFORMATION:

DATE GL 94-03 RESPONSE: August 23, 1994

BASIS FOR ACCEPTING JCO: Flaw evaluation of DR-3/OC-1 core shrouds

DATE OF CORE SHROUD INSPECTION/REPAIR: Inspection performed SP1994

NRC SERs: (1) SER regarding DR-3/OC-1 core shrouds, July 21, 1994

(2) SER regarding response to GL 94-03, January 31, 1995

(3) SER regarding confirmation of DR-3/QC-1 flaw evaluation, August 16, 1995

REMAIRKS: ComEd performed a comprehensive inspection of the OC-1 core shroud in SP1994. Inspections included enhanced VT-1 examinations of welds $\mathrm{H1}-\mathrm{H} 7$ and UT examinations of welds H2, H5, H6, and H7. Results of ComEd's examinations indicated the presence of extensive circumferential cracking in the H5 weld. Cracks treated as extending $360^{\circ}$ around the weld. The NRC performed an independent flaw evaluation of the $\mathrm{H} 5$ weld. NRC determined that the H5 weld should have sufficient remaining ligaments in the weld to justify an additional 15 months of hot operation of the OC-1 unit. The NRC also determined that any cracking detected at other circumferential welds would be bounded by that at the $\mathrm{H} 5$ weld. 


\section{DRESDEN UNIT 2 DATA SHEET}

LICENSEE: Commonwealth Edison Company (ComEd)

PLANT NAME: Dresden Nuclear Power Plant, Unit 2 (DR-2)

DOCKET NO.: $50-237$

LICENSE NO.: DPR-19

BWRVIP CATEGORY GROUPING: Category "C"

SHROUD FABRICATION DATA:

SHROUD MANUFACTURER: Bingham Williamette

SHROUD SHELL CONSTRUCTION MATERIAL:_A 240 Type 304 SS rolled plate

CARBON CONTENT RANGE SHELL SECTIONS: $0.044 \% \mathrm{C}-0.063 \% \mathrm{C}$ (range for whole shroud)

SHROUD RING CONSTRUCTION MATERIAL: A 240 Type 304 SS rolled plate

CARBON CONTENT RANGE SHROUD RINGS: $0.044 \% \mathrm{C}-0.063 \% \mathrm{C}$ (range for whole shroud)

WELDING DATA:

INITIAL PASS TECHNIQUE: Technique not specified in response to GL 94-03

INITIAL PASS WELD MATERIAL: ASTM Type E308 electrode or ER308 filler material

SUBSEQUENT PASS TECHNIQUE: Technique not specified in response to GL 94-03

SUBSEQUENT PASS WELD MATERIAL:_ASTM Type E308 electrode or ER308 filler material

OPERATIONAL DATA:

AVERAGE CONDUCTIVITY VALUE OVER

THE FIRST FIVE YEARS OF OPERATION: $0.299 \mu \mathrm{S} / \mathrm{cm}$

ELAPSED TIME AT POWER OPERATION: >17.1 EFPY by F1994

GENERIC LETTER INFORMATION:

DATE GL 94-03 RESPONSE: August 23, 1994

BASIS FOR ACCEPTING JCO: Results of DR-3/OC-1 flaw evaluations bounding for DR-2/OC-2

DATE OF CORE SHROUD INSPECTION/REPAIR: Repair scheduled for F/W1995

NRC SERs: (1) SER regarding the ComEd response to GL 94-03 for DR-2/OC-2, January 31, 1995

REMARKS: ComEd opted to implement a modification of the DR-2 core shroud in lieu of performing comprehensive core shroud examinations. The design involves installation of $\mathrm{GE}$ designed tie rod assemblies around the OD of the shroud. Tie rod assemblies are designed to provide an alternate load bearing capability for the shroud during normal operating, transient and postulated design basis accident conditions, given the occurrence of a $360^{\circ}$ through-wall failure of a circumferential weld. Core shroud modification design currently under review by the NRC staff. 


\section{QUAD CITIES UNIT 2 DATA SHEET}

LICENSEE: Commonwealth Edison Company (ComEd)

PLANT NAME:_Quad Cities Nuclear Power Plant, Unit 2 (OC-2)

DOCIKET NO.: $50-265$

LICENSE NO.: DPR-30

BWRVIP CATEGORY GROUPING: Category "C"

\section{SHROUD FABRICATION DATA:}

SHROUD MANUFACTURER: Bingham Williamette

SHROUD SHELL CONSTRUCTION MATERIAL: A 240 Type 304 SS rolled plate

CARBON CONTENT RANGE SHELL SECTIONS: $0.044 \% \mathrm{C}-0.063 \% \mathrm{C}$ (range for whole shroud)

SHROUD RING CONSTRUCTION MATERIAL: A 240 Type 304 SS rolled plate

CAREION CONTENT RANGE SHROUD RINGS: $0.044 \% \mathrm{C}-0.063 \% \mathrm{C}$ (range for whole shroud)

\section{WELDING DATA:}

INITIAL PASS TECHNIQUE: Technique not specified in response to GL 94-03

INITIAL PASS WELD MATERIAL: ASTM Type E308 electrode or ER308 filler material

SUBSEQUENT PASS TECHNIQUE: Technique not specified in response to GL 94-03

SUBSEQUENT PASS WELD MATERIAL: ASTM Type E308 electrode or ER308 filler material

OPERATIONAL DATA:

AVERAGE CONDUCTIVITY VALUE OVER

THE FIRST FIVE YEARS OF OPERATION: $0.377 \mu \mathrm{S} / \mathrm{cm}$

ELAPSED TIME AT POWER OPERATION: >16.1 EFPY by F1994

\section{GENERIC LETTER NNFORMATION:}

DATE GL 94-03 RESPONSE: August 23, 1995

BASIS FOR ACCEPTING JCO: Results of DR-3/OC-1 flaw evaluation bounding for DR-2/OC-2

DATE OF CORE SHROUD INSPECTION/REPAIR: Repair implemented SP/S1995

NRC SERs: (1) SER regarding the response to GL-94-03 for DR-2/OC-2, January 31, 1995

(2) QC-2 core shroud repair (modification) SER, June 8, 1995

REMARKS: ComEd opted to implement a modification of the OC-2 core shroud in lieu of performing comprehensive core shroud examinations. The design involves installation of GE designed tie rod assemblies around the OD of the shroud. Tie rod assemblies are designed to provide an alternate load bearing capability for the shroud during normal operating transient and postulated design basis accident conditions, given the occurrence of a $360^{\circ}$ through-wall failure of a circumferential weld. The NRC approved the modification design for the OC-2 core shroud on June 8, 1995. 


\section{OYSTER CREEK DATA SHEET}

LICENSEE: General Public Utilities (GPU)

PLANT NAME: Oyster Creek Nuclear Generation Station (OCNGS)

DOCKET NO.: $50-219$

LICENSE NO.: DPR-16

BWRVIP CATEGORY GROUPING: Category " ${ }^{n}$

SHROUD FABRICATION DATA:

SHROUD MANUFACTURER: P.F. Avery

SHROUD SHELL CONSTRUCTION MATERIAL: A 240 Type 304 SS rolled plates

CARBON CONTENT RANGE SHELL SECTIONS: $0.042 \%$ C $-0.062 \%$ c

SHROUD RING CONSTRUCTION MATERIAL: A 240 Type 304 SS rolled plates

CARBON CONTENT RANGE SHROUD RINGS: $0.056 \% \mathrm{C}-0.064 \% \mathrm{C}$

\section{WELDING DATA:}

INITIAL PASS TECHNIQUE: Information not provided in response to GL 94-03

INITIAL PASS WELD MATERIAL: Information not provided in response to GL 94-03

SUBSEQUENT PASS TECHNIQUE: Information not provided in response to GL 94-03

SUBSEQUENT PASS WELD MATERIAL: Information not provided in response to GL 94-03

OPERATIONAL DATA:

AVERAGE CONDUCTIVITY VALUE OVER

THE FIRST FIVE YEARS OF OPERATION: $0.526 \mu \mathrm{S} / \mathrm{cm}$

ELAPSED TIME AT POWER OPERATION: > 15.5 EFPY by F1994

\section{GENERIC LETTER INFORMATION:}

DATE GL 94-03 RESPONSE: August 24, 1994

BASIS FOR ACCEPTING JCO: Generic Safety Assessment and Short time to F1994 RFO

DATE OF CORE SHROUD INSPECTION/REPAIR: Inspection, Repair during F1994 RFO

NRC SERs: (1) SER regarding the OCNGS core shroud repair, November 25, 1994

(2) SER regarding the response to GL 94-03 for OCNGS, February 23, 1995

REMARKS: GPU performed comprehensive UT ( $w /$ some VT-1) inspections of the OCNGS core shroud during the F1994 RFO. Inspection coverages ranged from $12 \%-27 \%$ for welds $\mathrm{H} 1-\mathrm{H} 3$, and $31 \%-49 \%$ for welds H4-H6B. Welds $\mathrm{H} 7$ and $\mathrm{H} 8$ were not included in the inspections due to the presence of additional structural brackets in the shroud design. Inspections of the $\mathrm{H} 4$ revealed the presence of substantial cracking (taken to be $360^{\circ}$ ) in the welds HAZ. OCNGS opted to perform a corrective repair of the OCNGS core shroud prior to restart of the OCNGS unit. The repair involved the installation of a number of MPR-designed tie rod assemblies around the outer circumference of the shroud. GPU's core shroud modification design for the OCNGS was approved by the staff prior to restart of the unit. 


\section{HATCH UNIT 1 DATA SHEET}

LICENSEE: Georgia Power Company (GPC)

PLANT NAME: Edwin I. Hatch Nuclear Plant, Unit 1 (HAT-1)

DOCKET NO.: $50-321$

LICENSE NO.: DPR-57

BWRVIP CATEGORY GROUPING: Category "C"

\section{SHROUD FABRICATION DATA:}

SHROUD MANUFACTURER: Sun Ship Building and Dry Dock Co.

SHROUD SHELL CONSTRUCTION MATERIAL: A/SA 240 Type 304 SS rolled plate

CARBON CONTENT RANGE SHELL SECTIONS: Information not provided in the response to GL 94-03

SHROUD RING CONSTRUCTION MATERIAL:A/SA 240 Type 304 SS rolled plate

CARBON CONTENT RANGE SHROUD RINGS: Information not provided in the response to GL 94-03

\section{WELDING DATA:}

INITIAL PASS TECHNIQUE: Information not provided in the response to GL 94-03

INITIAL PASS WELD MATERIAL: Information not provided in the response to GL 94-03

SUBSEQUENT PASS TECHNIQUE: Information not provided in the response to GL 94-03

SUBSEQUENT PASS WELD MATERIAL: Information not provided in the response to GL 94-03

OPERATIONAL DATA:

AVERAGE CONDUCTIVITY VALUE OVER

THE FIRST FIVE YEARS OF OPERATION: $0.411 \mu \mathrm{S} / \mathrm{cm}$

ELAPSED TIME AT POWER OPERATION: $>12.8$ EFPY by F1994

\section{GENERIC LETTER INFORMATION:}

DATE GL 94-03 RESPONSE: August 24, 1994

BASIS FOR ACCEPTING JCO: Generic Safety and Assessment and Short time duration until the F1994 RFO

DATE OF CORE SHROUD INSPECTION/REPAIR: Repair, September/October 1994

NRC SERs: (1) SER regarding the HAT-1 core shroud repair, September 30, 1994

(2) SER regarding GPC's response to GL 94-03 for HAT-1/HAT-2, February 23, 1995

REMARKS: GPC opted to perform pre-emptive repair of the HAT-1 core shroud during the September 1994 RFO in lieu of comprehensive core shroud examinations. HAT-1 shroud modification design submitted to the staff on September 2, 1994. The design involves installation of GE designed tie rod assemblies around the OD of the shroud. Tie rod assemblies are designed to provide an alternate load bearing capability for the shroud during normal operating, transient and postulated design basis accident conditions, given the occurrence of a $360^{\circ}$ throughwall failure of a circumferential weld. Design approved by the NRC prior to restart of the HAT-1 unit. 


\section{HATCH UNIT 2 DATA SHEET}

LICENSEE: Georgia Power Company (GPC)

PLANT NAME: Edwin I. Hatch Nuclear Plant, Unit 2 (HAT-2)

DOCKET NO.: $50-366$

LICENSE NO.: NPF-5

BWRVIP CATEGORY GROUPING: Category "C"

\section{SHROUD FABRICATION DATA:}

SHROUD MANUFACTURER: Sun Ship Building and Dry Dock Co.

SHROUD SHELL CONSTRUCTION MATERIAL: A/SA 240 Type 304 SS rolled plate

CARBON CONTENT RANGE SHELL SECTIONS: Information not provided in the response to GL 94-03

SHROUD RING CONSTRUCTION MATERIAL:A/SA 240 Type 304 SS rolled plate

CARBON CONTENT RANGE SHROUD RINGS: Information not provided in the response to GL 94-03

\section{WELDING DATA:}

INITIAL PASS TECHNIQUE: Information not provided in the response to GL 94-03

INITIAL PASS WELD MATERIAL: Information not provided in the response to GL 94-03

SUBSEQUENT PASS TECHNIQUE: Information not provided in the response to GL 94-03

SUBSEQUENT PASS WELD MATERIAL:_Information not provide in the response to GL 94-03

\section{OPERATIONAL DATA:}

AVERAGE CONDUCTIVITY VALUE OVER

THE FIRST FIVE YEARS OF OPERATION: $0.459 \mu \mathrm{S} / \mathrm{cm}$

ELAPSED TIME AT POWER OPERATION: $\geq 10.0$ EFPY bY F1994

\section{GENERIC LETTER INFORMATION:}

DATE GL 94-03 RESPONSE: August 24, 1994

BASIS FOR ACCEPTING JCO: Inspection results and flaw evaluations of the HAT-2 shroud during SP1994 RFO DATE OF CORE SHROUD INSPECTION/REPAIR: Inspection SP1994; repair scheduled for F1995

NRC SERs: (1) SER regarding GPC's response to GL 94-03, February 23, 1995

(2) SER regarding the HAT-2 core shroud repair, September 25,1995

REMARKS: GPC performed UT inspections of the H1-H4 circumferential welds during the HAT-2 SP1994 RFO: GPC also performed partial VT-1 examinations of welds H5-H8. UT examinations of accessible portions of the H2 weld indicated the presence of cracking totaling $5.54 \mathrm{~m}(218 \mathrm{in})$ in length, with the longest indication being $\approx 159$ inches in length. UT inspections of the HAT-2 shroud also revealed a minor amount of cracking at welds $\mathrm{H} 1, \mathrm{H} 3$, and $\mathrm{H} 4$ welds. Partial VT-1 examinations of the lower shroud welds were negative for flaw indications. The results of flaw evaluations of the HAT-2 shroud justified operation of the unit to the F1995 RFO. Repair design will involve the installation of a number of GE-design tie rod assemblies around the outer circumference of the shroud. Repair design approved by the NRC in September 1995. 


\section{DUANE ARNOLD ELECTRIC CENTER DATA SHEET}

LICENSEE: IES Utilities, Inc. (IES)

PLANT NAME:_Duane Arnold Energy Center (DAEC)

DOCKET NO.: $50-331$

LICENSE NO.: DPR-49

BWRVIP CATEGORY GROUPING: Category " $C$ "

SHROUD FABRICATION DATA:

SHROUD MANUFACTURER: Bingham Williamette

SHROUD SHELL CONSTRUCTION MATERIAL: Type 304L stainless steel

CARBON CONTENT RANGE SHELL SECTIONS: Information not provided in the response to GL 94-03

SHROUD RING CONSTRUCTION MATERIAL: Type 304L stainless steel

CARBON CONTENT RANGE SHROUD RINGS: Information not provided in the response to GL 94-03

\section{WELDING DATA:}

INITIAL PASS TECHNIQUE: Information not provided in the response to GL 94-03

INITIAL PASS WELD MATERIAL:_Information not provided in the response to GL 94-03

SUBSEQUENT PASS TECHNIQUE: Information not provided in the response to GL 94-03

SUBSEQUENT PASS WELD MATERIAL: Information not provided the in response to GL 94-03

OPERATIONAL DATA:

AVERAGE CONDUCTIVITY VALUE OVER

THE FIRST FIVE YEARS OF OPERATION: near mid range conductivity for the industry $(\approx 0.3 \mu \mathrm{S} / \mathrm{cm})$

ELAPSED TIME AT POWER OPERATION: $>13.5$ EFPY by F1994

\section{GENERIC LETTER INFORMATION:}

DATE GL 94-03 RESPONSE: August 24, 1994

BASIS FOR ACCEPTING ICO: Generic safety assessment

DATE OF CORE SHROUD INSPECTION/REPAIR: Comprehensive UT examinations during W/SP1995 RFO

NRC SERs:_SER regarding response to GL 94-03, March 1, 1995

REMARKS: Comprehensive UT examinations of DAEC core shroud during W/SP1995 RFO. Examinations covered accessible portions of $\mathrm{H1}-\mathrm{H} 7$ from the OD. IES performed the UT examinations using the GE OD Tracker, with $45^{\circ}$ shear wave, $60^{\circ}$ longitudinal wave and creep UT techniques. Weld coverage ranged from $52.4 \%$ at weld $\mathrm{H} 2$ to $78.8 \%$ at weld $\mathrm{H} 4$. No flaw indications evident as a result of the examinations performed during the W1995 RFO. 


\section{NINE MILE POINT UNIT 1 DATA SHEET}

LICENSEE: Niagara Mohawk Power Corporation (NMPC)

PLANT NAME: Nine Mile Point Station, Unit 1 (NMP-1)

DOCKET NO.: $50-220$

LICENSE NO.: DPR-63

BWRVIP CATEGORY GROUPING: Category " $\mathrm{C}^{n}$

SHROUD FABRICATION DATA:

SHROUD MANUFACTURER: P.F. Avery

SHROUD SHELL CONSTRUCTION MATERIAL: A 240 Type 304 SS plate

CARBON CONTENT RANGE SHELL SECTIONS: $0.042 \% \mathrm{C}-0.062 \% \mathrm{C}$

SHROUD RING CONSTRUCTION MATERIAL:A 240 Type 304 SS plate (shroud support ring: SA 336 type F8

CARBON CONTENT RANGE SHROUD RINGS: $0.056 \% \mathrm{C}-0.064 \% \mathrm{C}$

\section{WELDING DATA:}

INITIAL PASS TECHNIQUE: SAW

INITIAL PASS WELD MATERIAL: A-371 Type ER308 Filler (5\% minimum ferrite content)

SUBSEQUENT PASS TECHNIQUE: SAW

SUBSEQUENT PASS WELD MATERIAL: A-371 Type ER308 Filler (5\% minimum ferrite content)

OPERATIONAL DATA:

AVERAGE CONDUCTIVITY VALUE OVER

THE FIRST FIVE YEARS OF OPERATION: $0.457 \mu \mathrm{S} / \mathrm{cm}$

ELAPSED TIME AT POWER OPERATION: > 14.4 EFPY bY F1994

GENERIC LETTER INFORMATION:

DATE GL 94-03 RESPONSE: August 23, 1994

BASIS FOR ACCEPTING JCO: Generic Safety Assessment

DATE OF CORE SHROUD INSPECTION/REPAIR: Repair of NMP-1 SP1995 RFO

NRC SERs: (1) SER regarding the response to GL 94-03 for NMP-1, January 13, 1995

(2) SER regarding the NMP-1 core shroud repair, March 31, 1995

REMARKS: NMPC performed a pre-emptive repair (modification) of the NMP-1 core shroud in SP1995 RFO. This modification was implemented in lieu of performing in depth core shroud examinations. NMPC submitted the modification design on Jan. 6, 1995. The modification design involves the use of tie rod assemblies designed by the GE Company. The tie rod assemblies are designed to provide an alternate load path for the core shroud, and are designed to assume the worst case loading conditions during normal operating, transient, and postulated design basis accident conditions, given the occurrence of a $360^{\circ}$ through-wall failure of a circumerential weld. The NRC approved the modification for implementation on March 31, 1995. 


\section{COOPER NUCLEAR STATION DATA SHEET}

LICENSEE: Nebraska Public Power District (NPPD)

PLANT NAME: Cooper Nuclear Station (CNS)

DOCKET NO.: $50-298$

LICENSE NO.: DPR-46

BWRVIP CATEGORY GROUPING:_Category "C"

SHROUD FABRICATION DATA:

SHROUD MANUFACTURER: Bingham Williamette

SHROUD SHELL CONSTRUCTION MATERIAL: A 240 Type 304 SS hot rolled, annealed plate

CARBON CONTENT RANGE SHELL SECTIONS: $0.043 \% \mathrm{C}-\mathbf{0 . 0 6 8 \% \mathrm { C }}$

SHROUD RING CONSTRUCTION MATERIAL:A 240 Type 304 SS hot rolled annealed plate

CARBON CONTENT RANGE SHROUD RINGS: $0.052 \% \mathrm{C}-0.058 \% \mathrm{C}$

\section{WELDING DATA:}

INITIAL PASS TECHNIQUE:_SAW

INITIAL PASS WELD MATERIAL: ER308 Filler

SUBSEQUENT PASS TECHNIQUE: SAW

SUBSEQUENT PASS WELD MATERIAL:ER308 Filler

OPERATIONAL DATA:

AVERAGE CONDUCTIVITY VALUE OVER

THE FIRST FIVE YEARS OF OPERATION: $0.188 \mu \mathrm{S} / \mathrm{cm}$

ELAPSED TIME AT POWER OPERATION: > 14.6 EFPY by F1994

\section{GENERIC LETTER INFORMATION:}

DATE GL 94-03 RESPONSE: August 26, 1994

BASIS FOR ACCEPTING JCO: Generic Safety Assessment; coupled with history of clean reactor coolant

DATE OF CORE SHROUD INSPECTION/REPAIR: Comprehensive UT Inspection scheduled for October 1995 NRC SERs:_(1) SER regarding response to GL 94-03, April 12, 1995

(2) Acknowledgement letter of core shroud inspection scope, September 20, 1995

REMARKS: Last licensee with a Category " $C$ " plant to inspect its core shroud. This inspection will complete the initial set of inspections/repairs Category " $\mathrm{C}$ " shrouds. The proposed inspection scope for CNS shroud is consistent with the content of other Category " $\mathrm{C}$ " inspection scopes that have been submitted to the NRC. Inspection scope approved by NRR. 


\section{MILLSTONE UNIT 1 DATA SHEET}

LICENSEE: Northeast Nuclear Energy Company (NNECO)

PLANT NAME: Millstone Unit 1 (MS-1)

DOCKET NO.: $50-245$

LICENSE NO.: DPR-21

BWRVIP CATEGORY GROUPING: Category "C"

\section{SHROUD FABRICATION DATA:}

SHROUD MANUFACTURER: P.F. Avery

SHROUD SHELL CONSTRUCTION MATERIAL: Type 304 SS plate

CARBON CONTENT RANGE SHELL SECTIONS: Information not provided in the response to GL 94-03

SHROUD RING CONSTRUCTION MATERIAL: Type 304 SS plate

CARBON CONTENT RANGE SHROUD RINGS: Information not provided in the response to GL 94-03

WELDING DATA:

INITIAL PASS TECHNIQUE: Information not provided in the response to GL 94-03

INITIAL PASS WELD MATERIAL: Information not provided in the response to GL 94-03

SUBSEQUENT PASS TECHNIQUE: Information not provided in the response to GL 94-03

SUBSEQUENT PASS WELD MATERIAL: Information not provided in the response to GL 94-03

OPERATIONAL DATA:

AVERAGE CONDUCTIVITY VALUE OVER

THE FIRST FIVE YEARS OF OPERATION: $<<0.160 \mu \mathrm{S} / \mathrm{cm}$

ELAPSED TIME AT POWER OPERATION: $>10.0$ EFPY by F1994

\section{GENERIC LETTER INFORMATION:}

DATE GL 94-03 RESPONSE: August 24, 1994

BASIS FOR ACCEPTING JCO: Results of VT-1 examinations performed during W1994 RFO (Cycle 14 RFO)

DATE OF CORE SHROUD INSPECTION/REPAIR: In depth UT scheduled for Cycle 15 RFO (F1995)

NRC SERs: (1) SER regarding response to GL 94-03, January 4, 1995

(2) Acknowledgement letter regarding MS1 core shroud inspection scope, August 7, 1995

REMARKS: NNECO performed enhanced VT-1 examinations of the MS1 core shroud during the Cycle 14 RFO (W1994-95). The scope of the VT-1 examinations covered welds $\mathrm{H} 1-\mathrm{H} 4$ and $\mathrm{H} 6 \mathrm{~A}-\mathrm{H} 7$ from the OD and H3, H4, and H5 from the ID. Results of the VT-1 examinations indicated the presence of only minor cracking in the MS1 core shroud. Only 6 indications were identified with the longest being $0.292 \mathrm{~m}(11.5 \mathrm{in})$. All indications were found acceptable per NNECO NCR 194-097. Furthermore, all indications were less than the initial screening criteria approved for evaluations of the BR-1 core shroud. Results of the MS1 flaw evaluation justify operation of MS1 to the Cycle 15 RFO. 


\section{MONTICELLO NUCLEAR GENERATION PLANT DATA SHEET}

LICENSEE: Northern States Power Company (NSP)

PLANT NAME: Monticello Nuclear Generation Plant (MNGP)

DOCKET NO.: $50-263$

LICENSE NO.: DPR-22

BWRVIP CATEGORY GROUPING: Category "C"

SHROUD FABRICATION DATA:

SHROUD MANUFACTURER: Rotterdam Dry Dock

SHROUD SHELL CONSTRUCTION MATERIAL: A 240 TP304 SS plate

CARBON CONTENT RANGE SHELL SECTIONS: $0.043 \% \mathrm{C}-0.050 \% \mathrm{C}$

SHROUD RING CONSTRUCTION MATERIAL: A 182 F304 SS forgings

CARBON CONTENT RANGE SHROUD RINGS: $0.031 \% \mathrm{C}-0.056 \% \mathrm{C}$

WELDING DATA:

INITIAL PASS TECHNIQUE: manual GTAW, manual SMAW, or automatic SAW

INITIAL PASS WELD MATERIAL: E308 or ER 308

SUBSEQUENT PASS TECHNIQUE: manual GTAW, manual SMAW, or automatic SAW

SUBSEQUENT PASS WELD MATERIAL: E308 or ER308

OPERATIONAL DATA:

AVERAGE CONDUCTIVITY VALUE OVER

THE FIRST FIVE YEARS OF OPERATION: $0.299 \mu \mathrm{S} / \mathrm{cm}$ (chlorides $10.6 \mathrm{ppb}$ )

ELAPSED TIME AT POWER OPERATION: $>17.8$ EFPY bY F1994

\section{GENERIC LETTER INFORMATION:}

DATE GL 94-03 RESPONSE: August 23, 1994

BASIS FOR ACCEPTING JCO: Generic Safety Assessment, extremely short time to F1994 RFO (Sept. 1994)

DATE OF CORE SHROUD INSPECTION/REPAIR: In depth UT examinations during F1994 RFO (Sept. 1994)

NRC SERs:_(1) SER regarding response to GL 94-03 and NSP's core shroud inspection results and

flaw evaluations, January 20, 1995

REMARKS: In depth UT/VT-1 examinations of the MNGP core shroud during the F1994 RFO (Sept. 15, 1994). UT inspections performed with GE OD-Tracker, using $45^{\circ} \mathrm{S}$ and $60^{\circ} \mathrm{L}$ transducers. Creeping wave used for near side surface examinations. Inspection scope covered UT examinations of accessible portions of the $\mathrm{H1}-\mathrm{H} 5$ welds from the OD (coverage ranged from $32 \%-54 \%$ ), and enhanced VT-1 examinations of the H4, H5, H6, H8, and H9 welds to supplement the UT examinations $(\approx 8-15 \%$ coverage). Welds $\mathrm{H} 6-\mathrm{H} 9$ were inaccessible to the tracker (Weld $\mathrm{H7}$ was notable to the obstruction from a backing ring). All indications less than $0.25 \mathrm{~m}(10 \mathrm{in})$ in length. All indications less than initial screening criteria limit approved for evaluation of the BR-1 shroud. Operation justified. 


\section{PEACH BOTTOM UNIT 2 DATA SHEET}

LICENSEE:_Philadelphia Electric Company (PECo)

PLANT NAME: Peach Bottom Atomic Power Station, Unit 2 (PB-2)

DOCKET NO.: $50-277$

LICENSE NO.: DPR-44

BWRVIP CATEGORY GROUPING: Category "C"

\section{SHROUD FABRICATION DATA:}

SHROUD MANUFACTURER: Rotterdam Dry Dock

SHROUD SHELL CONSTRUCTION MATERIAL: A 240 Type 304 SS plate

CARBON CONTENT RANGE SHELL SECTIONS: $0.056 \% \mathrm{C}-0.062 \% \mathrm{C}$

SHROUD RING CONSTRUCTION MATERIAL:A 182 F304 SS forgings

CARBON CONTENT RANGE SHROUD RINGS: $0.028 \% \mathrm{C}-0.035 \% \mathrm{C}$

\section{WELDING DATA:}

INITIAL PASS TECHNIQUE: H7 by GMAW; other welds by SAW

INITIAL PASS WELD MATERIAL: H7 using Alloy 82; other welds using ASTM A371 ER308

SUBSEQUENT PASS TECHNIQUE: $\mathrm{H} 7$ by GMAW: other welds by SAW

SUBSEQUENT PASS WELD MATERIAL: H7 using Alloy 82; other welds using ASTM A317 ER308

OPERATIONAL DATA:

AVERAGE CONDUCTIVITY VALUE OVER

THE FIRST FIVE YEARS OF OPERATION: $0.593 \mu \mathrm{S} / \mathrm{cm}$

ELAPSED TIME AT POWER OPERATION: >11.8 EFPY by F1994

\section{GENERIC LETTER INFORMATION:}

DATE GL 94-03 RESPONSE: August 24, 1994

BASIS FOR ACCEPTING JCO: Any cracking at PB-2 would be bounded by evaluations of cracking at PB-3 DATE OF CORE SHROUD INSPECTION/REPAIR:_RFO 2R010, Sept./Oct. 1994

NRC SERs: (1) SER regarding the PECo response to GL 94-03 for the Peach Bottom Units, February 6, 1995

REMARKS: PECo's performed UT inspections of the PB-2 core shroud during RFO 2R010. UT examinations were performed using the GE OD Tracker $\left(45^{\circ} \mathrm{S}, 60^{\circ} \mathrm{L}\right.$ and creeping wave transducers). UT examinations covered $30 \%$ of weld $\mathrm{H} 1,83 \%-89 \%$ of welds $\mathrm{H2}-\mathrm{H} 5$, and $9-10 \%$ of welds $\mathrm{H} 6$ and $\mathrm{H} 7$. An additional $13 \%$ of weld $\mathrm{H} 6$ was inspected by enhanced VT-1 methods. UT examinations revealed some indications at welds $\mathrm{H} 1, \mathrm{H} 3$, and $\mathrm{H} 4$, totaling $0.861 \mathrm{~m}(33.9 \mathrm{in}), 1.74 \mathrm{~m}(68.5 \mathrm{in})$, and $0.292 \mathrm{~m}(11.5 \mathrm{in})$ in length, respectively. Extremely minor cracking was also detected at welds $\mathrm{H} 5$ and $\mathrm{H} 6$ (one indication at each weld, both less than $0.13 \mathrm{~m}[5 \mathrm{in}]$ in length). Flaw evaluations indicate that safety margins requirements for the PB-2 shroud would be satisfied for the next cycle. 


\section{PEACH BOTTOM UNIT 3 DATA SHEET}

LICENSEE: Philadelphia Electric Company (PECo)

PLANT NAME: Peach Bottom Atomic Power Station, Unit 3 (PB-3)

DOCKET NO.: 50-278

LICENSE NO.: DPR-56

BWRVIP CATEGORY GROUPING:_Category "C"

SHROUD FABRICATION DATA:

SHROUD MANUFACTURER: Rotterdam Dry Dock

SHROUD SHELL CONSTRUCTION MATERIAL: A 240 Type 304 SS plate

CARBON CONTENT RANGE SHELL SECTIONS: $0.050 \% \mathrm{C}-0.065 \% \mathrm{C}$

SHROUD RING CONSTRUCTION MATERIAL: A 182 F304 SS forgings

CARBON CONTENT RANGE SHROUD RINGS: $0.030 \% \mathrm{C}-0.035 \% \mathrm{C}$

\section{WELDING DATA:}

INITIAL PASS TECHNIQUE: H7 by GMAW; other welds by SAW

INITIAL PASS WELD MATER1AL: H7 using Alloy 82; other welds using ASTM A371 ER 308

SUBSEQUENT PASS TECHNIQUE: $\mathrm{H} 7$ by GMAW; other welds by SAW

SUBSEQUENT PASS WELD MATERIAL: H7 using Alloy 82; other welds using ASTM A317 ER308

\section{OPERATIONAL DATA:}

AVERAGE CONDUCTIVITY VALUE OVER

THE FIRST FIVE YEARS OF OPERATION: $0.695 \mu \mathrm{S} / \mathrm{cm}$

ELAPSED TIME AT POWER OPERATION: $>11.0$ EFPY as of F1994

GENERIC LETTER INFORMATION:

DATE GL 94-03 RESPONSE: August 24, 1994

BASIS FOR ACCEPTING JCO:_VT-1 examinations and evaluations of the PB-3 shroud justify operation of PB3. DATE OF CORE SHROUD INSPECTION/REPAIR:_Enhanced VT-1 examinations during RFO 3R9, Oct. 1993 NRC SERs: (1) SER regarding PECo response to GL 94-03 for the Peach Bottom Units, February 6, 1995

REMARKS: Enhanced VT-1 examinations performed during RFO 3R9. Inspection scope covered 100\% of the accessible areas of the $\mathrm{H} 3$ and $\mathrm{H} 4$ welds from the ID and $100 \%$ of the accessible area of the H4 weld from the OD. Partial VT-1 examinations were performed on the H6, H7, and $\mathrm{H} 8$ welds. In addition, one vertical weld located between the $\mathrm{H} 3$ and $\mathrm{H} 4$ welds was examined. The VT- 1 examinations identified some cracking at weld $\mathrm{H} 3$, totaling $2.67 \mathrm{~m}$ (105 in) in length. Less extensive cracking identified at weld $\mathrm{H} 4(<0.76 \mathrm{~m}[30 \mathrm{in}]$ in length), and minor cracking identified at weld $\mathrm{H} 1$ and the vertical weld. The results of PECo's flaw evaluation of the PB-3 core shroud justify operation of the PB-3 unit for the cycle leading to RFO 3R10 (F1995). 


\section{FITZPATRICK DATA SHEET}

LICENSEE: Power Authority of the State of New York (NYPA)

PLANT NAME: James A. FitzPatrick Nuclear Power Plant (FITZ)

DOCKET NO.: $50-333$

LICENSE NO.: DPR-59

BWRVIP CATEGORY GROUPING: Category " $\mathrm{C}$ "

SHROUD FABRICATION DATA:

SHROUD MANUFACTURER: Sun Ship Building and Dry Dock Co.

SHROUD SHELL CONSTRUCTION MATERIAL: A240 Type 304 SS plates

CARBON CONTENT RANGE SHELL SECTIONS: $0.036 \%$ C $-0.069 \%$ C

SHROUD RING CONSTRUCTION MATERIAL: A240 Type 304 SS plates

CARBON CONTENT RANGE SHROUD RINGS: $0.056 \% \mathrm{C}-0.078 \% \mathrm{C}$

\section{WELDING DATA:}

INITIAL PASS TECHNIQUE: Fabrication should be similar to that of the Brunswick Units.

INITIAL PASS WELD MATERIAL: E308 weld wire

SUBSEQUENT PASS TECHNIQUE: Fabrication should be similar to that of the Brunswick Units.

SUBSEQUENT PASS WELD MATERIAL: E308 weld wire

OPERATIONAL DATA:

AVERAGE CONDUCTIVITY VALUE OVER

THE FIRST FIVE YEARS OF OPERATION: $0.631 \mu \mathrm{S} / \mathrm{cm}$ NYPA calculation $(0.718 \mu \mathrm{S} / \mathrm{cm}$ by BWRVIP)

ELAPSED TIME AT POWER OPERATION: $>12.8$ EFPY by F1994

\section{GENERIC LETTER INFORMATION:}

DATE GL 94-03 RESPONSE: August 24, 1994

BASIS FOR ACCEPTING JCO: Short duration until W1994-95 RFO; bounded by evaluations of BR-1

DATE OF CORE SHROUD INSPECTION/REPAIR: Repair (modification) W1994-95 RFO

NRC SERs:_(1) SER regarding FITZ core shroud repair, January 5, 1995

(2) SER regarding NYPA's response to GL 94-03, February 5, 1995

REMARKS: NYPA opted to perform a modification of the FITZ core shroud in lieu of performing comprehensive core shroud examinations. The FITZ core shroud modification design involves installation of a series of MPRdesign tie rod assemblies around the circumference of the shroud. The tie rod assemblies are designed to assume the loading of the shroud in the event of a $360^{\circ}$ through-wall failure of the shroud during normal operating, transient and postulated design basis accident conditions. The NRC approved NYPA's proposed shroud modification design on January $5,1995$. 


\section{BROWNS FERRY UNIT 1 DATA SHEET}

LICENSEE: Tennessee Valley Authority (TVA)

PLANT NAME: Browns Ferry Nuclear Plant, Unit 1 (BF-1)

DOCKET NO.: $50-259$

LICENSE NO.:_DPR-33

BWRVIP CATEGORY GROUPING: Category "C"

SHROUD FABRICATION DATA:

SHROUD MANUFACTURER: Rotterdam Dry Dock

SHROUD SHELL CONSTRUCTION MATERIAL: A240 Type 304 SS plates (Inconel 600 below H7)

CARBON CONTENT RANGE SHELL SECTIONS: $0.030 \% \mathrm{C}-0.060 \% \mathrm{C}$

SHROUD RING CONSTRUCTION MATERIAL: A182 F304 forgings

CARBON CONTENT RANGE SHROUD RINGS: $0.030 \% \mathrm{C}-0.060 \% \mathrm{C}$

WELDING DATA:

INITIAL PASS TECHNIQUE: Techniques not provided in the response to GL 94-03

INITIAL PASS WELD MATERIAL: E308 or ER308 (INCO182 for H7)

SUBSEQUENT PASS TECHNIQUE: Techniques not provided in the response to GL 94-03

SUBSEQUENT PASS WELD MATERIAL: E308 or ER308 (INCO182 for H7)

OPERATIONAL DATA:

AVERAGE CONDUCTIVITY VALUE OVER

THE FIRST FIVE YEARS OF OPERATION: $0.364 \mu \mathrm{S} / \mathrm{cm}$

ELAPSED TIME AT POWER OPERATION: $\approx 6.5$ EFPY

\section{GENERIC LETTER INFORMATION:}

DATE GL 94-03 RESPONSE: August 23, 1994

BASIS FOR ACCEPTING JCO: Reactor is currently in indefinite shutdown and defueled condition

DATE OF CORE SHROUD INSPECTION/REPAIR: Deferred

NRC SERs:_(1) SER regarding response to GL 94-03, January 13, 1995

REMARKS: BF-1 is currently in an indefinite shutdown, defueled condition. TVA has indicated that it would perform inspections of the BF-1 core shroud prior to any reloading and restart of the BF-1 reactor. No inspections of the $\mathrm{BF}-1$ reactor are needed at this time. 


\section{BROWNS FERRY UNIT 2 DATA SHEET}

LICENSEE: Tennessee Valley Authority (TVA)

PLANT NAME: Browns Ferry Nuclear Plant, Unit 2 (BF-2)

DOCKET NO.: $50-260$

LICENSE NO.: DPR-52

BWRVIP CATEGORY GROUPING: Category " $\mathrm{C}$ "

SHROUD FABRICATION DATA:

SHROUD MANUFACTURER:_Rotterdam Dry Dock

SHROUD SHELL CONSTRUCTION MATERIAL: A240 Type 304 SS plates (Inconel 600 below H7)

CARBON CONTENT RANGE SHELL SECTIONS: $0.030 \% \mathrm{C}-0.060 \% \mathrm{C}$

SHROUD RING CONSTRUCTION MATERIAL: A182 F304 forgings

CARBON CONTENT RANGE SHROUD RINGS: $0.030 \% \mathrm{C}-0.060 \% \mathrm{C}$

WELDING DATA:

INITIAL PASS TECHNIQUE: Technique not provided in the response to GL 94-03

INITIAL PASS WELD MATERIAL: E308 or ER308 (INCO182 for H7)

SUBSEQUENT PASS TECHNIQUE: Technique not provided in the response to GL 94-03

SUBSEQUENT PASS WELD MATERIAL: E308 or ER308 (INCO182 for H7)

OPERATIONAL DATA:

AVERAGE CONDUCTIVITY VALUE OVER

THE FIRST FIVE YEARS OF OPERATION: $0.384 \mu \mathrm{S} / \mathrm{cm}$

ELAPSED TIME AT POWER OPERATION: $>9.0$ EFPY by F1994

\section{GENERIC LETTER INFORMATION:}

DATE GL 94-03 RESPONSE: August 23, 1994

BASIS FOR ACCEPTING JCO: Improved material of construction and short time to F1994 RFO

DATE OF CORE SHROUD INSPECTION/REPAIR: Inspected September/October 1994

NRC SERs:_(1) SER regarding response to GL 94-03, January 13, 1995

REMARKS:-TVA performed UT inspections of the BF-2 core shroud during the September/October 1994 RFO. The UT inspections were performed using the GE OD Tracker System. The UT examinations included $45^{\circ} \mathrm{S}, 60^{\circ} \mathrm{L}$, and creeping wave techniques. Inspections covered approximately $33 \%$ of weld $\mathrm{H} 1,61-63 \%$ of welds $\mathrm{H} 2-\mathrm{H} 5$ and 2-3\% welds $\mathrm{H} 6$ and $\mathrm{H} 7$. The majority of the $\mathrm{H} 6$ and $\mathrm{H} 7$ welds were inaccessible to the tracker. The inspections of the BF-2 shroud revealed minor cracking of the shroud at welds $\mathrm{H} 2, \mathrm{H} 3$, and $\mathrm{H} 5$. Total lengths of indications at the $\mathrm{H} 2, \mathrm{H} 3$, and $\mathrm{H} 5$ welds were all less than $0.25 \mathrm{~m}(10.0 \mathrm{in})$. The results of TVA's flaw evaluation of the BF-2 shroud justifies operation of the BF-2 unit for the current cycle. 


\section{BROWNS FERRY UNIT 3 DATA SHEET}

LICENSEE: Tennessee Valley Authority (TVA)

PLANT NAME: Browns Ferry Nuclear Plant, Unit 3 (BF-3)

DOCKET NO.: $50-296$

LICENSE NO.: DPR-68

BWRVIP CATEGORY GROUPING:_Category "C"

SHROUD FABRICATION DATA:

SHROUD MANUFACTURER: Rotterdam Dry Dock

SHROUD SHELL CONSTRUCTION MATERIAL: A240 Type 304 SS plates (Inconel 600 below H7)

CARBON CONTENT RANGE SHELL SECTIONS: $0.030 \% \mathrm{C}-0.060 \% \mathrm{C}$

SHROUD RING CONSTRUCTION MATERIAL: A182 F304 forgings

CARBON CONTENT RANGE SHROUD RINGS: $0.030 \% \mathrm{C}-0.060 \% \mathrm{C}$

\section{WELDING DATA:}

INITIAL PASS TECHNIQUE: Technique not provided in the response to GL 94-03

INITIAL PASS WELD MATERIAL: E308 or ER308 (INCO182 for H7)

SUBSEQUENT PASS TECHNIQUE: Technique not provided in the response to GL 94-03

SUBSEQUENT PASS WELD MATERIAL: E308 or ER308 (INCO182 for H7)

OPERATIONAL DATA:

AVERAGE CONDUCTIVITY VALUE OVER

THE FIRST FIVE YEARS OF OPERATION: $0.303 \mu \mathrm{S} / \mathrm{cm}$

ELAPSED TIME AT POWER OPERATION: $\approx 5.0$ EFPY

\section{GENERIC LETTER INFORMATION:}

DATE GL 94-03 RESPONSE: August 23, 1994

BASIS FOR ACCEPTING JCO: Reactor is currently in indefinite defueled condition

DATE OF CORE SHROUD INSPECTION/REPAIR: UT and VT-1 inspections during July 1994 RFO

NRC SERs: (1) SER regarding response to GL 94-03, January 13, 1995

REMARKS: TVA performed UT and VT-1 inspections of the BF-3 core shroud during the July 1994 RFO. The UT inspections were performed using the GE OD Tracker System. The UT examinations included $45^{\circ} \mathrm{S}, 60^{\circ} \mathrm{L}$, and creeping wave techniques. The inspections covered approximately $40-41 \%$ of welds $\mathrm{H} 1$ and $\mathrm{H} 5,68-83 \%$ of welds $\mathrm{H} 2-\mathrm{H} 4$, and $4 \%$ of welds $\mathrm{H} 6$ and $\mathrm{H} 7$. The majority of the $\mathrm{H} 6$ and $\mathrm{H} 7$ welds were inaccessible to the tracker. The inspections of the BF-3 shroud revealed some cracking at $H 5$, totaling $2.1 \mathrm{~m}(82 \mathrm{in})$ in length. Minor cracking of was detected at shroud welds $\mathrm{H} 1$ and $\mathrm{H} 4$ (less than $0.05 \mathrm{~m}[2$ in] in total length). The results of TVA's flaw evaluation of the BF-3 shroud satisfy ASME safety margins. 


\section{VERMONT YANKEE NUCLEAR POWER PLANT DATA SHEET}

LICENSEE: Vermont Yankee Nuclear Power Corporation (VYNPC)

PLANT NAME: Vermont Yankee Nuclear Power Station (VY)

DOCKET NO.: $50-271$

LICENSE NO.: DPR-28

BWRVIP CATEGORY GROUPING: Category "C"

SHROUD FABRICATION DATA:

SHROUD MANUFACTURER: Rotterdam Dry Dock

SHROUD SHELL CONSTRUCTION MATERIAL: ASTM A240 Type stainless steel plates

CARBON CONTENT RANGE SHELL SECTIONS: $\leq 0.070 \% \mathrm{C}$

SHROUD RING CONSTRUCTION MATERIAL: ASTM A182 Grade F304 stainless steel forgings

CARBON CONTENT RANGE SHROUD RINGS: $<0.060 \% \mathrm{C}$

\section{WELDING DATA:}

INITIAL PASS TECHNIQUE: Information not provided in the response to GL 94-03

INITIAL PASS WELD MATERIAL: Information not provided in the response to GL 94-03

SUBSEQUENT PASS TECHNIQUE: Information not provided in the response to GL 94-03

SUBSEQUENT PASS WELD MATERIAL: Information not provided in the response to GL 94-03

OPERATIONAL DATA:

AVERAGE CONDUCTIVITY VALUE OVER

THE FIRST FIVE YEARS OF OPERATION: $0.286 \mu \mathrm{S} / \mathrm{cm}$

ELAPSED TIME AT POWER OPERATION: > 16.9 EFPY by F1994

GENERIC LETTER INFORMATION:

DATE GL 94-03 RESPONSE: August 17, 1994

BASIS FOR ACCEPTING JCO: Generic Safety Assessment and results of RFO No. 17 VT-1 exams. (Oct. 93)

DATE OF CORE SHROUD INSPECTION/REPAIR: Comprehensive UT, April 1995 (RFO No.18)

NRC SERs: (1) SER regarding initial response to GL 94-03, January 5, 1995

(2) Acknowledgement letter of VY core shroud inspection scope, April 25, 1995

(3) SER regarding VY core shroud flaw evaluation, April 27, 1995

REMARKS: Comprehensive UT inspection of the VY shroud using new inspection technology by Babcock and Wilcox Nuclear Technology (BWNT). BWNT inspection technology approved for use by NRC. UT examinations included $45^{\circ} \mathrm{S}, 60^{\circ} \mathrm{L}$, and creeping wave UT techniques. Results of core shroud examinations indicate the presence of significant cracking at weld H5. Cracks at the H5 welds encompass approximately 11/12 of weld's circumference. Flaw evaluations of $\mathrm{H} 5$ weld indicate that the $\mathrm{H} 5$ weld will have sufficient remaining structural ligaments to justify operation for the next cycle. Evaluations of any cracking discovered at other circumferential welds bounded by evaluation of cracking at weld $\mathrm{H} 5$. 


\section{SUSQUEHANNA UNIT 1 DATA SHEET}

LICIENSEE:_Pennsylvania Power \& Light Company (PP\&L)

PLANT NAME: Susquehanna Steam Electric Station, Unit 1 (SSES-1)

DOCKET NO.: $50-387$

LICIENSE NO.: NPF-14

BWRVIP CATEGORY GROUPING: Category "B"

SHROUD FABRICATION DATA:

SHROUD MANUFACTURER: Chicago Bridge and Iron Works

SHROUD SHELL CONSTRUCTION MATERIAL:_SA 240 TP 304L hot rolled plate

CARBON CONTENT RANGE SHELL SECTIONS: $0.014 \% \mathrm{C}-0.027 \% \mathrm{C}$

SHROUD RING CONSTRUCTION MATERIAL:SA $240 \mathrm{TP}$ 304L hot rolled plate

CARBON CONTENT RANGE SHROUD RINGS: $0.025 \% \mathrm{C}-0.026 \% \mathrm{C}$

WELDING DATA:

INITIAL PASS TECHNIQUE: SMAW for $\mathrm{H} 1-\mathrm{H} 6$ and $\mathrm{H} 8-\mathrm{H} 9$ welds; GTAW for $\mathrm{H} 7$ weld

INITIAL PASS WELD MATERIAL: SFA 5.4 E308 for SMAW; SFA 5.14 ERNiCr-3 for GTAW

SUBSEQUENT PASS TECHNIQUE: SAW for $\mathrm{H} 1-\mathrm{H} 3$ and $\mathrm{H} 6 \mathrm{a}-\mathrm{H} 6 \mathrm{~b}$ welds, SMAW for $\mathrm{H} 4-\mathrm{H} 5, \mathrm{H} 7-\mathrm{H} 9$

SUBSEQUENT PASS WELD MATERIAL:SFA E308 most welds; SFA 5.9 ER308L for H1; ERNiCrFe-3 for H7

OPERATIONAL DATA:

AVERAGE CONDUCTIVITY VALUE OVER

THE FIRST FIVE YEARS OF OPERATION: $0.205 \mu \mathrm{S} / \mathrm{cm}$

ELAPSED TIME AT POWER OPERATION: $\sim 9$ EFPY at the time of RFO No. 8RIO

\section{GENERIC LETTER INFORMATION:}

DATE GL 94-03 RESPONSE: August 24, 1994

BASIS FOR ACCEPTING JCO:Category "B" criteria and results of limited VT-1s at RFO No. 7RIO (F1993)

DATE OF CORE SHROUD INSPECTION/REPAIR: Limited UT examinations during Spring 1995 RFO (8RIO)

NRC SERs: (1) SER regarding response to GL 94-03, March 23, 1995.

(2) Acknowledgement letter of SSES-1 inspection scope, April 10, 1995.

(3) SER regarding the SSES-1 core shroud inspection results and flaw evaluation, May 3, 1995.

REMARKS: Limited inspection of the SSES-1 core shroud during RFO No. 8RIO. Scope in accordance with the recommendations of the BWRVIP for Category "B" core shrouds. Inspections included UT of H3, H4, H5, H6a, $\mathrm{H} 6 \mathrm{~b}$, and $\mathrm{H} 7$ welds, and enhanced VT-1 of the $\mathrm{H} 8$ and $\mathrm{H} 9$ welds. Results of the UT inspections revealed a significant number of flaw indications at welds $\mathrm{H} 2, \mathrm{H} 4, \mathrm{H} 5$, and $\mathrm{H} 6 \mathrm{~b}$ welds totalling $13.8 \mathrm{~m}(54.4 \mathrm{in}), 4.76 \mathrm{~m}$ $(187.5 \mathrm{in}), 4.80 \mathrm{~m}(189.9 \mathrm{in})$, and $1.66 \mathrm{~m}(65.3 \mathrm{in})$ in length at each weld, respectively. Minor amount of cracking also detected welds H1 and H6A (less than $0.13 \mathrm{~m} / 5 \mathrm{in}]$ total at each weld). Results of inspections of other welds were negative for indications. Flaw evaluations support operation for the next operating cycle. 


\section{SUSQUEHANNA UNIT 2 DATA SHEET}

LICENSEE: Pennsylvania Power \& Light Company (PP\&L)

PLANT NAME: Susquehanna Steam Electric Station, Unit 2 (SSES-2)

DOCKET NO.: $50-388$

LICENSE NO.: NPF-22

BWRVIP CATEGORY GROUPING:_Category "B"

SHROUD FABRICATION DATA:

SHROUD MANUFACTURER: Chicago Bridge and Iron Works

SHROUD SHELL CONSTRUCTION MATERIAL: SA 240 TP 304L hot rolled plate

CARBON CONTENT RANGE SHELL SECTIONS: $0.014 \%$ C $-0.025 \%$ C

SHROUD RING CONSTRUCTION MATERIAL:SSA 240 TP 304L hot rolled plate

CARBON CONTENT RANGE SHROUD RINGS: $0.025 \% \mathrm{C}-0.027 \% \mathrm{C}$

WELDING DATA:

INITIAL PASS TECHNIQUE: SMAW for $\mathrm{H1} 1-\mathrm{H} 6$ and $\mathrm{H} 8-\mathrm{H} 9$ welds: GTAW for $\mathrm{H} 7$ weld

INITIAL PASS WELD MATERIAL: SFA 5.4 E308 for SMAW; SFA 5.14 ERNiCr-3 for GTAW

SUBSEQUENT PASS TECHNIQUE: SAW for $\mathrm{H} 1-\mathrm{H} 3$ and $\mathrm{H} 6 \mathrm{a}-\mathrm{H} 6 \mathrm{~b}$ welds, SMAW for $\mathrm{H} 4-\mathrm{H} 5, \mathrm{H} 7-\mathrm{H} 9$

SUBSEQUENT PASS WELD MATERIAL:SFA E308 most welds; SFA 5.9 ER308L for H1; ERNiCrFe-3 for $\mathrm{H} 7$

\section{OPERATIONAL DATA:}

AVERAGE CONDUCTIVITY VALUE OVER

THE FIRST FIVE YEARS OF OPERATION: $0.198 \mu \mathrm{S} / \mathrm{cm}$

ELAPSED TIME AT POWER OPERATION: 6.2 EFPY at RFO No. 6RIO; $~ 8.0$ EPFY at RFO No. 7RIO

\section{GENERIC LETTER INFORMATION:}

DATE GL 94-03 RESPONSE: August 24, 1994

BASIS FOR ACCEPTING JCO:Category "B" criteria

DATE OF CORE SHROUD INSPECTION/REPAIR:Scheduled for U2 RFO No. 7RIO

NRC SERs: (1) SER regarding PP\&L's response to GL 94-03 for SSES-1/SSES2, March 23, 1995.

REMARKS: No limited examinations performed during U2 RFO No. 6RIO since unit had not operated for more than 8 EPFY. Limited examinations scheduled for U2 RFO No. 7RIO in September/October 1995. 


\section{LASALLE UNIT 1 DATA SHEET}

LICENSEE: Commonwealth Edison Company

PLANT NAME: Lasalle Unit 1 (LA-1)

DOCKET NO.: $50-373$

LICENSE NO.: NPF-11

BWRVIP CATEGORY GROUPING:_Category "B"

SHROUD FABRICATION DATA:

SHROUD MANUFACTURER: Sun Ship Building and Dry Dock Co.

SHROUD SHELL CONSTRUCTION MATERIAL: SA 240 Type 304L Stainless Steel

CARBON CONTENT RANGE SHELL SECTIONS: $0.019 \% \mathrm{C}-0.028 \% \mathrm{C}$

SHROUD RING CONSTRUCTION MATERIAL: SA 240 Type 304L Stainless Steel

CARBON CONTENT RANGE SHROUD RINGS: $0.021 \% \mathrm{C}-0.024 \% \mathrm{C}$

\section{WELDING DATA:}

INITIAL PASS TECHNIQUE: Not provided in the response to GL 94-03

INITIAL PASS WELD MATERIAL: Not provided in the response to GL 94-03

SUBSEQUENT PASS TECHNIQUE: Not provided in the response to GL 94-03

SUBSEQUENT PASS WELD MATERIAL: Not provided in the response to GL 94-03

OPERATIONAL DATA:

AVERAGE CONDUCTIVITY VALUE OVER

THE FIRST FIVE YEARS OF OPERATION: $0.272 \mu \mathrm{S} / \mathrm{cm}$

ELAPSED TIME AT POWER OPERATION: As of February 1994, 8.04 years at power

\section{GENERIC LETTER INFORMATION:}

DATE GL 94-03 RESPONSE: August 23, 1994

BASIS FOR ACCEPTING JCO: Inspection results of April 1994 core shroud inspections.

DATE OF CORE SHROUD INSPECTION/REPAIR: Inspection, April 20-May 2, 1994.

NRC SERs: (1) SER regarding the ComEd response to Generic Letter for LA-1/LA-2, February 16, 1995.

REMARKS: Enhanced VT-1 inspection of the LA-1 shroud using ETV-1250 black and white video camera with "twin 50" type lighting. Inspections covered accessible portions of welds $\mathrm{Hl}-\mathrm{H} 8$ from the $\mathrm{OD}$, and portions of the $\mathrm{H} 3, \mathrm{H} 4$, and $\mathrm{H} 5$ welds that were accessible from the ID through open cell locations during refueling. No indications detected during the examinations. 


\section{LASALLE UNIT 2 DATA SHEET}

LICENSEE: Commonwealth Edison Company (ComEd)

PLANT NAME: Lasalle Unit 2 (LA-2)

DOCKET NO: $50-374$

LICENSE NO.: NPF-18

BWRVIP CATEGORY GROUPING: Category "B"

SHROUD FABRICATION DATA:

SHROUD MANUFACTURER: Sun Shipbuilding and Dry Dock Co.

SHROUD SHELL CONSTRUCTION MATERIAL: SA 240 Type 304L Stainless Steel

CARBON CONTENT RANGE SHELL SECTIONS: $0.018 \mathrm{C}-0.024 \% \mathrm{C}$

SHROUD RING CONSTRUCTION MATERIAL: SA 240 Type 304L Stainless Steel

CARBON CONTENT RANGE SHROUD RINGS: $0.022 \% \mathrm{C}-0.028 \% \mathrm{C}$

WELDING DATA:

INITIAL PASS TECHNIQUE: Not provided in the response to GL 94-03

INITIAL PASS WELD MATERIAL: Not provided in the response to GL 94-03

SUBSEQUENT PASS TECHNIQUE: Not provided in the response to GL 94-03

SUBSEQUENT PASS WELD MATERIAL: Not provided in the response to GL 94-03

OPERATIONAL DATA:

AVERAGE CONDUCTIVITY VALUE OVER

THE FIRST FIVE YEARS OF OPERATION: $0.272 \mu \mathrm{S} / \mathrm{cm}$

ELAPSED TIME AT POWER OPERATION: 8.53 EFPY projected to the February 1995 RFO

\section{GENERIC LETTER INFORMATION:}

DATE GL 94-03 RESPONSE: August 23, 1994

BASIS FOR ACCEPTING JCO: Results of the April 1994 LA-1 core shroud inspections bounding for LA-2. DATE OF CORE SHROUD INSPECTION/REPAIR: Inspection, March 20-April 10, 1995.

NRC SERs: (1) SER regarding the ComEd response to Generic Letter for LA-1/LA-2, February 16, 1995.

(2) Acknowledgement Letter of LA-2 core shroud inspection scope, February 6, 1995.

REMARKS: UT Inspection of the LA-2 shroud performed using the GE O.D. Tracker, including $45^{\circ} \mathrm{S}, 60^{\circ} \mathrm{L}$, and creeping wave UT techniques. Inspections covered accessible portions of welds $\mathrm{H} 3-\mathrm{H} 6$ and weld $\mathrm{H} 8$ from the $O D$. No indications detected during the examinations. 


\section{GRAND GULF UNIT 1 DATA SHEET}

LICENSEE: Entergy Operations, Incorporated (EOI)

PLANT NAME: Grand Gulf Unit 1 (GG-1)

DOCKET NO.: $50-416$

LICENSE NO.: NPF-29

BWRVIP CATEGORY GROUPING:_Category "B"

\section{SHROUD FABRICATION DATA:}

SHROUD MANUFACTURER: Bingham Williamette

SHROUD SHELL CONSTRUCTION MATERIAL: SA 240 Type 304L hot Rolled Plate

CARBON CONTENT RANGE SHELL SECTIONS: $0.015 \% \mathrm{C}-0.019 \% \mathrm{C}$

SHROUD RING CONSTRUCTION MATERIAL: SA 240 Type 304L hot Rolled Plate

CARBON CONTENT RANGE SHROUD RINGS: $0.011 \% \mathrm{C}-0.016 \% \mathrm{C}$

WELDING DATA:

INITIAL PASS TECHNIQUE: H1-H6B welds, SAW

INITIAL PASS WELD MATERIAL: ER308L filler metal

SUBSEQUENT PASS TECHNIQUE: H1-H6B welds, SAW

SUBSEQUENT PASS WELD MATERIAL: ER308L filler metal

OPERATIONAL DATA:

AVERAGE CONDUCTIVITY VALUE OVER

THE FIRST FIVE YEARS OF OPERATION: $0.0235 \mu \mathrm{S} / \mathrm{cm}(0.222 \mu \mathrm{S} / \mathrm{cm}$ full life to date)

ELAPSED TIME AT POWER OPERATION: $\approx 8.6$ EFPY as of April 1995 RFO (No. RFO7)

\section{GENERIC LETTER INFORMATION:}

DATE GL 94-03 RESPONSE: August 19, 1994

BASIS FOR ACCEPTING JCO: Category "B" criteria

DATE OF CORE SHROUD INSPECTION/REPAIR:_Limited inspections performed April 1995 RFO (No. RFO7) NRC SERs:_(1) SER regarding the response to GL 94-03 for GG-1, March 29, 1995

REMARKS: Limited UT inspections of the GG-1 core shroud performed in accordance with the BWRVIP guidelines for Category "B" core shrouds. Inspection scope covered H3, H4, H6A, and H7 welds. Creeping wave technique used as a supplement for examining the OD surface. No evidence of cracking detected as a result of the examinations. 


\section{LIMERICK UNIT 1 DATA SHEET}

LICENSEE: Philadelphia Electric Company (PECo)

PLANT NAME: Limerick Unit 1 (LIM-1)

DOCKET NO.: $50-352$

LICENSE NO.: NPF-39

BWRVIP CATEGORY GROUPING:_Category "B"

SHROUD FABRICATION DATA:

SHROUD MANUFACTURER: Sun Ship Building and Dry Dock

SHROUD SHELL CONSTRUCTION MATERIAL: A 240 Type 304L Stainless Steel

CARBON CONTENT RANGE SHELL SECTIONS: $0.018 \% \mathrm{C}-0.024 \% \mathrm{C}$

SHROUD RING CONSTRUCTION MATERIAL: A 240 Type 304L Stainless Steel

CARBON CONTENT RANGE SHROUD RINGS: $0.024 \% \mathrm{C}-0.026 \% \mathrm{C}$

WELDING DATA:

INITIAL PASS TECHNIQUE: Not provided in the response to GL 94-03

INITIAL PASS WELD MATERIAL: Not provided in the response to GL 94-03

SUBSEQUENT PASS TECHNIQUE: Not provided in the response to GL 94-03

SUBSEQUENT PASS WELD MATERIAL: Not provided in the response to GL 94-03

\section{OPERATIONAL DATA:}

AVERAGE CONDUCTIVITY VALUE OVER

THE FIRST FIVE YEARS OF OPERATION: $0.15 \mu \mathrm{S} / \mathrm{cm}$

ELAPSED TIME AT POWER OPERATION: As of August 24, 1994, 6.4 EFPY

GENERIC LETTER INFORMATION:

DATE GL 94-03 RESPONSE: August 24, 1994

BASIS FOR ACCEPTING JCO: Category "B" criteria: average RCS conductivity, shroud construction material DATE OF CORE SHROUD INSPECTION/REPAIR: Limited inspection scheduled for RFO 1R06, January 1996 NRC SERs: (1) SER regarding the PECo response to GL 94-03 for LIM-1, March 7, 1995

REMARKS: 


\section{HOPE CREEK UNIT 1 DATA SHEET}

LICENSEE: Public Service Electric and Gas Company (PSE\&G)

PLANT NAME: Hope Creek Station Unit 1 (HC-1)

DOCKET NO.: $50-354$

LICENSE NO.: NPF-57

BWRVIP CATEGORY GROUPING: Category "A"

SHROUD FABRICATION DATA:

SHROUD MANUFACTURER: Rotterdam Dry Dock

SHROUD SHELL CONSTRUCTION MATERIAL: ASTM A-240 Type 304L Stainless Steel Plates

CARBON CONTENT RANGE SHELL SECTIONS: $0.008 \% \mathrm{C}-0.025 \% \mathrm{C}$

SHROUD RING CONSTRUCTION MATERIAL: SA 102 Type 304L Stainless Steel Forgings

CARBON CONTENT RANGE SHROUD RINGS: $0.021 \% \mathrm{C}-0.030 \% \mathrm{C}$

WELDING DATA:

INITIAL PASS TECHNIQUE: Not provided in the response to GL 94-03

INITIAL PASS WELD MATERIAL: Not provided in the response to GL 94-03

SUBSEQUENT PASS TECHNIQUE: Not provided in the response to GL 94-03

SUBSEQUENT PASS WELD MATERIAL: Not provided in the response to GL 94-03

OPERATIONAL DATA:

AVERAGE CONDUCTIVITY VALUE OVER

THE FIRST FIVE YEARS OF OPERATION: $0.155 \mu \mathrm{S} / \mathrm{cm}$

ELAPSED TIME AT POWER OPERATION: 7.7 EFPY by the 6th RFO

GENERIC LETTER INFORMATION:

DATE GL 94-03 RESPONSE: August 24, 1994

BASIS FOR ACCEPTING JCO: Category "A" criteria

DATE OF CORE SHROUD INSPECTION/REPAIR: Deferred to the March 1997 RFO

NRC SERs: (1) SER regarding the PSE\&G response to GL 94-03 for $\mathrm{HC}-1$ (issue date was October 10, 1995).

REMIARKS: The SER for Hope Creek was issued on October 10, 1995. This date is outside the time frame scope of this NUREG. However, the date is listed in this data sheet to indicate that an SER was issued to PSE\&G regarding its response to GL 94-03. 


\section{NINE MILE POINT UNIT 2 DATA SHEET}

LICENSEE: Niagara Mohawk Power Corporation (NMPC)

PLANT NAME: Nine Mile Point Unit 2 (NMP-2)

DOCKET NO.: $50-410$

LICENSE NO.: NPF-69

BWRVIP CATEGORY GROUPING:_Category "A"

SHROUD FABRICATION DATA:

SHROUD MANUFACTURER: Sun Ship Building and Dry Dock

SHROUD SHELL CONSTRUCTION MATERIAL: SA 240 Type 304L Plate

CARBON CONTENT RANGE SHELL SECTIONS: $0.017 \%$ C $-0.030 \%$ C

SHROUD RING CONSTRUCTION MATERIAL: SA 240 Type 304L Plate

CARBON CONTENT RANGE SHROUD RINGS: $0.014 \%$ C $-0.021 \%$ C

\section{WELDING DATA:}

INITIAL PASS TECHNIQUE: SAW for circ. and vert. welds; SMAW for flange segments

INITIAL PASS WELD MATERIAL: ASME SFA-5.9 ER308 (SAW)

SUBSEQUENT PASS TECHNIQUE: SAW for circ. and vert. welds; SMAW for flange segments

SUBSEQUENT PASS WELD MATERIAL: ASME SFA-5.9 ER308 (SAW)

\section{OPERATIONAL DATA:}

AVERAGE CONDUCTIVITY VALUE OVER

THE FIRST FIVE YEARS OF OPERATION: $0.0129 \mu \mathrm{S} / \mathrm{cm}$

ELAPSED TIME AT POWER OPERATION: 8 EFPY projected in September 1998 assuming 18 month cycles

\section{GENERIC LETTER INFORMATION:}

DATE GL 94-03 RESPONSE: August 23, 1994

BASIS FOR ACCEPTING JCO:Category "A" criteria

DATE OF CORE SHROUD INSPECTION/REPAIR: Deferred

NRC SERs: SER regarding response to GL 94-03, Feb. 2, 1995.

REMARKS: Limited VT-1 of NMP-2 core shroud performed during the October 1993 RFO (RF-03). No indications were evident as a result of the examinations. 


\section{RIVER BEND UNIT 1 DATA SHEET}

LICENSEE: Entergy Operations, Incorporated (EOI)

PLANT NAME: River Bend Unit 1 (RVR-1)

DOCKET NO.: $50-458$

LICENSE NO.: NPF-47

BWRVIP CATEGORY GROUPING: Category "A"

SHROUD FABRICATION DATA:

SHROUD MANUFACTURER: Sun Ship Building and Dry Dock

SHROUD SHELL CONSTRUCTION MATERIAL: SA 240 Type 304L Stainless Steel

CARBON CONTENT RANGE SHELL SECTIONS: $0.022 \% \mathrm{C}-0.025 \% \mathrm{C}$

SHROUD RING CONSTRUCTION MATERIAL: SA 240 Type 304L Stainless Steel

CARBON CONTENT RANGE SHROUD RINGS: $0.018 \% \mathrm{C}-0.029 \% \mathrm{C}$

WELDING DATA:

INITIAL PASS TECHNIQUE:_Automated SAW

INITIAL PASS WELD MATERIAL:ER-308L Filler

SUBSEQUENT PASS TECHNIQUE: Automated SAW

SUBSEQUENT PASS WELD MATERIAL:ER-308L Filler

OPERATIONAL DATA:

AVERAGE CONDUCTIVITY VALUE OVER

THE FIRST FIVE YEARS OF OPERATION: $0.160 \mu \mathrm{S} / \mathrm{cm}$

ELAPSED TIME AT POWER OPERATION: Projected to be 7.3 EFPY at RFO No. 6 (September 1995)

GENERIC LETTER INFORMATION:

DATE GL 94-03 RESPONSE: August 24, 1994

BASIS FOR ACCEPTING JCO: Category "A" criteria

DATE OF CORE SHROUD INSPECTION/REPAIR: Deferred in accordance with Category "A" guidelines

NRC SERs: SER regarding response to GL 94-03, February 3, 1995

REMARKS: 


\section{FERMI UNIT 2 DATA SHEET}

LICENSEE: Detroit Edison Company (DECo)

PLANT NAME: Fermi Unit 2 (FRM-2)

DOCKET NO.: $50-341$

LICENSE NO.: NPF-43

BWRVIP CATEGORY GROUPING:_Category "A"

SHROUD FABRICATION DATA:

SHROUD MANUFACTURER: Core Shroud: Rotterdam Dry Dock; Core Support Plate: Combustion Eng. SHROUD SHELL CONSTRUCTION MATERIAL: 304L rolled plate

CARBON CONTENT RANGE SHELL SECTIONS: $0.013 \%$ C $-0.029 \%$ C

SHROUD RING CONSTRUCTION MATERIAL: 304L forged rings

CARBON CONTENT RANGE SHROUD RINGS: $0.020 \% \mathrm{C}-0.035 \% \mathrm{C}$

\section{WELDING DATA:}

INITIAL PASS TECHNIQUE: Not provided in the response to GL 94-03

INITIAL PASS WELD MATERIAL: ER308L

SUBSEQUENT PASS TECHNIQUE: Not provided in the response to GL 94-03

SUBSEQUENT PASS WELD MATERIAL: ER308L

OPERATIONAL DATA:

AVERAGE CONDUCTIVITY VALUE OVER

THE FIRST FIVE YEARS OF OPERATION: Better than the norm for the industry; value not provided

ELAPSED TIME AT POWER OPERATION: As of December 25, 1993, 4.36 EFPY

\section{GENERIC LETTER INFORMATION:}

DATE GL 94-03 RESPONSE: August 24, 1994

BASIS FOR ACCEPTING JCO: Category "A" criteria, and results of previous shroud examinations.

DATE OF CORE SHROUD INSPECTION/REPAIR: Enhanced VT-1 in accordance with SIL 054, April 1991

NRC SERs: SER regarding Response to GL 94-03, January 24, 1995

REMARKS: Enhanced VT-1 examinations performed at recommendation of GE after event at KKM. Examinations included VT- 1 of accessible portions of welds $\mathrm{H} 1-\mathrm{H} 7$ from the OD, and VT-1 of $\mathrm{H} 2, \mathrm{H3}$, and $\mathrm{H} 4$ from the ID, through accessible portions of peripheral fuels cells with control rod blades withdrawn. VT-1 exams performed using a color camera system and a S-VHS high resolution video recording system, capable of resolving a 1 mil wire (calibration standard). No flaw indications detected as a result of the VT-1 examinations. 


\section{LIMERICK UNIT 2 DATA SHEET}

LICENSEE: Philadelphia Electric Company (PECo)

PLANT NAME: Limerick Unit 2 (LIM-2)

DOCKET NO.: $50-353$

LICENSE NO.: NPF-85

BWRVIP CATEGORY GROUPING: Category "A"

\section{SHROUD FABRICATION DATA:}

SHROUD MANUFACTURER: Not provided in the response to GL 94-03

SHROUD SHELL CONSTRUCTION MATERIAL: A 240 Type 304L Stainless Steel

CARBON CONTENT RANGE SHELL SECTIONS: $0.018 \% \mathrm{C}-0.024 \% \mathrm{C}$

SHROUD RING CONSTRUCTION MATERIAL: A 240 Type 304L Stainless Steel

CARBON CONTENT RANGE SHROUD RINGS: $0.024 \% \mathrm{C}-0.026 \% \mathrm{C}$

WELDING DATA:

INITIAL PASS TECHNIQUE: Not provided in the response GL 94-03

INITIAL PASS WELD MATERIAL:_Not provided in the response GL 94-03

SUBSEQUENT PASS TECHNIQUE: Not provided in the response to GL 94-03

SUBSEQUENT PASS WELD MATERIAL: Not provided in the response to GL 94-03

OPERATIONAL DATA:

AVERAGE CONDUCTIVITY VALUE OVER

THE FIRST FIVE YEARS OF OPERATION: $0.123 \mu \mathrm{S} / \mathrm{cm}$

ELAPSED TIME AT POWER OPERATION: As of August 24, 1994, 3.6 EFPY

\section{GENERIC LETTER INFORMATION:}

DATE GL 94-03 RESPONSE:_August 24, 1994

BASIS FOR ACCEPTING JCO: Category "A" criteria

DATE OF CORE SHROUD INSPECTION/REPAIR: Deferred in accordance with Category " $A^{\text {" Guidelines }}$

NRC SERs: SER regarding response to GL 94-03, March 13, 1995

REMARKS: 


\section{CLINTON DATA SHEET}

LICENSEE: Illinois Power Company (IPC)

PLANT NAME: Clinton Power Station (CPS)

DOCKET NO.: $50-461$

LICENSE NO.: NPF-62

BWRVIP CATEGORY GROUPING: Category "A"

SHROUD FABRICATION DATA:

SHROUD MANUFACTURER: Sun Ship Building and Dry Dock (Shroud Support - CBIW)

SHROUD SHELL CONSTRUCTION MATERIAL: SA 240 Type 304L

CARBON CONTENT RANGE SHELL SECTIONS: $0.018 \% \mathrm{C}-0.021 \% \mathrm{C}$

SHROUD RING CONSTRUCTION MATERIAL: SA 240 Type 304L

CARBON CONTENT RANGE SHROUD RINGS: $0.024 \% \mathrm{C}-0.026 \% \mathrm{C}$

WELDING DATA:

INITIAL PASS TECHNIQUE: Not provided in the response to GL 94-03

INITIAL PASS WELD MATERIAL: Either ER308 Filler or ER308L Filler

SUBSEQUENT PASS TECHNIQUE: Not provided in response to GL 94-03

SUBSEQUENT PASS WELD MATERIAL: Either ER308 Filler or ER308L Filler

OPERATIONAL DATA:

AVERAGE CONDUCTIVITY VALUE OVER

THE FIRST FIVE YEARS OF OPERATION: $0.188 \mu \mathrm{S} / \mathrm{cm}$

ELAPSED TIME AT POWER OPERATION: 5.4 EFPY

GENERIC LETTER INFORMATION:

DATE GL 94-03 RESPONSE: August 24, 1994

BASIS FOR ACCEPTING JCO: Category "A" inspection criteria

DATE OF CORE SHROUD INSPECTION/REPAIR: Deferred according the Category "A" guidelines

NRC SERs: SER regarding response to GL 94-03, Feb. 10, 1995

REMARKS: (1) Avg. sulfate for first five years: $3.40 \mathrm{ppb}$. (2) Avg. chloride for first five years: $2.10 \mathrm{ppb}$.

(3) Avg. Chromate for first five years: $34.2 \mathrm{ppb}$. 


\section{PERRY UNIT 1 DATA SHEET}

LICENSEE: Centerior Energy, Inc. (CEI)

PLANT NAME: Perry Nuclear Power Plant (PRY)

DOCIKET NO.: $50-440$

LICENSE NO.: NPF-58

BWRVIP CATEGORY GROUPING:_Category "A"

\section{SHROUD FABRICATION DATA:}

SHROUD MANUFACTURER: Bingham Williamette

SHROUD SHELL CONSTRUCTION MATERIAL: SA 240 Type 304L Stainless Steel

CARBON CONTENT RANGE SHELL SECTIONS: $0.021 \% \mathrm{C}$ Max.

SHROUD RING CONSTRUCTION MATERIAL: SA 240 Type 304L Stainless Steel

CARBON CONTENT RANGE SHROUD RINGS: $0.016 \%$ C Max.

\section{WELDING DATA:}

INITIAL PASS TECHNIQUE: SAW

INITIAL PASS WELD MATERIAL: E308L Filler

SUBSEQUENT PASS TECHNIQUE: SAW

SUBSEQUENT PASS WELD MATERIAL: E308L Filler

OPERATIONAL DATA:

AVERAGE CONDUCTIVITY VALUE OVER

THE FIRST FIVE YEARS OF OPERATION: $0.20 \mu \mathrm{S} / \mathrm{Cm}(0.13 \mu \mathrm{S} / \mathrm{cm}$ last two cycles)

ELAPSED TIME AT POWER OPERATION: As of August 24, 1994, 4.1 EFPY (4 Cycles of operation)

\section{GENERIC LETTER INFORMATION:}

DATE GL 94-03 RESPONSE: August 24, 1994

BASIS FOR ACCEPTING JCO:_Category "A" plant criteria

DATE OF CORE SHROUD INSPECTION/REPAIR: Deferred

NRC SERs: GL 94-03 Response SER, February 10, 1995

REMARKS: (1) Limited examinations of the $\mathrm{H3}$ and $\mathrm{H} 4$ welds during RFO No. 4. No evidence of cracking. Additional inspections deferred until 8 EFPY has been surpassed. 


\section{WNP-2 DATA SHEET}

LICENSEE: Washington Public Power Supply System (WPPSS)

PLANT NAME: Washington Nuclear Plant, Unit 2 (WNP-2)

DOCKET NO.: $50-397$

LICENSE NO.: NPF-21

BWRVIP CATEGORY GROUPING:_Category "A"

SHROUD FABRICATION DATA:

SHROUD MANUFACTURER: Chicago Bridge and Iron Works

SHROUD SHELL CONSTRUCTION MATERIAL: SA 240 Type 304L Stainless Steel

CARBON CONTENT RANGE SHELL SECTIONS: Shell \& Ring carbon contents range: $0.010 \% \mathrm{C}-0.024 \% \mathrm{C}$

SHROUD RING CONSTRUCTION MATERIAL: SA 240 Type 304L Stainless Steel

CARBON CONTENT RANGE SHROUD RINGS: Shell \& Ring carbon contents range: $0.010 \% \mathrm{C}-0.024 \% \mathrm{C}$

WELDING DATA:

INITIAL PASS TECHNIQUE: Not provided in the response to GL 94-03

INITIAL PASS WELD MATERIAL: Not provided in the response to GL 94-03

SUBSEQUENT PASS TECHNIQUE: Not provided in the response to GL 94-03

SUBSEQUENT PASS WELD MATERIAL: Not provided in the response to GL 94-03

\section{OPERATIONAL DATA:}

AVERAGE CONDUCTIVITY VALUE OVER

THE FIRST FIVE YEARS OF OPERATION: $0.242 \mu \mathrm{S} / \mathrm{cm}(0.175 \mu \mathrm{S} / \mathrm{cm}$ over last five cycles)

ELAPSED TIME AT POWER OPERATION: As of the April 1994 RFO, 5.8 EFPY

GENERIC LETTER INFORMATION:

DATE GL 94-03 RESPONSE: August 24, 1994

BASIS FOR ACCEPTING JCO: Category "A" plant criteria.

DATE OF CORE SHROUD INSPECTION/REPAIR: Deferred

NRC SERs: SER regarding response to GL 94-03, May 8, 1995

REMARKS: (1) Limited Examination of $\mathrm{H} 3$ and $\mathrm{H} 4$ welds during April 1994 RFO. No indications of IGSCC. (2) Average shroud Phosphorous Content: $0.020 \%$ P.

(3) Average Shroud Sulfur Content: $0.014 \% \mathrm{~S}$. 



\section{APPENDIX C LIST OF BWR UTILITIES AND REACTORS}

Boston Edison Company

Abbreviation

BECo

.... Pilgrim Nuclear Power Station

PNPS

Carolina Power \& Light Company

CP\&L

... Brunswick Steam Electric Plant Unit 1

BR-1

$\ldots \ldots$ Brunswick Steam Electric Plant Unit $2 \ldots \ldots \ldots \ldots \ldots$

BR-2

Centerior Energy, Incorporated

CEI

.... Perry Nuclear Power Station

PRY

Commonwealth Edison Company

ComEd

Dresden Unit 2

DR-2

Dresden Unit 3

DR-3

Quad Cities Unit 1

QC-1

.... Quad Cities Unit 2

QC-2

$\ldots$ Lasalle Unit 1

LA-1

... Lasalle Unit 2

LA-2

Detroit Edison Company

DECo

..... Fermi Unit 2 .

FRM-2

Entergy Operation, Incorporated

EOI

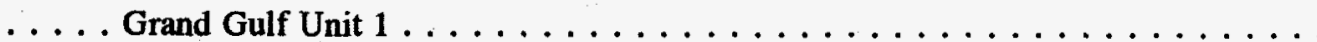

GG-1

River Bend Unit 1

RVR-1

General Public Utilities ............................... GPU

Oyster Creek Nuclear Generation Station

OCNGS 
Abbreviation

GPC

$\ldots \ldots$ Edwin I. Hatch Unit $1 \ldots \ldots \ldots \ldots \ldots \ldots \ldots \ldots \ldots \ldots \ldots \ldots \ldots$ HAT-1

$\ldots \ldots$ Edwin I. Hatch Unit $2 \ldots \ldots \ldots \ldots \ldots \ldots \ldots \ldots$ HAT-2

Illinois Power Company $\ldots \ldots \ldots \ldots \ldots \ldots \ldots \ldots \ldots \ldots \ldots \ldots \ldots \ldots \ldots$

$\ldots \ldots$ Clinton Power Station $\ldots \ldots \ldots \ldots \ldots \ldots \ldots \ldots \ldots \ldots \ldots$ CPS

IES Utilities, Incorporated $\ldots \ldots \ldots \ldots \ldots \ldots \ldots \ldots \ldots \ldots \ldots \ldots \ldots \ldots \ldots \ldots$

$\ldots \ldots$ Duane Arnold Energy Center $\ldots \ldots \ldots \ldots \ldots \ldots \ldots \ldots \ldots \ldots \ldots \ldots$

Nebraska Public Power District $\ldots \ldots \ldots \ldots \ldots \ldots \ldots \ldots \ldots \ldots \ldots \ldots \ldots$

$\ldots \ldots$ Cooper Nuclear Station $\ldots \ldots \ldots \ldots \ldots \ldots \ldots \ldots \ldots$ CNS

Niagara Mohawk Power Corporation $\ldots \ldots \ldots \ldots \ldots \ldots \ldots \ldots \ldots \ldots \ldots \ldots \ldots$

$\ldots \ldots$ Nine Mile Point Unit $1 \ldots \ldots \ldots \ldots \ldots \ldots \ldots \ldots \ldots \ldots \ldots \ldots$ NMP-1

$\ldots \ldots$ Nine Mile Point Unit $2 \ldots \ldots \ldots \ldots \ldots \ldots \ldots \ldots \ldots \ldots \ldots$ NMP-2

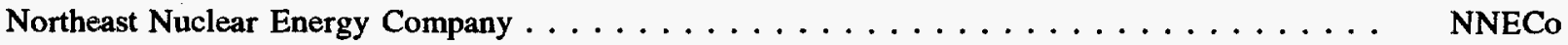

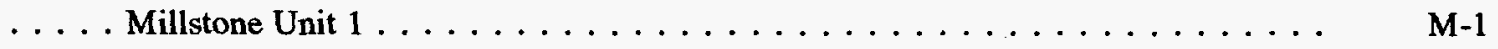

Northern States Power Company $\ldots \ldots \ldots \ldots \ldots \ldots \ldots \ldots \ldots \ldots \ldots \ldots \ldots \ldots$

$\ldots \ldots$ Monticello Nuclear Generation Plant $\ldots \ldots \ldots \ldots \ldots \ldots$ MNGP

Pennsylvania Power \& Light Company $\ldots \ldots \ldots \ldots \ldots \ldots \ldots \ldots \ldots \ldots \ldots \ldots \ldots \ldots$

$\ldots \ldots$ Susquehanna Steam Electric Station, Unit $1 \ldots \ldots \ldots \ldots \ldots$ SSES-1

$\ldots \ldots$ Susquehanna Steam Electric Station, Unit $2 \ldots \ldots \ldots \ldots$ SSES-2

Philadelphia Electric Company $\ldots \ldots \ldots \ldots \ldots \ldots \ldots \ldots \ldots \ldots \ldots \ldots \ldots \ldots \ldots$

$\ldots \ldots$ Limerick Unit $1 \ldots \ldots \ldots \ldots \ldots \ldots \ldots \ldots \ldots \ldots \ldots$ LIM-1

$\ldots \ldots$ Limerick Unit $2 \ldots \ldots \ldots \ldots \ldots \ldots \ldots \ldots \ldots \ldots \ldots \ldots$ LIM-2

$\ldots \ldots$ Peach Bottom Unit $2 \ldots \ldots \ldots \ldots \ldots \ldots \ldots \ldots \ldots$ PB-2

$\ldots \ldots$ Peach Bottom Unit $3 \ldots \ldots \ldots \ldots \ldots \ldots \ldots \ldots \ldots$ PB-3 
Power Authority of the State of New York

$\underline{\text { Abbreviation }}$

NYPA

.... James A. FitzPatrick Nuclear Power Plant . . . . . . . . . . . . . . FITZ

Public Services Electric and Gas Company . . . . . . . . . . . . . . . . . PSE\&G

$\ldots \ldots$ Hope Creek Station Unit $1 \ldots \ldots \ldots \ldots \ldots \ldots$ HC-1

Tennessee Valley Authority $\ldots \ldots \ldots \ldots \ldots \ldots \ldots \ldots \ldots \ldots$

$\ldots \ldots$ Browns Ferry Unit $1 \ldots \ldots \ldots \ldots \ldots \ldots \ldots \ldots \ldots \ldots$

$\ldots \ldots$ Browns Ferry Unit $2 \ldots \ldots \ldots \ldots \ldots \ldots \ldots \ldots \ldots \ldots \ldots$

Browns Ferry Unit $3 \ldots \ldots \ldots \ldots \ldots \ldots$ BF-3

Vermont Yankee Nuclear Power Corporation $\ldots \ldots \ldots \ldots \ldots \ldots \ldots \ldots$

$\ldots \ldots$ Vermont Yankee Nuclear Power Station $\ldots \ldots \ldots \ldots \ldots \ldots$

Washington Public Power Supply System . . . . . . . . . . . . . . . . . WPPSS

Washington Nuclear Plant Unit $2 \ldots \ldots \ldots \ldots \ldots$ WNP-2 


\section{APPENDIX D ABBREVIATIONS AND NOMENCLATURE}

\section{CFR Title 10, Code of Federal Regulations}

AHC Access Hole Cover

ASME American Society of Mechanical Engineers

ASTM American Society for Testing and Materials

BWNT Babcock and Wilcox Nuclear Technology

BWR boiling water reactor

BWROG Boiling Water Reactor Owners Group

BWRVIP BWR Vessel and Internals Project

circ. circumferential

CS core spray system

ECCS emergency core cooling systems

ECP electrochemical potential

EDM electrodischarge machined

EFPY effective full-power years

EOC end of cycle

EOL end of life

EPFM elastic plastic fracture mechanics

EPRI Electric Power Research Institute

ET eddy current testing

F19xx Fall, Year 19xx

GE General Electric Company

GL generic letter

GMAW gas metal arc welding
GTAW gas tungsten arc welding

HAZ heat affected zone

ID inner diameter

IGSCC intergranular stress corrosion cracking

IN information notice

JCO justification for continued operation

JPHDB jet pump hold down beam

LEFM linear elastic fracture mechanics

LLA limit load analysis

LOCA loss of coolant accident

MPR MPR Associates

MSLB main steam line break

NCR Nonconformance Report

NDE nondestructive examination

NRC Nuclear Regulatory Commission

OD outer diameter

PRA probabilistic risk assessment

RAI request for additional information

RCS reactor coolant system

RFO refueling outage

RICSIL Rapid Information Communication Services Information Letter

RLB recirculation line break 
S19xx Summer, Year 19xx

$\mathrm{U} 2$

Unit 2

SAW submerged arc welding

U3 Unit 3

SER safety evaluation report

UT ultrasonic testing

SIL Services Information Letter

VT visual testing

SLCS standby liquid control system

vert. vertical

SMAW shielded metal arc welding

W19xx Winter, Year 19xx

SP19xx Spring, Year 19xx

W/SP19xx Late Winter, Early Spring, Year 19xx

stainless steel

\section{Commonly Used Scientific Units}

in length in inches

in $/ \mathrm{hr} \quad$ velocity or growth rate in inches per hour

m

$\mathrm{m} / \mathrm{s}$ length in meters

velocity or growth rate in meters per second $\mu \mathrm{S} / \mathrm{cm}$ microSiemens per centimeter, unit of electrical conductivity (this is equivalent to a unit in $\mu$ mhos $/ \mathrm{cm}$, micromhos per centimeter)

V volt, unit of electrochemical potential (ECP) 


\section{APPENDIX E LIST OF STAFF CONTRIBUTORS TO NUREG-1544}

This report was compiled by Mr. James Medoff of the Materials and Chemical Engineering Branch in the Office of Nuclear Reactor Regulation, Division of Engineering. Other contributors to this report and to the staff's efforts regarding the issue of IGSCC in BWR internal components are listed below. The efforts of these staff members have made issuance of this report possible.

Materials and Chemical Engineering Branch, Division of Engineering

Jack R. Strosnider

Robert A. Hermann

David Terao

Edwin M. Hackett

James Medoff

William H. Koo

Phillip J. Rush

Bamidele E. Akins
Branch Chief

Senior Level Materials Engineer

Chief, Chemical Engineering and Metallurgy Section

Senior Materials Engineer, Materials Integrity Section

Materials Engineer, Materials Integrity Section

Senior Materials Engineer, Chemical Engineering and Metallurgy Section

Materials Engineer, Inservice Inspection Section

Engineering Aide - Chemical Engineering COOP Student

Mechanical Engineering Branch. Division of Engineering

Richard H. Wessman

Kamal A. Manoly

Jai R. Rajan

C. Gary Hammer

Mark Hartzman

Pat Patnaik
Branch Chief

Section Chief, Component Integrity Section

Mechanical Engineer, Component Integrity Section

Mechanical Engineer, Component Integrity Section

Senior Mechanical Engineer, Component Integrity Section

Mechanical Engineer, Component Integrity Section

Reactor Systems Branch, Division of Systems and Safety Assessment

Robert C. Jones

Laurence E. Phillips

Kerri A. Kavanagh

Amy E. Cubbage
Branch Chief

Section Chief, BWR Reactor Section

Reactor Systems Engineer, BWR Reactor Section

Reactor Systems Engineer, Special Projects and Advanced Reactor Systems Section

Probabilistic Safety Assessment Branch, Division of Systems and Safety Assessment

Mark P. Rubin

Section Chief, Program Integration and Application Section

Project Directorate I-1, Division of Reactor Projects I/II

C. E. Carpenter

Project Manager - Project Directorate I-1 and

Lead Project Manager - BWR Internals Cracking Issue

Don S. Brinkman

Project Manager, Project Directorate I-1

Consultants

Carl J. Czajkowski

Brookhaven National Laboratory 


\begin{tabular}{|c|c|}
\hline 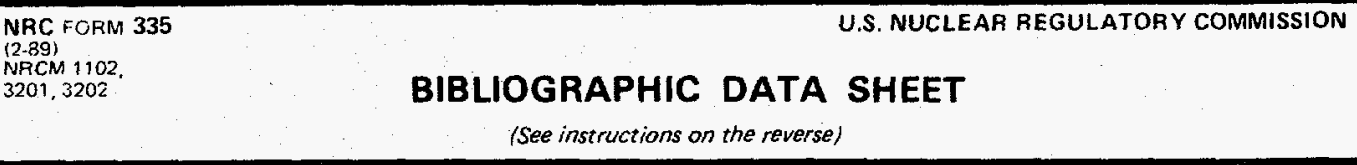 & $\begin{array}{l}\text { 1. REPORT NUMBER } \\
\text { (Assigned by NRC. Add Vol., Supp., Rev., } \\
\text { and Addendum Numbers, if any.l } \\
\text { NU RE G-1544 }\end{array}$ \\
\hline \multirow{4}{*}{$\begin{array}{l}\text { 2. TITLE AND SUBTITLE } \\
\text { StatUS Report: Intergranular Stress Corrosion Cracking } \\
\text { of BWR Core Shrouds and Other Internal Components }\end{array}$} & \\
\hline & DATE REPORT PUBLISHED \\
\hline & \begin{tabular}{|c|c|} 
MONTH & YEAR \\
March & 1996 \\
\end{tabular} \\
\hline & 4. FIN OR GRANT NUMBER \\
\hline $\begin{array}{l}\text { 5. AUTHOR(S) } \\
\text { NRC Staff Report }\end{array}$ & $\begin{array}{l}\text { 6. TYPE OF REPORT } \\
\text { Technical }\end{array}$ \\
\hline & $\begin{array}{l}\text { 7. PERIOD COVERED (Inclusive Datesi } \\
\text { Septe m ber } 30,1995\end{array}$ \\
\hline $\begin{array}{l}\text { 8. PERFORMING ORGANIZATION - NAME AND ADDRESS (It NRC, provide Division, Office or Region, U.S. Nuclear Regulatory Con } \\
\text { name andiling address.) } \\
\text { Division of Engineering } \\
\text { Office of Nuclear Reactor Regulation } \\
\text { U.S. Nuclear Regulatory Com mission } \\
\text { Washington, D.C. 20555-0001 }\end{array}$ & ission, and mailing address; if contractor, pr \\
\hline
\end{tabular}

9. SPONSORING ORGA
and mailing address.)

Same as above

10. SUPPLEMENTARY NOTES

J. Medoff, NRC Technical Monitor

11. ABSTRACT (200 words or less)

On July 25, 1994, the U.S. Nuclear Regulatory Commission (NRC) issued

Generic Letter (GL) 94-03 to obtain information needed to assess compliance with regulatory

requirements regarding the structural integrity of core shrouds in domestic boiling water

reactors ( $B W R s$ ).

This report begins with a brief description of the safety significance of intergranular stress corrosion cracking (IGSC C) as it relates to the design and function of BWR core shrouds and other internal components. It then presents a brief history of shroud cracking events both in the U.S. and abroad, followed by an indepth sum $\mathrm{m}$ ary of the industry actions to address the issue of IGSCC in BWR core shrouds and other internal components.

This report sum marizes the staff's basis for issuing GL 94-03, as well as the staff's assessment of plant-specific responses to GL 94-03. The staff is continually evaluating the Ticensee inspection programs and the results from examinations of BWR core shrouds and other internal components. This report is representative of submittals to and evaluations by the staff as of September 30, 1995. An update of this report will be issued at a later date.

12. KEY WORDS/DESCR!PTORS (List words or phrases that will assist researchers in lorating the renort.!

Boiling Water Reactor, Core Shroud, BWR Internal Components

Intergranular Stress Corrosion Cracking, IGSC C, Generic Letter 94-03

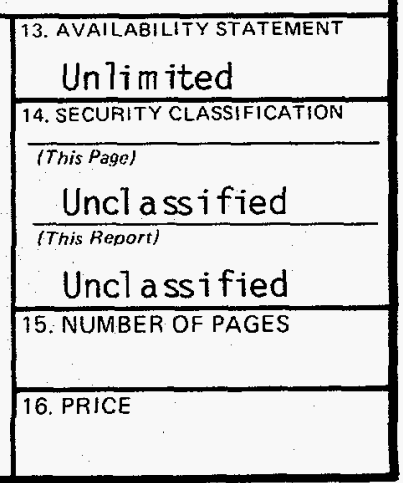




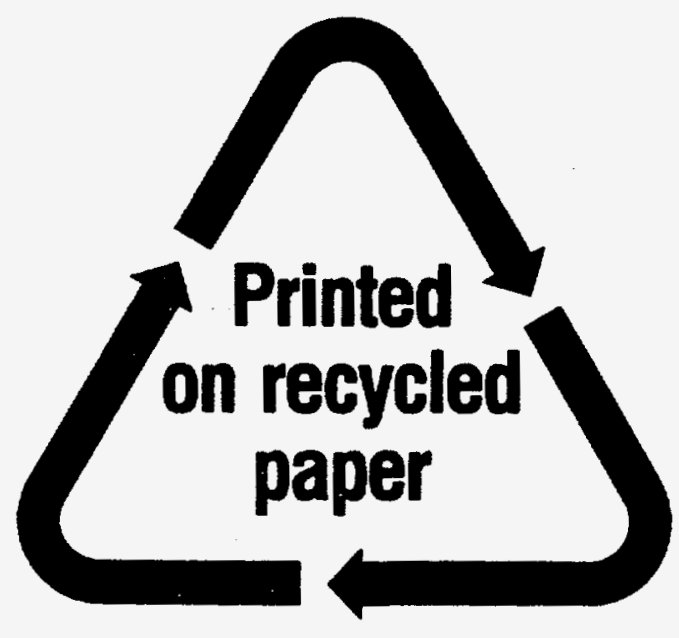

Federal Recycling Program 